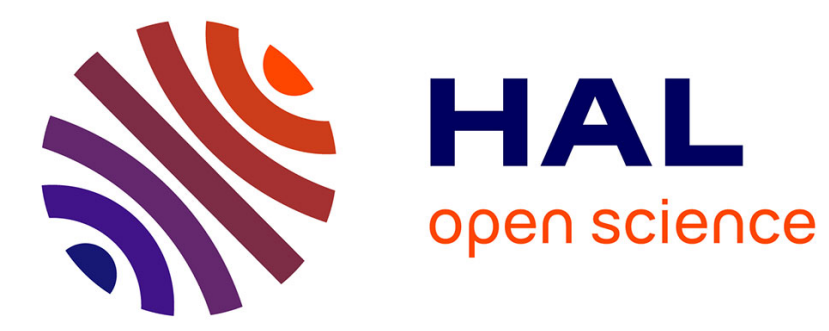

\title{
Observations sur les sculpteurs de statuettes religieuses du Hunan
}

\author{
Michela Bussotti
}

\section{To cite this version:}

Michela Bussotti. Observations sur les sculpteurs de statuettes religieuses du Hunan. Cahiers d'Extrême-Asie, 2010, 19 (1), pp.135-181. 10.3406/asie.2010.1351 . halshs-02510008

\section{HAL Id: halshs-02510008 \\ https://shs.hal.science/halshs-02510008}

Submitted on 17 Mar 2020

HAL is a multi-disciplinary open access archive for the deposit and dissemination of scientific research documents, whether they are published or not. The documents may come from teaching and research institutions in France or abroad, or from public or private research centers.
L'archive ouverte pluridisciplinaire HAL, est destinée au dépôt et à la diffusion de documents scientifiques de niveau recherche, publiés ou non, émanant des établissements d'enseignement et de recherche français ou étrangers, des laboratoires publics ou privés. 


\title{
Observations sur les sculpteurs de statuettes religieuses du Hunan
}

\section{Michela Bussotti}

\begin{abstract}
Occasionally, in a context in which information is sparse, exceptions arise. Since ancient times, Chinese woodworkers have, in certain circumstances, appended their signatures to the items they produced. This is, for example, true of engravers of printing plates who were sometimes obliged to account for their work, make claims for their artistic skill, etc. It is also true of sculptors of religious statues in Hunan, whose signatures implied a degree of "technical" competence not only in terms of woodworking but also of religious knowledge (consecration rituals, funeral rites, etc.). The inventory of these artisans in three collections of statuettes is remarkable for both its wealth and precision: all the names are accompanied by dates and places. However, a problem remains - how can this information be made to "speak" about ordinary people when traditional historical sources are obviously lacking. The article focuses on contemporary materials, which provide information about present-day practices and shed retrospective light on what such practices may have been in the past, before moving on to a comparative analysis of the data drawn from the statuettes and their certificates of consecration, ranging from the 16th to the 20th centuries. The "portraits" of the sculptors remain imprecise and the ancient secrets of the "profession" obscure-but how could it be otherwise for a practice reserved to initiates? However, the article does succeed in describing the role of the sculptors, a role as important as that of other "actors" presented in this volume, within the ambit of a local rural society in which religion is a central part of life and gives structure to the social network.
\end{abstract}

\section{Citer ce document / Cite this document :}

Bussotti Michela. Observations sur les sculpteurs de statuettes religieuses du Hunan. In: Cahiers d'Extrême-Asie, vol. 19, 2010. Religions et sociétés locales. Etudes interdisciplinaires sur la région centrale du Hunan. pp. 135-181;

doi : https://doi.org/10.3406/asie.2010.1351

https://www.persee.fr/doc/asie_0766-1177_2010_num_19_1_1351

Fichier pdf généré le 06/02/2019 


\title{
OBSERVATIONS SUR LES SCULPTEURS DE STATUETTES RELIGIEUSES DU HUNAN
}

\author{
Michela Bussotti
}

\begin{abstract}
Occasionally, in a context in which information is sparse, exceptions arise. Since ancient times, Chinese woodworkers bave, in certain circumstances, appended their signatures to the items they produced. This is, for example, true of engravers of printing plates who were sometimes obliged to account for their work, make claims for their artistic skill, etc. It is also true of sculptors of religious statues in Hunan, whose signatures implied a degree of "technical" competence not oniy in terms of woodworking, but also of religious knowledge (consecration rituals, funeral rites, etc.). The inventory of these artisans in three collections of statuettes is remarkable for botb its wealth and precision: all the names are accompanied by dates and places. However, a problem remains-bow can this information be made to "speak" about ordinary people when traditional bistorical sources are obviously lacking. The article focuses on contemporary materials, which provide information about present-day practices and shed retrospective light on what such practices may bave been in the past, before moving on to a comparative analysis of the data drawn from the statuettes and their certificates of consecration, ranging from the i6th to the $20^{\text {th }}$ centuries. The "portraits" of the sculptors remain imprecise and the ancient secrets of the "profession" obscure-but bow could it be otherwise for a practice reserved to initiates? However, the article does succeed in describing the role of the sculptors, a role as important as that of other "actors" presented in this volume, within the ambit of a local rural society in which religion is a central part of life and gives structure to the social network.
\end{abstract}

En septembre 2003, nous avons rendu visite à Yang Hui 㛫耀, sculpteur de statuettes, âgé d'environ 50 ans et habitant dans la banlieue de la ville de Lengshui jiang 冷水汇. Dans cette campagne à l'époque assez pauvre et dévastée par de petites mines à ciel ouvert, Yang Hui ne semblait pas être très riche. Certes, il avait une maison à deux étages, mais les pièces étaient en partie vides et le bâtiment était en hauteur par rapport à la route qui y parvenait : plutôt que la distance entre la route et la maison elle-même, l'absence d'un aménagement minimal de l'accès, a priori pourtant nécessaire pour un artisan tenant son propre commerce, apparaissait étonnant. L'atelier de menuiserie était situé à l'étage et, sur une terrasse, des rondins de bois étaient disposés pour sécher (fig. Ia). Selon Yang, c'était du bois de camphrier zhangmu 樟木, destiné à reposer un an avant usage. Au moment de notre visite il était en train de sculpter quatre statues, deux « maîtres de famille » jiazbu 家主, un dieu du Pic du Sud (Nanyue shengdi 南獄聖篣) et un dieu de la Richesse (Caishen 財神 ; fig. Ic). Il s'agissait probablement de commandes destinées à être livrées le mois suivant. Cette première partie du travail, consistant à sculpter le bois, était selon ses dires désignée comme le « dégrossissage » (maopei 毛坏) de la pièce (fig. Ic) 
et son «polissage » (damo fJ床). Il raconta avoir eu deux maîtres, dont un du district de Xinhua 新化 et l'autre venant de la province du Zhejiang 浙汭 qui lui avait cédé ses précieux outils de travail : en fait, il s'agissait d'un set complet mais ordinaire de couteaux utilisés pour la xylographie'.

Toujours au deuxième étage, Yang Hui conservait des peintures religieuses assez frustes ainsi que des modèles de dessins, réalisés au trait, eux aussi plutôt simples : un répertoire iconographique probablement utile pour les différents travaux, artisanaux mais aussi rituels, qu'il devait accomplir à la demande ${ }^{2}$.

En retournant au rez-de-chaussée, on passait par une petite pièce où Yang Hui terminait ses statuettes. Selon la même méthode que l'on peut aussi reconnaitre dans des pièces anciennes, il appliquait sur le bois sculpté un enduit de couleur blanche ; cet enduit était normalement associé à une feuille de papier fin, posée essentiellement sur le devant de la statue ${ }^{3}$. Ces étapes de la préparation étaient appelées «étaler la chaux»(pibui 披灰) ou [poser la] 《peau»(pizi 皮f). À l'occasion de notre visite, cinq statuettes statuettes de trois formats différents, toutes blanches, étaient en train de sécher : deux Guanyin 䍜音, un maître de famille (jiazhu 家上) et encore deux maitres des lieux (dizhu 地主), ces derniers représentés avec le bol d'eau talismanique (fushui wan 符水琬) porté par la main gauche formant la $m u d r a \bar{~}$ des «Trois montagnes " (sanshan jue 三山該) et le bâton de commandement (lingpai

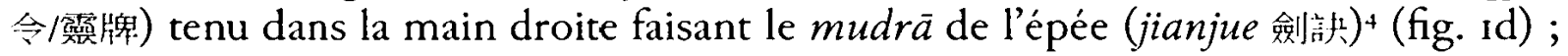
ce sont des pièces de trois formats différents. Sur la même table, en plus de la photo d'une femme défunte et de cadres vides, ordinaires et industriels, étaient posés des

I. Ces petits couteaux peuvent avoir servi à graver les détails ainsi que les "canaux " invisibles mais présents dans certaines pièces. Toures les statues ont le dos creusé pour recevoir documents écrits et materia medica au moment de la consécration. À l'occasion d'un exposé sur ce sujet présenté à l'International Convention of Asia Scholars en 2005, après avoir travaillé sur les pièces d'Anhua 'is: 化 de la collection Fava (pour une description de ce corpus, voir l'article d'Alain Arrault dans ce volume), nous avions constaté qu'environ $15 \%$ des statues comportaient un canal de trachée artère (bouguan 唃管) remontant du ventre et parfois connecté à une deuxième cavité faite au niveau de la nuque. $20 \%$ des pièces montraient des trous au niveau de la bouche, parfois reliés aux canaux percés dans le corps du bois (pour symboliser la circulation du souffle $q i$ 我). Il arrive que ces cavités, plutôt que percées, soient symboliquement peintes : ceci est plus évident sur des pièces modernes, le temps ayant probablement rendu invisibles ces minuscules points sur les pièces plus anciennes.

2. Le jour de la visite, il ne travaillait pas aux statues, mais préparait les objets en papier destinés à des funérailles.

3. On a parfois l'impression que cet enduit est rouge, mais en réalité du papier coloré peut avoir été utilisé et le pigment du papier avoir ainsi coloré la pâte blanche.

4. Ces deux mudrä sont très fréquentes parmi ces statuettes religieuses. Dans le corpus présenté à la note 1 ci-dessus, plus de $60 \%$ des pièces étaient représentées avec la mudrã des «Trois montagnes » et $80 \%$ portaient le bol d'eau lustrale ; dans $64 \%$ des cas y était associée la tablette de commandement. Seules $13 \%$ des statues étaient sans attribut, les autres portant des objets de tradition taoïste et/ou bouddhiste, ou encore des attributs typiques de certaines divinités : livres (pour Lu Ban), épées, bouteilles et gourdes (bulu ifijli), éventails, cornes de bouf, blocs

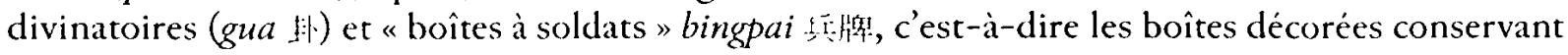
les documents d'ordination, etc. 

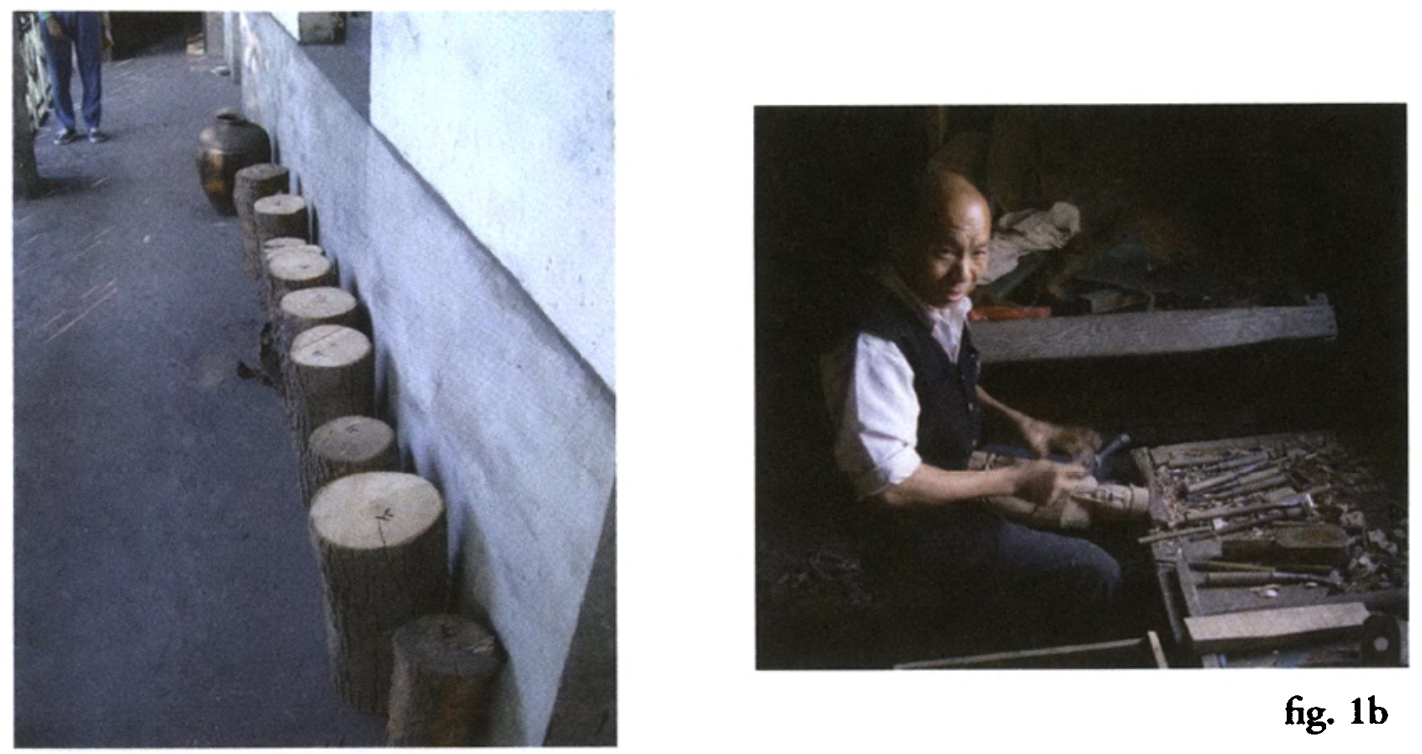

fig. 1b

fig. 1a
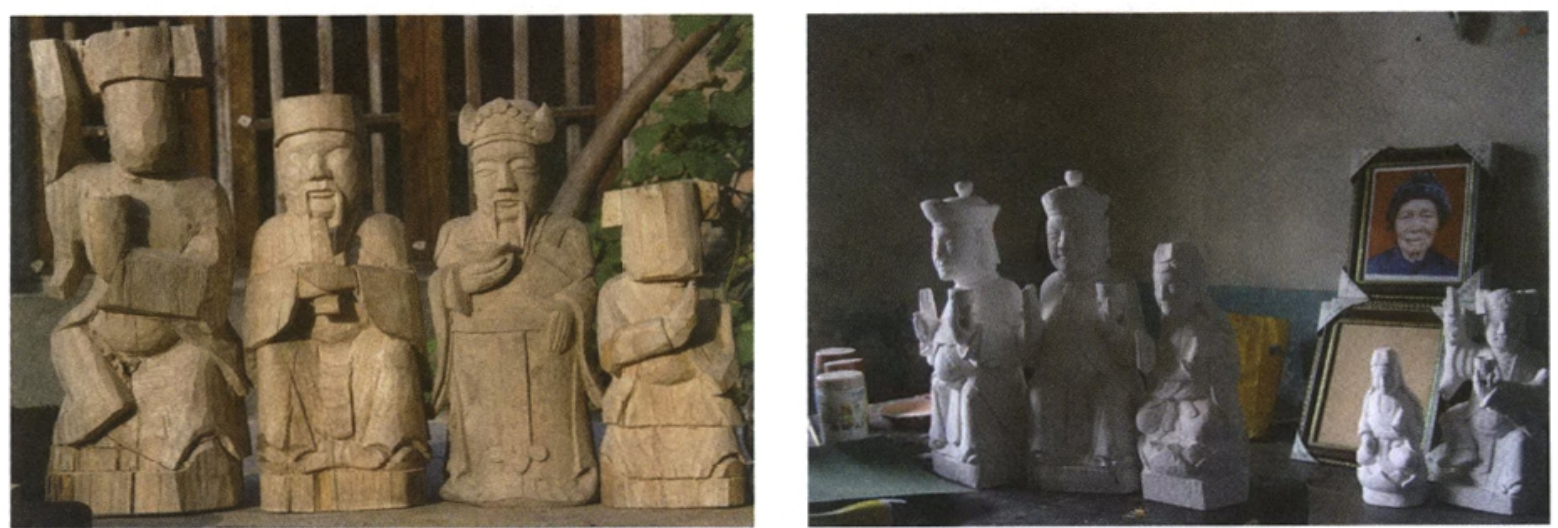

fig. 1c

fig. 1d
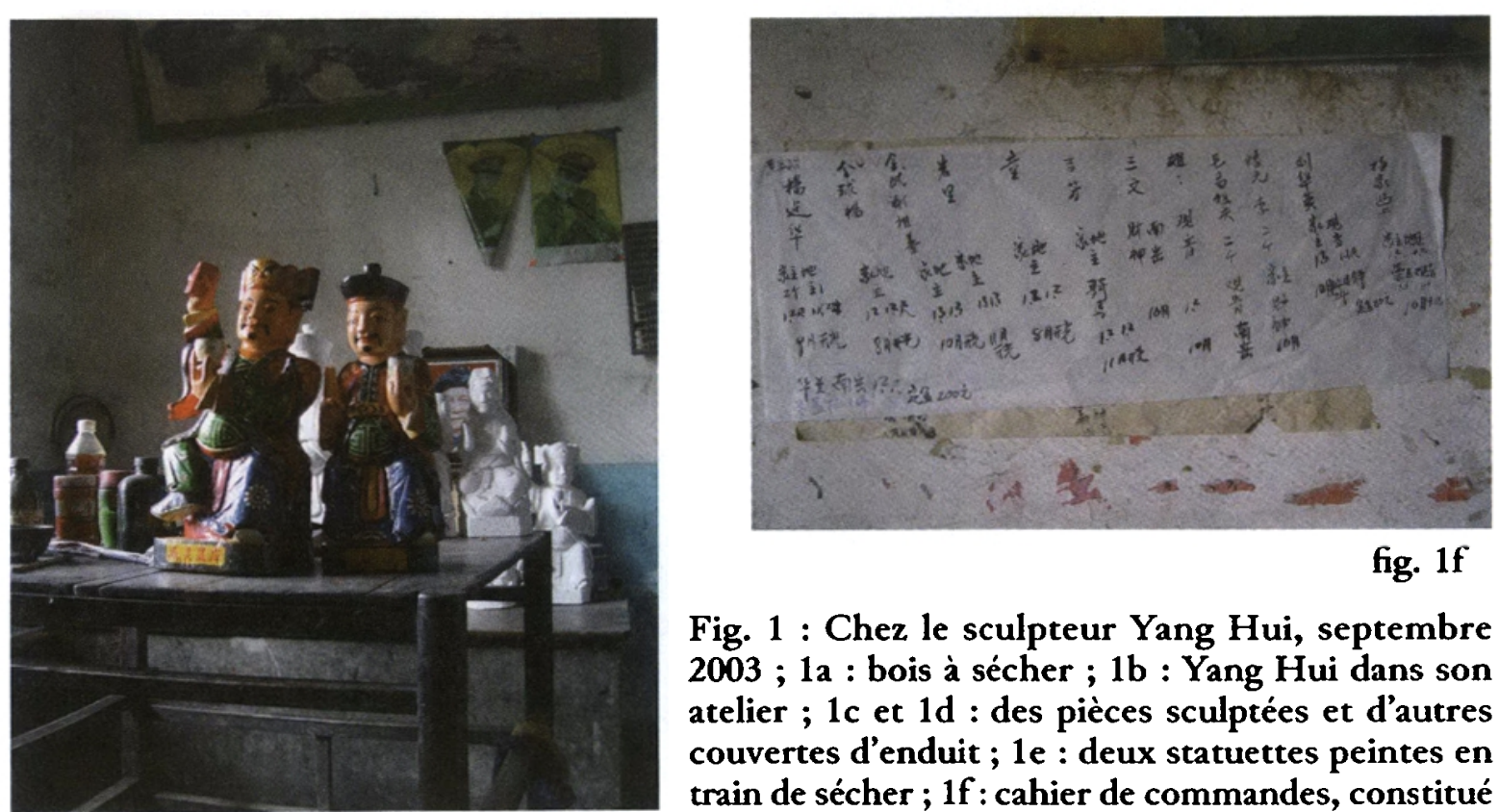

fig. 1f

Fig. 1 : Chez le sculpteur Yang Hui, septembre 2003 ; $1 \mathrm{a}$ : bois à sécher ; $1 \mathrm{~b}$ : Yang Hui dans son atelier ; 1c et $1 \mathrm{~d}$ : des pièces sculptées et d'autres couvertes d'enduit ; $1 \mathrm{e}$ : deux statuettes peintes en train de sécher ; if : cahier de commandes, constitué fig. 1e d'une feuille collée au mur. Photos : Alain Arrault. 
bouteilles et pots de couleurs et de vernis (les expressions choisies par Yang pour

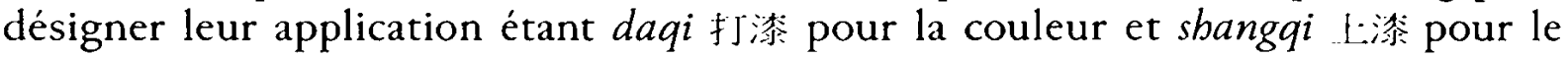
vernis transparent). Deux pièces achevées étaient en attente de «livraison » : encore un maître des lieux, avec un chapeau à la mode des Qing, et un maître de famille (fig. Ie). Pour la première statuette, le nom était inscrit sur le socle ; la deuxième présentait une formule propitiatoire (weiling xianying 㛌灵显应). Cette pièce était surtout habillée des vêtements typiques de beaucoup de statuettes anciennes, dont le

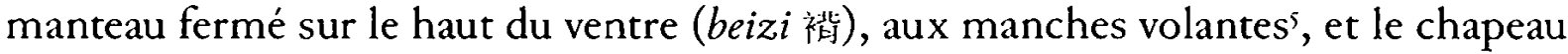
ailéb. Les explications de Yang Hui à propos de ces représentations n'entrèrent pas dans les détails : il préférait utiliser pour ses statues le terme d'« icônes bouddhiques » (foxiang 佛像)', et les identifier aux couleurs du vêtement (par exemple : le "bouddha » au manteau rouge ou à la veste verte, etc.). Il y a fort à parier que les spécialistes des religions porteraient, de ce fait, un regard sceptique sur les compétences rituelles de cet homme qui, apparemment, n'occupait pas une place très élevée dans la hiérarchie locale des «maîtres exorcistes » (shigong 㕞公) $)^{8}$. Certains de ses « collègues », résidant « en ville » et visités à la même occasion, semblaient avoir une situation économique et sociale plus élevée ; lors de notre passage, ils étaient occupés à des commandes plus importantes et se montrèrent parfois plus précis dans l'identification des personnages représentés dans leurs sculptures ${ }^{9}$. Cependant, dans leur production, certains détails avaient été modifiés par rapport à une préparation plus traditionnelle : par exemple les épaisseurs d'enduit, de papier et de vernis superposés étaient substituées par des couches épaisses de vernis moderne ou de peinture, essentiellement de couleur or, rouge et noire. La standardisation de ces pièces ne laissait plus de place aux motifs d'autrefois, colorés et parfois inattendus, que l'on voyait encore sur certaines pièces de Yang Hui, finalement plus « authentiques».

5. Sur la difficulté à choisir un terme désignant ce manteau parmi les termes de vêtements utilisés dans les rituels taoïstes, voir Michela Bussotti, 2006.

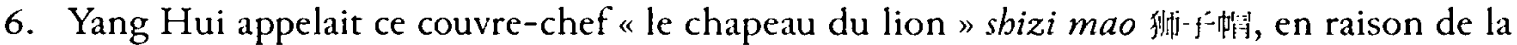
tête d'animal sur le front. Mais nous savons que d'autres termes sont utilisés, tel que " chapeau [ou

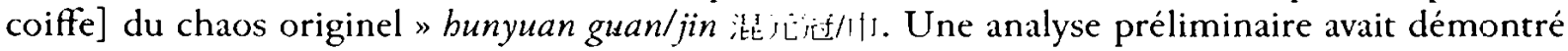
les limites de ces définitions, certes utilisées localement, mais pour lesquelles il reste difficile d'établir une correspondance avec le passé, entre autres à cause d'une tradition où description et représentation d'objets se présentent rarement ensemble. À ce propos, voir mon texte non publié :

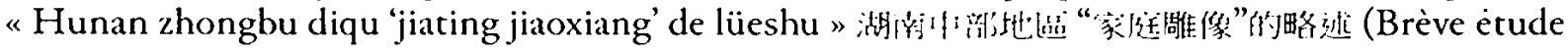
sur la production " familiale » de statuettes sculptées dans le Hunan central), 2006.

7. D'ailleurs, au moment de consacrer de nouveau une pièce représentant Kang Miaoling 恼少 \% (né en 1783, Tor66) en 2000 , le nom noté dans un nouveau certificat rédigé par Chen Kuanren

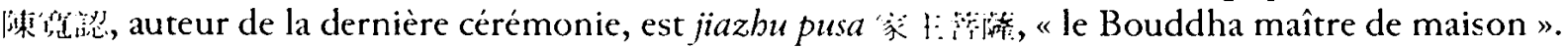

8. Dans le certificat établi pour une statuette que nous lui avons commandée (voir plus bas),

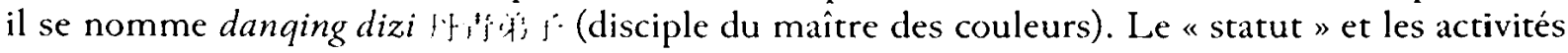
de Yang Hui et de ses confrères cités dans cet article peuvent être comparés à ceux de certaines catégories de "spécialistes " d'activités religieuses et rituelles décrites dans les travaux d'Adam Yuet Chau, notamment "'Superstition Specialist Households...'?: The Household Idiom in Chinese Religious Practices ", Journal of Chinese Ritual, Theatre and Folklore, 2006, 153, p. 183-184.

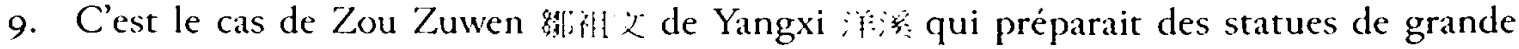
dimension et habitait dans une maison confortable et tout a fait accessible. 
Le cahier de commandes de Yang Hui était cependant loin d'être très rempli. Sur une feuille collée sur un mur de sa maison (fig. If $)^{10}$, on pouvait lire des notes indiquant les noms des commanditaires suivis d'une brève description de la commande :

- Yang Zhanhua 㛫趈化: : maitre de famille, deux pièces de 1,2 chi 人 ; maître des lieux, une pièce de $\mathrm{I}, 2 \mathrm{cbi}$; [cérémonie de] consécration en septembre.

- Jin Qiuyang 金球楊: maître de famille,1,2 ; maître des lieux,1,2 chi ; [cérémonie de] consécration en août.

- Jin Qiu[xie] zushan 全球[謝]祙缮: maitre de famille, maitre des lieux,I,3 [chacun] ; [cérémonie de] consécration en octobre.

- Yan[li] 艺[里] : maître de famille, maître des lieux,r,3 [chacun] ; lcérémonie de] consécration en novembre.

- Tong 望: maître de famille, maître des lieux,1,2 [chacun] ; [cérémonie de] consécration en août.

- Jifang 占管 : maitre de famille, maître des lieux, à cheval, 1,2 [chacun] ; [cérémonie de] consécration en novembre.

- Sanwen 二文: Caishen 財神 et Nanyue 南盾 [dadi 大爰 ?] ; octobre.

- jiejie 姐姐: Guanyin,1,2; octobre.

- Maoyi Zuqing 毛罧祙慶 : deux pièces, Guanyin et Nanyue [dadi] ; octobre.

- Fuyuan $\mathrm{Li}$ 福元 1 : : deux pièces, maitre de famille et Caishen ; octobre.

- Liu Huaying 刘华热：maitre de famille, I,3 ; Guanyin, I,I ; le 24 octobre ; acompte (dingjin 定全) de 20 yuan.

- Yangjia tu shang 杨家政上: maître de famille, I,2 ; maître des lieux,1,2 ; Yaowang 棦F:, I,I Guanyin, I,I ; ... octobre..."

À partir de cette liste, on constate que les typologies se répètent, apparemment moins personnalisées que par le passé. Les statuettes dont la préparation était en cours semblaient correspondre aux commandes pour le dixième mois, que nous interprétâmes au sens moderne de mois d'octobre, soit un mois après notre visite. Une partie des commandes concernaient des membres de la famille, comme dans le cas de la "grande sœur » (?, jiejie), qui avait demandé une statuette de Guanyin ; d'autres appellations abrégées pouvaient indiquer que Yang Hui connaissait bien une partie de ses commanditaires. Sur un lot de douze commandes, la plupart comportant deux statuettes, cinq commanditaires semblaient avoir demandé à Yang Hui une cérémonie de consécration et, parmi eux, un seul avait fixé le jour précis et donné

Io. Ce détail montre bien le caractère éphémère de cetre sorte de notation, et explique les difficulrés que nous avons à établir prix et dépense pour les différents secteurs de l'artisanat traditionnel, à plus forte raison si l'on veut produire une histoire économique de cette sorte d'activité. Le papier en question était collé sur une feuille plus ancienne. À l'évidence, Yang collait sur le mur les feuilles de commande les unes sur les autres jusqu'au moment où l'ensemble était éliminé pour recommencer.

II. À certe occasion nous ferons aussi une commande, au nom de Hua Lan 任: (湅) et Migaila 米着fit: un Nanyue [dadi] de 1,2 chi de hauteur ; l'acompte est alors de 200 yuan, qui correspond au prix total payé à l'avance, la statue du dieu du Pic du Sud étant à récupćrcr lors d'une prochaine visite (ce qui fut le cas : voir une photo de cette pièce consacrée dans "Statuettes religieuses et certificats de consécration en Chine du Sud, XvII'-XVIII" siècle " (avec Alain Arrault), Arts Asiatiques, 63, 2008, p. 59, fig. 35 . 
un acompte. Dans la liste des commandes, était aussi indiquée la dimension des statuettes, de I,I, I,2 et I,3 chi $(36,39$ et $42 \mathrm{~cm}$ environ respectivement). En fait, dans son atelier, des pièces de trois tailles différentes étaient disponibles ${ }^{12}$.

Deux mois plus tard, lors d'une deuxième visite, la feuille des commandes avait évolué (fig. 2) : dans la liste déjà évoquée, les commandes de Yang Zhanhua, Jin Qiuyang, Sanwen et jiejie étaient biffées, ayant probablement été réalisées ; celles pour Jin Qiu[xie] zushan, Liu Huaying et Yangjia tu shang avaient quant à elles une date fixée pour la cérémonie de consécration, tandis que Tong avait repoussé sa commande de deux mois. Une deuxième feuille, collée à la suite de la précédente, portait des commandes de personnes de patronymes Yang 䅄 et Duan 段 :

- Yang [Yuan]zong 楊 [范]宗: maitre de famille, maître des lieux, I,3 [chacun] ; [cérémonie de consécration déjà effectuée] en septembre (commande biffée).

- Yang Xintang 楊心垈 : maittre de famille, mâtre des lieux, I,3 [chacun] ; [cérémonie de consécration], 20 octobre.

- Duan Xutou 段緒头: Guanyin, maître de famille, maître des lieux, Nanyue [dadi], Yaowang, I chi [chacun]; [cérémonie de consécration au] début du mois de décembre.

- Yang Yuanqian 槛元遷 : maître de famille, Guanyin, Dieu de la richesse, de I à 1,3 chi.

- Yang [Mei]fan 㛫 [美]凡 de la montagne [-]che de la mine du Nord (北喽[-]沶Ll) : maître de famille, maître des lieux, 1,3 [chacun] ; [cérémonie de consécration prévue pour le] 8 novembre; acompte (dingjin 定叙) de roo yuan.

Yang Hui, qui cette fois était accompagné de son épouse, travaillait de plus à une commande de divinités en papier (xiangyi 椎衣, litt. "visages et habits ") ${ }^{13}$ de cent pièces, dont 40 de grande dimension et 60 de petite dimension, à livrer pour le 18 octobre. Parmi les xiangyi commandés à cette occasion, il y avait toutes sortes de divinités, y compris une figure représentant Mao Zedong 毛澤束 : leur liste était accrochée, au mur de la cuisine, près des commandes de statuettes et à la gauche d'une image bienveillante et protectrice montrant les leaders historiques du parti communiste (fig. 2).

Cette brève description nous a transportés auprès des graveurs du Hunan par l'évocation d'un cas particulier, celui du " disciple du maître des couleurs » Yang Hui, de ses modestes commandes et de sa production colorée. Dans les pages suivantes nous chercherons à fournir d'autres informations sur ces " artisans religieux » contemporains, comme sur ceux du passé.

12. Les informations économiques sont très rares; voir un document sur les participations données pour une statuette, présenté dans ce volume par A. Arrault, fig. 40 et 41, p. no.

13. Les xiangyi sont des portraits de divinités en papier à figure entière, souvent utilisés dans des ensembles (autrement dit pour représenter des assemblées de divinités), dont les visages sont parfois peints, parfois imprimés par des gravures frustes, comparables à celles des papiers d'offrande. 


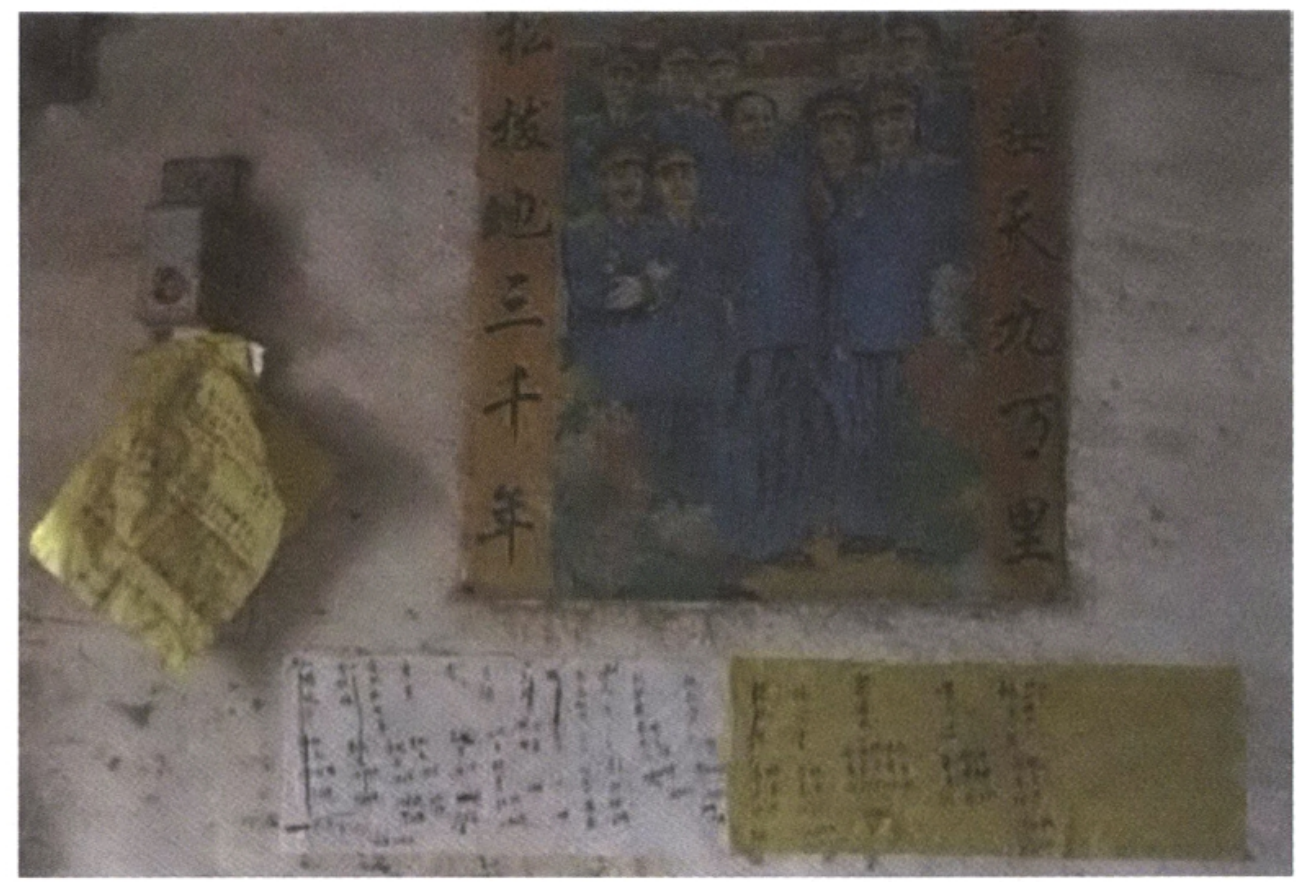

Fig. 2 : Chez le sculpteur Yang Hui, octobre 2003. Feuilles de commande des statuettes et de xiangyi 相长 apposées au mur de la cuisine, au dessous et à la gauche du portrait du président Mao accompagné des principaux leaders du parti communiste chinois. Image du documentaire de Jean-François Dars et Anne Papillault, CNRS Images media.

\section{Sculpteurs et sculptures contemporains}

Certaines publications chinoises contemporaines revendiquent pour le Hunan une tradition d'arts populaires basés sur le travail du bois. Une partie d'entre elles est consacrée aux centres de production d'estampes populaires et d'estampes du Nouvel An, nécessitant la gravure de planches pour l'impression, dans le Sud de la province, dans des lieux connus aussi pour la production du papier de bambou ${ }^{14}$. Un type d'imprimé qui demande, également, la gravure du bois ainsi que la pratique du dessin et de la peinture est représenté par les papiers d'offrande (zbima 紙馬). Dans un récent article, «À propos du papier d'offrande de Meishan " $^{15}$, Hu Nenggai 胡能改

14. Dans Minjian jianzbi muban bua 民間剪纸术版畫 (in Hunan minjian meishu quanji 湖 南氏間美術全集, vol. 4, Changsha 長沙, Hunan meishu chubanshe 湖南罢術出版社, 1995) sont présentées les estampes populaires faites à Tantou 灘頭, dans l'actuel territoire de Shaoyang 讧 隄 (appelé par le passé Baoqing 賔鹿), pour lesquelles la gravure de planches de bois (multiples pour la réalisation d'estampes en couleurs) est nécessaire. On y reproduit aussi des exemples de zbima 紙馬, les papiers d'offrande à impression monochrome destinés à être brûlés : présentant des sujets religieux assez simples, ils rappellent certaines estampes incluses au dos des statuettes dont nous verrons des exemples plus bas.

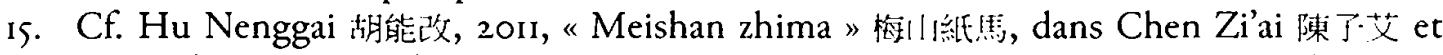
Hua Lan 萿瀾 (Alain Arrault), éds., "Xiangzhong zongjiao yu xiangtu shebui" diaocha baogao ji 
relate ses enquêtes conduites dès 2004 dans son village natal de Baixi et d'autres localités près de Xinhua (le village de Huashan 花山桄, la commune de Shangmei 上梅鎮, etc.) chez les producteurs de zhima et de xiangyi (fig. 3$)^{16}$. À cette occasion, il a collecté des «Album[s] de visages et d'habits » (xiangyi pu 相衣語) et des «Livre[s] d'initiation》(benjing 本經); en dehors de leur contenu, ces documents sont intéressants car ils impliquent une «transmission » de maitre à disciple et une initiation, aussi élémentaire soit-elle ${ }^{17}$. L'auteur retrace par ailleurs une transmission sur plusieurs générations pour les artisans de Baixi, à partir d'un certain Ya Xizhong 亞錫仲, un maitre ancestral ( $z u s h i$ 祖秥i) dont les origines ne sont pas données et qui serait probablement un immigré, ayant introduit la pratique sur place. Le savoir-faire se transmet sur plusieurs générations, à de nombreuses personnes de patronyme Zhang 㢭, puis à Cheng Caishen 成才申 et Cheng Caihui 成才恵等. On arrive ainsi à l'époque contemporaine : Cheng Caihui instruit $\mathrm{Hu}$ Liji 胡江基 (1902-1968), père de Hu Fading 胡法定. Zhang Deqi 伥德奇 (1918-1990), qui était d'abord l'élève de Cheng Caihui, étudie ensuite auprès de Hu Liji et il transmet enfin son savoir à Zhang Yongyan 浐永延, toujours en activité aujourd'hui, qui reçoit aussi de Zhang Deqi (le degré de parenté entre les deux n'étant pas expliqué) les

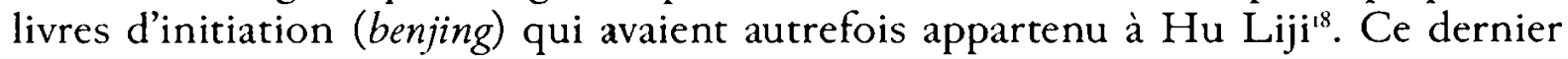
nom est intéressant car, parmi les sculpteurs de statuettes religieuses actifs à Xinhua pendant la période républicaine, on trouve des $\mathrm{Hu}$ ayant le même caractère $l i$ ir dans leur prénom : il pourrait donc s'agir de frères, ou plutôt de cousins, proches ou éloignés, l'un produisant des zbima, les autres des statuettes't.

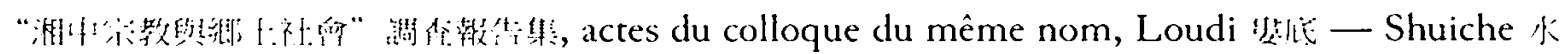
H, 24-29 juin 2006, Beijing, Zongjiao wenhua chubanshe

16. Voir aussi fig. 38 dans l'article d'Alain Arrault dans ce volume. Des danqing dizi y f'f i comme Yang Hui peuvent réaliser des séries de xiangyi, voir fig. 2 ci-dessus.

17. Les xiangyi pu donnent les indications des caractéristiques que chaque divinité doit présenter lors de sa représentation. Le terme benjing signifie "notre livre ", mais on traduit par "livre d'initiation " : il s'agit des textes du maitre que le disciple doit recopier et apprendre par cœur tout au long de son apprentissage ; dans notre cas, ce sont des listes de noms de divinités : ce sont les esprits sur lesquels l'auteur de zhima peut intervenir par sa pratique. Des exemples de ces textes sont reproduits à la fin de l'article de Hu Nenggai, 2orı, s. p.

18. Deux autres cas de transmissions sont décrits par Hu Nenggai, art. cit. Dans un cas, deux benjing auraient existé, dont un aurait été détruit lors de la Révolution culturelle. Leurs

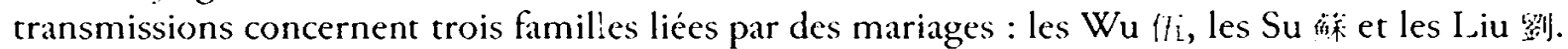
Wu Shengdian ffi月勝具, jadis patron d'un magasin de zhima à Wuhan 武㴖 (Hubei 湖远), était le

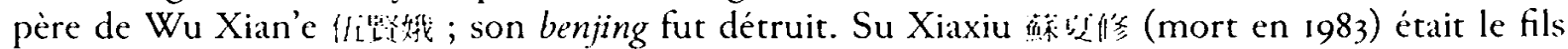
de Su Zhaoguang 稣兆炶 et l'apprenti de Wu Shengdian depuis l'âge de douze ans. Il finit par épouser la fille de ce dernier, Wu Xian'e. Leur fille Su Shimei 莉们Y aurait récupéré à la mort du père son benjing, transmis donc par les $\mathrm{Su}$, pour le passer à son époux, Liu Dengyong 制

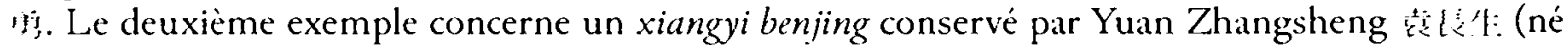
en 1917) depuis 1938. Ce document aurait auparavant été copié quatre fois, puis remis à Yuan par Xiao Youfa iflifir
}

19. 1)ans notre corpus (décrit à la note 45), une statuette avec un certificat daté de 1929, qui a comme adresse un village du district de Xinhua, est attribuée au "maitre local " (chusbi liti $\mathrm{t}$ ) Hu Lixin th ir fo (To539); une pièce, postérieure de deux ans mais sans adresse, porte le nom de 

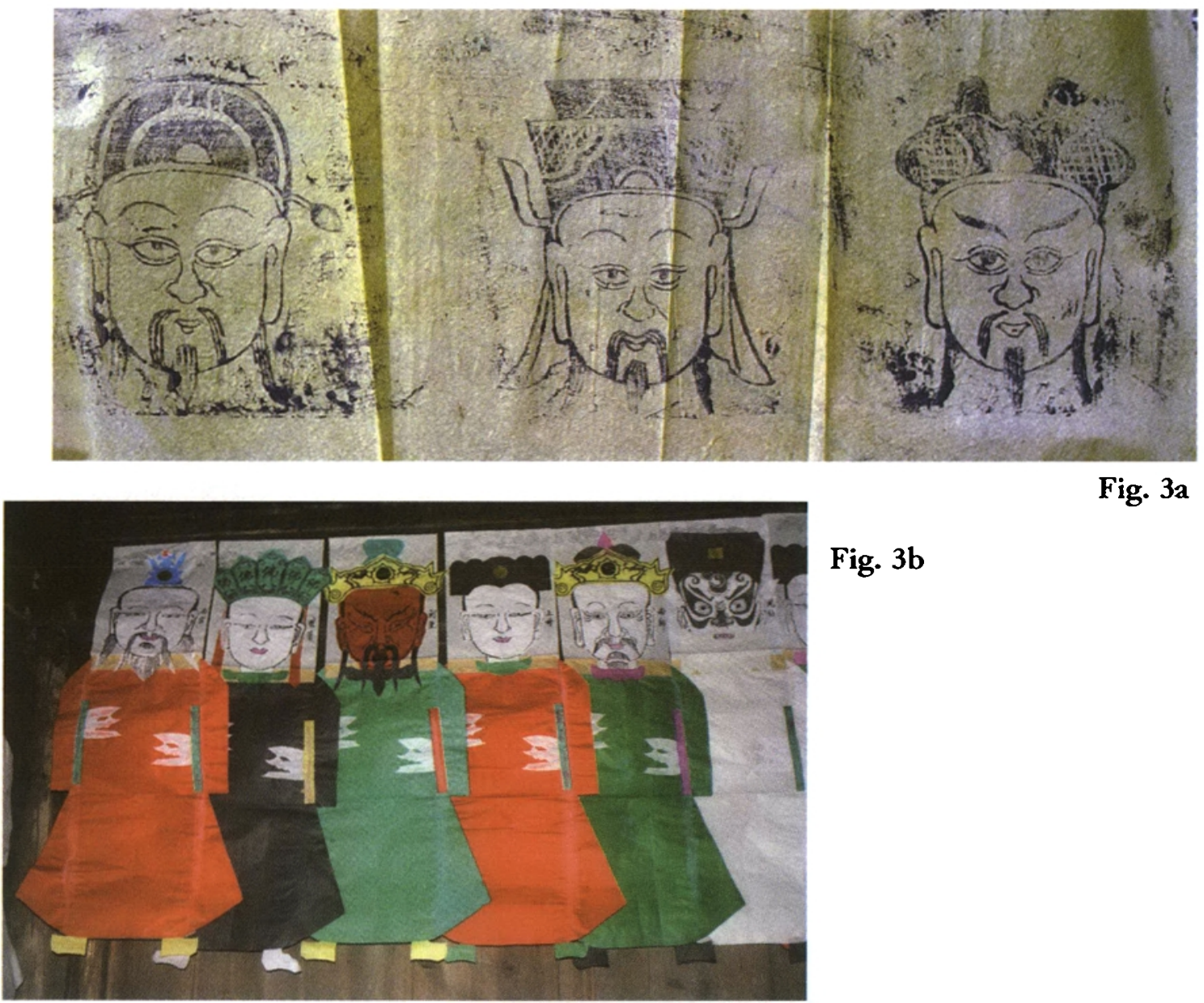

Fig. 3a

Fig. 3b

Fig. 3c

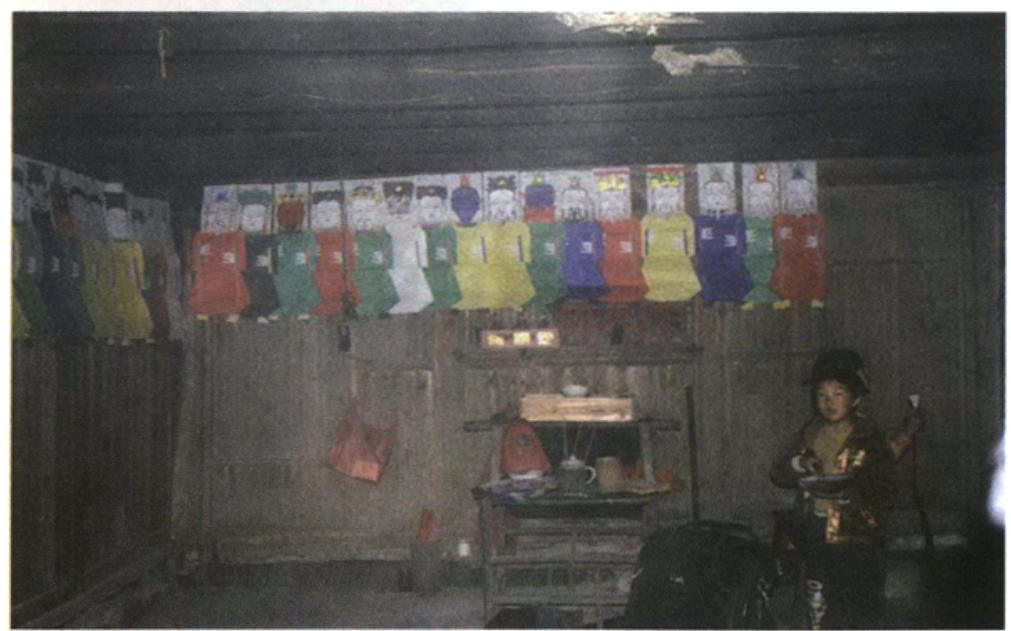

Fig. 3 : Visages et habits de divinités (xiangyi) ; 3-a, détail de têtes imprimées à Tantou en 2003 ; photo : Michela Bussotti ; 3-b, quelques personnages à figure entière ; 3-c, disposition de l'ensemble des xiangyi autour d'un petit autel pour le rituel Leipan jiao 雷盤醮. La tête de chaque personnage est imprimée, colorée et complétée du nom écrit sur le côté, le reste du corps est en papier découpé. La technique de fabrication très élémentaire des xiangyi et la pauvreté du décor de l'image ici reproduite, ne doivent pas occulter le travail relativement important qui est nécessaire pour constituer cette sorte d'autel, notamment lorsque la totalité des divinités est convoquée dans ces déploiements éphémères. Les xiangyi, comme les zhima, sont brûlés à la fin du rituel. Images collectées à Baishui $\boxminus$ 水 (Shuichezhen 水車鋲, district de Xinhua), 2009. Photos : Alain Arrault. 
D'autres publications consacrées au Hunan parlent de la sculpture du bois sous toutes ses formes, réunissant dans des recueils des photographies de bas-reliefs ou de hauts-reliefs et de sculptures en rond de bosse ${ }^{20}$. Ces livres illustrés, avec quelques légendes et des introductions générales, présentent les éléments en bois du bâtiment ou du mobilier travaillés en relief - fenêtres, portes, panneaux, etc. - ainsi que les pièces sculptées en rond pour la construction, par exemple pour décorer les jonctions des poutres ou la base de colonnes. S'y trouvent aussi des statuettes à figure entière ou des têtes seules, des marionnettes et des masques. Effectivement, de la même façon que Yang Hui réalisait des objets rituels en bois et en papier, d'autres sculpteurs, dont nous parlerons plus bas dans cette section, travaillaient (et travaillent) des objets de bois différents du point de vue de la forme - plate ou ronde - et de l'usage, même si la finalité cultuelle semble être dominante. Si les reproductions de ce type d'objets ne manquent donc pas, explications et analyses sont (volontairement ?) négligées et les sculpteurs de ces pièces ne sont pas mis en avant ${ }^{21}$.

Il faut donc une fois de plus se baser sur des textes appartenant aux sculpteurs euxmêmes, ou sur des enquêtes menées par des personnes vivant sur place, directement impliquées dans ces affaires. C'est le cas par exemple de Feng Guanghua 奉光萑, décrivant l'histoire et les compétences d'un membre de sa famille, Feng Xiaoyuan

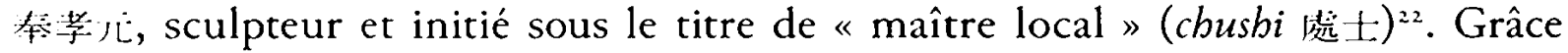
à ces documents de première main, nous pouvons constater l'existence de deux " lignées » de sculpteurs (qui pourraient aussi se succéder faute de dates connues), l'une commençant avec Yang Wu zushi 陽武祖師i, l'autre avec Dun Faxian 頓法仙： selon les mots de Feng Xiaoyuan lui-même, le premier serait à considérer comme le maitre spirituel des cbusbi (cbusbi zushi 處 t.神们i, littéralement " maître ancestral des maîtres locaux », en quelque sorte le " maître des maîtres ») et le second comme l'initiateur d'un lignage (shijiao zushi 師教祖郎, littéralement " maître ancestral de la doctrine des maitres »), Dun Faxian étant en fait un des fondateurs de la secte Yuanhuang 元是 (Souverain de l'Origine) des maitres exorcistes (shigong 舅公) ${ }^{23}$.

Hu Ligai 胡渻 (050I/C:1356) ; dans les certificats, nous recensons également un nombre très important de Hu montrant le même caractère générationnel li, qui ont été actifs quelques décennies plus tôt : par exemple, Hu Lirong 胡割获 est mentionné dans un autre certificat indiquant le district de Xinhua, daté de 1879 (To095). On explique parfois ce décalage entre gens portant, dans leurs prénoms, les mêmes caractères générationnels, par le fait que les différentes branches d'un même clan étaient plus ou moins fortunées ; ainsi les mariages se célébraient plus ou moins rapidement, entraînant un décalage important sur plusieurs générations.

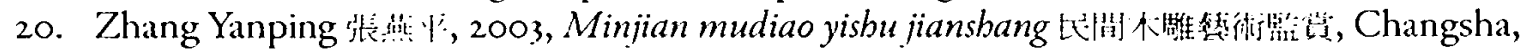

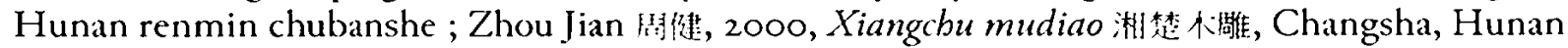
meishu chubanshe.

21. C'est le cas dans Zhou Jian, 2000, p. 8. Plus haut dans le même ouvrage on présente dans le détail quelques sculpteurs du $\mathrm{xx}^{\circ}$ siècle, mais dont la renommée est due à d'autres catégories d'objets sculptés.

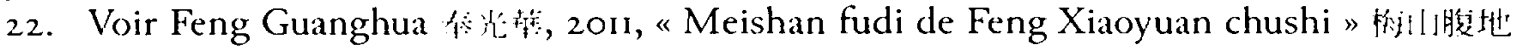

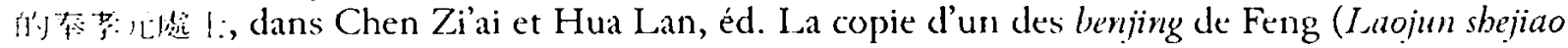

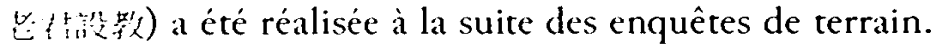

23. Sur le personnage de Dun Faxian, voir A. Arrault, 2008, "Analytic Essay on the Domestic 

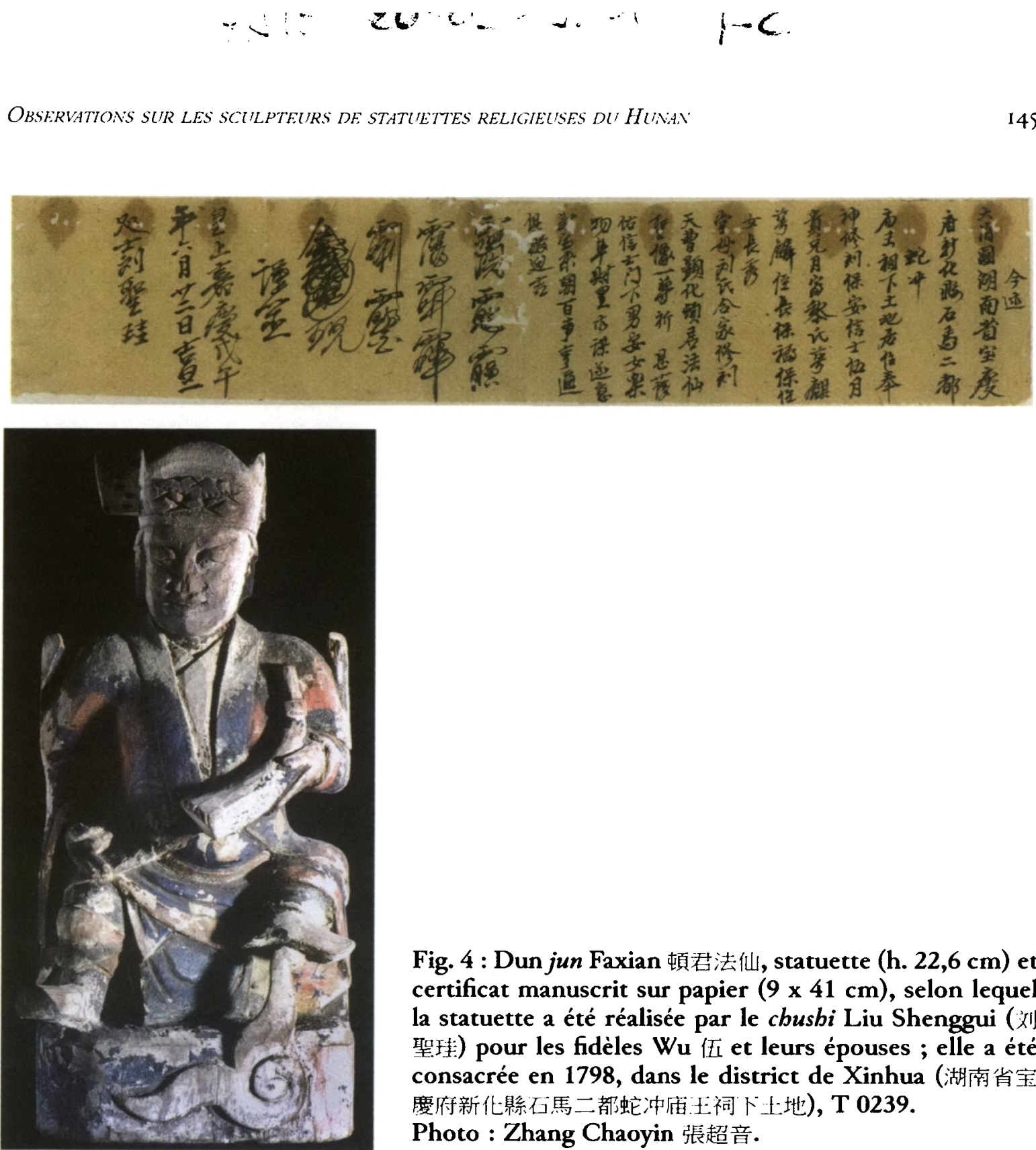

Fig. 4 : Dun jun Faxian 頓君法仙, statuette (h. $22,6 \mathrm{~cm})$ et certificat manuscrit sur papier $(9 \times 41 \mathrm{~cm})$, selon lequel la statuette a été réalisée par le cbushi Liu Shenggui (刘 聖珪) pour les fidèles $W u$ 伍 et leurs épouses ; elle a été consacrée en 1798, dans le district de Xinhua (湖南省宝 慶府新化縣石馬二都蛇冲庙玨袷卜土地), T 0239.

Photo : Zhang Chaoyin 張超音.

Les livres d'initiation de Dun seraient passés dans les mains de quinze personnes différentes avant d'arriver à Luo Falian 羅法連. À la mort de ce dernier, son fils, Luo Faxing 羅法興 (1900-1964) ${ }^{24}$, n'avait que six ans et il alla étudier avec Li Yizhuan 李揖傳, dont le nom est également noté parmi ceux de la lignée d'initiés qui débute avec Dun Faxian. Une fois adulte, Luo Faxing eut parmi ses disciples Feng Xiaoyuan (né en 1928) qui devint à son tour chushi à seulement seize ans.

Statuary of Central Hunan: The Cult to Divinities, Parents and Masters ", Journal of Chinese Religions, 36, p. 37-38 et note 34 à propos de la secte Yuanhuang. Les interprétations à propos de Yang Wu et Dun sont multiples, comme le démontrent les témoignages recueillis par Feng Guanghua à la fin de son enquête (op. cit.) : cela n'a rien d'étonnant dans un cadre qui échappe aux normes d'une tradition institutionnalisée, où chaque lignée est porteuse de ses propres interprétations.

24. Dans la collection de statuettes de Yan Xinyuan on trouve celle d'un certain Luo Faxian mais malheureusement les dates ne correspondent pas (Y.113057-2-2). 
Selon la pratique locale, un chusbi choisissait un seul apprenti parmi les candidats à l'initiation qui, à la fin d'une pratique de trois ans, pouvait être lui-même ordonné chushi. En cas d'échec, l'apprenti pouvait continuer ailleurs sa préparation ou pratiquer à son compte, sans toutefois pouvoir utiliser le titre de chushi. Feng fut accepté par Luo en 1941, sous " contrat » établi entre le maître et ses parents : l'adolescent ne devait pas être payé, seulement nourri et hébergé par le chusbi. La première année, il allait simplement aider et ce n'est qu'au cours des deux dernières années qu'il pouvait apprendre véritablement l'art du cbusbi. En échange de ce transfert de connaissances, Feng s'engageait à s'occuper de Luo pour toujours en cas de nécessité, comme s'il s'agissait de son père. Il devait aussi se soumettre à des règles de diététique pendant son apprentissage. Une première rencontre ayant permis aux parents de présenter la requête pour leur fils et la formulation des conditions posées par le maître, la deuxième rencontre prévoyait des rituels et des offrandes (aliments, habits, objets pour les rituels) de la part des Feng à Luo. Après quoi Feng Xiaoyuan put se rendre chez Luo Faxing, où il resta trois ans comme s'il était un membre de sa famille.

En 1943, l'apprentissage terminé, eut lieu une nouvelle cérémonie, plus importante que celle du début, d'une durée de trois jours, au terme desquels Feng devint finalement chushi. Cependant, histoire du xx $x^{e}$ siècle oblige, il semblerait que Feng n'ait pas eu beaucoup d'occasions de pratiquer son art, vivant plutôt de l'agriculture et de l'élevage. Ce n'est qu'à la fin des années 1980, avec le démarrage des travaux pour la (re)construction des temples, qu'il aurait été plus sollicité pour réaliser des statues en bois mais aussi en argile ${ }^{25}$. Ce renouveau ne l'aurait pas enrichi, un point de peu d'importance pour lui, l'une des obligations d'un véritable chushi étant précisément de conduire une vie très modeste, sa paye devant être calculée sur la base des salaires des artisans ordinaires ${ }^{26}$.

En plus de ces informations objectives, l'enquête sur Feng Xiaoyuan nous dévoile certains des gestes et quelques-unes des formules religieux qui accompagnent le travail matériel du chushi en tant que sculpteur, des éléments autrement difficiles à saisir lors d'une visite à l'atelier ou même lors du déroulement du rituel, car justement propres à l'initié. Le chushi Feng pratique aussi l'écriture de talismans, à tracer dans l'air ou sur divers supports, pour éviter les intempéries, invoquer la pluie nécessaire aux moissons, chasser démons et maladies, assurer la longue vie et le bien-être de la famille et de ses animaux, etc. ${ }^{27}$. Trois de ces talismans -

25. Feng Guanghua, zon1, s. p., donne une liste détaillée des productions de Feng Xiaoyuan, essentiellement pour des temples, composées de statuettes de divinités bouddhistes et taoïstes, mais aussi de divinités locales. Il paraît évident que beaucoup d'autres statuettes n'ont pas été répertoriées, par exemple des petites sculptures pour des particuliers, moins importantes et surtout utilisées pour des rites familiaux.

26. Si l'on accepte cette explication, la modeste existence de Yang Hui, décrite plus haut, pourrait prendre un autre sens.

27. Ces talismans sont classifiés : pour Feng Xiaoyuan, deux talismans sont à écrire dans l'air, dont l'un sert de purification au moment de sculpter les statuettes, l'autre pour la pacification de la maison et la protection des animaux domestiques. Les autres sont des talismans à tracer sur des drapeaux pour des cérémonies (dont un pour demander la pluie, l'autre pour la pluie nécessaire 


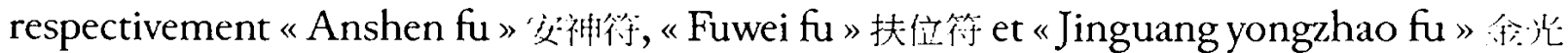
永駑符 - sont nécessaires à la cérémonie de consécration des statuettes, inclus dans les pièces elles-mêmes ou utilisés pour purifier et protéger les lieux.

Mais revenons au début du processus, au moment du choix de la qualité du bois ${ }^{28}$. Une fois les morceaux triés sur la base des dimensions nécessaires, il faut les purifier. Le chusbi prépare alors un bol d'eau lustrale et des mets appropriés (vin, végétaux et fruits, pâté de soja et bouillon [sans viande pour les statues bouddhiques]) pour un bref rituel où il invoque l'intervention du «maître ancestral " (shizu lifilil) et conclut par l'écriture dans l'air d'un talisman de purification. La sculpture doit être réalisée dans un état de pureté. Si le chusbi est appelé pour d'autres affaires en cours de travail, il doit se purifier de nouveau avant de recommencer à sculpter, soit par un simple lavage des mains, soit par la purification de tout son corps, selon la gravité de ce qu'il a eu à traiter. À une date faste établie en accord avec le commanditaire, on procède au remplissage de la cache au dos de la statuette avec les médicaments ${ }^{29}$, le certificat de consécration et les talismans (aspergés du sang d'un coq sacrifié). S'ensuit la cérémonie de consécration elle-même qui, dans le cas de Feng, se déroule en cinq étapes, conformément à ses livres d'initiation, le Qingshengke benjing 請望: 科本經 (Livre rituel d'invitation des saints) et le Chusbi kaiguang dianxiang benjing 處 1:開光點像本經 (Livre de consécration des statuettes par le chushi). La première étape consiste à préparer, selon les règles, l'environnement, les objets et les offrandes nécessaires pour la cérémonie (xuanbei gongpin 選備供品). Sont ensuite convoquées les divinités, en brûlant de l'encens et des papiers d'offrande (fenxiang qingshen 焚甭 請神) et en proclamant à voix haute et basse une série de formules qui s'adressent entre autres au "maître ancestral » et aux dieux célestes et généraux du Tonnerre (tianshen leijiang 大神笛將). Vient ensuite la consécration proprement dite de la statue (kaiguang dianxiang 開光點像), quand le chusbi répète des formules en pointant à l'aide d'un pinceau les différentes parties de la pièce : les yeux, les oreilles, le nez, la bouche, le cour, la poitrine et le ventre, les mains et les pieds. Les deux dernières étapes de la cérémonie incluent le positionnement de la statue sur l'autel familial (shenxiang anwei 神像安位) et le remerciement aux fidèles - commanditaires (xiezbu

aux cinq céréales) ou à coller dans les différentes parties de la maison (de cinq sortes différentes, ils sont efficaces contre les mauvais esprits, les maladies, les incendies, etc.). Trois talismans sont à tracer sur la surface de l'eau lustrale et autant à porter sur la personne (ayant une puissance démonifuge, assurant une vie longue et saine, éliminant les souffrances et les maladies, physiques ou mentales. Par exemple, le talisman de Wang yuanshuai 王元帥 est utilisé contre la démence). En conclusion, sont mentionnés des talismans pour des cérémonies spécifiques, propitiatoires ou exorcistes, et d'autres nécessaires à la préparation des espaces et des objets utilisés pour des rituels. Rappelons qu'il s'agit des talismans appris par Feng et sa lignée : autant que les outils pour peindre ou à sculpter les statuettes, ils constituent les « instruments » de travail du chushi.

28. Le bois choisi par Feng étant, par ordre de préférence, le gingko, le camphrier, le pin et le cyprès, l'érable et l'acacia. Sur les bois effectivement utilisés, voir dans ce volume l'article de Mechtild Mertz et Itoh Takao.

29. Selon Feng (art. cit.), les composants doivent représenter les différents éléments naturels : des insectes ou des parties d'oiseaux, car ceux-ci volent dans le ciel; des végétaux et des pierres pour le monde terrestre et ses produits; des perles ou des hippocampes pour représenter l'eau. 
$z h u c i$ 謝王祝詞), ce qui revient aussi à congédier les divinités évoquées au début de la cérémonie de consécration.

Dans le cas de Feng Xiaoyun, l'ensemble de ses activités a été retracé par une tierce personne. Le récit de Chen Yisong 陳益松, qui réside dans la circonscription de Daxiongshan 大熊l] à Xinhua, est en revanche autobiographique ${ }^{30}$. Sa formation ${ }^{31}$ et ses compétences se révèlent multiples, et sa vocation de sculpteur est tardive. Il expose chez lui un autel du tonnerre (Huizhen leitan 曾貞笛壇), des statuettes gravées de sa main représentant maîtres et ancêtres, ou encore des objets propres aux cultes médiumniques féminins ${ }^{32}$. Il revendique aussi d'importants travaux collectifs de sculpture, par exemple pour un temple de Guanyin 觀音 proche de sa maison (fig. 5 f). Bien qu'il se décrive lui-même comme " maître des couleurs - maître local " (danqing chusbi 丹青處士), le lecteur ne décèle pas dans son récit les détails d'une initiation précise, comme c'est le cas pour Feng. Il faut peut-être en déduire que Chen ne souhaite pas en dire trop ou qu'il a pu recevoir plusieurs formations sans toutes les mener à leur terme. C'est peut-être en raison de son parcours multiple (ou par une propension inconsciente à l'accumulation des savoirs), que Chen Yisong possède un nombre très important de livres d'initiation (fig. 5a), dont au moins 89 manuscrits qu'il présente comme les « classiques » (jingshu經書) nécessaires aux différents rites qu'il peut dispenser dans son autel du tonnerre ${ }^{33}$, et dont un est intitulé « À utiliser par Chen Yisong dans les dix directions : Album des images du maître des couleurs » (Chen Yisong shifang yingyong Danqing xiangpu 陳真松十; 隹用打清 [寺] 像譄, fig. Sb). Ce fascicule manuscrit d'une quinzaine de feuilles, qu'il dit être un manuel pour réaliser des statuettes, réunit les indications pour préparer environ 250 représentations différentes : pour chacune sont fournis le nom, la typologie (représentation féminine, d'enfant ou de vieillards, de divinités civiles ou guerrières, etc.), éventuellement la couleur du visage, ainsi que la présence d'une barbe ou non, ainsi que des indications sur la couleur et le type de vêtement, les

30. Chen Yisong, 2011, "Xinghuaxian Daxiongshan qu de bufen leitan gaikuang ji huizhen

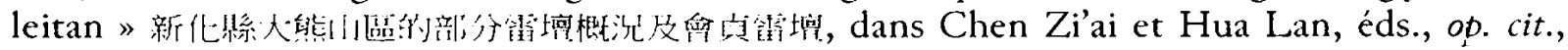
sous presse.

31. Chen Yisong est né en 1962. Il a suivi une première préparation entre 1980 et 1985 auprès d'un oncle maternel Hu Jiake 胡稣打 $(1919-1996)$ et, à son ordination de $c b u s h i$, il a pris les noms

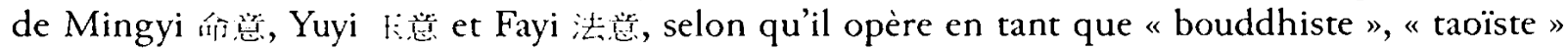
ou " maître exorciste ", de la même manière que son maître qui s'appelait Hu Huike 胡隹啝,

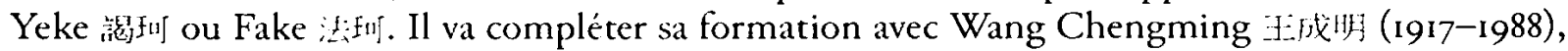
qui revendique seulement deux noms d'initiés, l'un bouddhiste Changxi 常冴 et l'autre taoïste Yexi 諰雅. Sa formation est essentiellement religieuse, il ne se mettra à la gravure qu'après ses trente ans, mais il dit cependant que cette pratique est une affaire de famille, car son père Chen Jihe 陳等利 aurait appris les méthodes de danqing de son père Chen Yushi 陳 1 1 1 , lequel avait épousé Hushi xianniang 胡氏仙娘, héritière de cet art par son père Hu Fali 胡法利 (fig. $5 \mathrm{~d}$ ), et parce qu'il se revendique de l'école du maitre ancestral Hu Fazhao 胡法照祖师i : les liens entre le Chen et les Hu sont étroits au point que sur son autel sont présentes plusieurs statuettes des Hu.

32. Dont la «Terrasse des dames" (Niangniang tai 娘娘个i); à ce sujet, voir dans ce volume l'article de A. Arrault, p. 113, note nio.

33. Selon sa classification, 31 relèvent de la tradition taoïste, 39 de celle bouddhiste et 17 appartiennent à la tradition exorciste. 


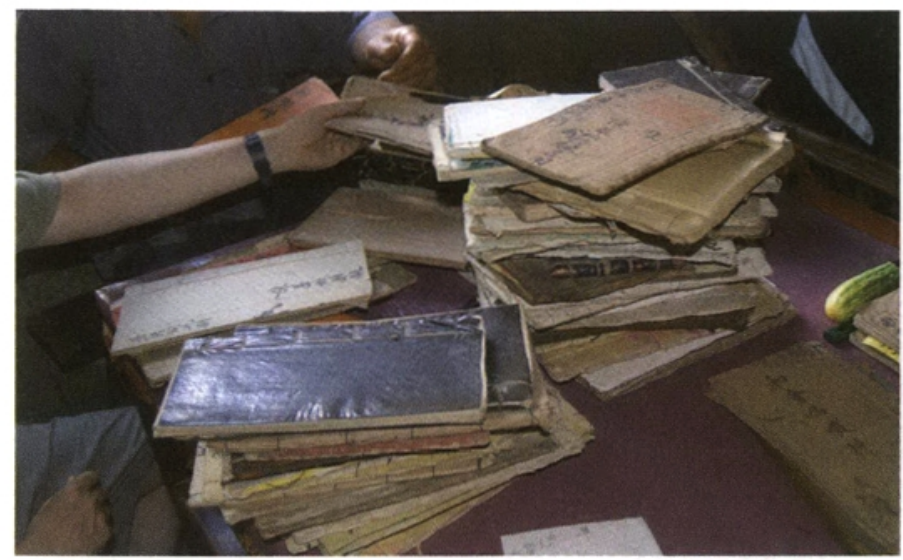

Fig. 5a

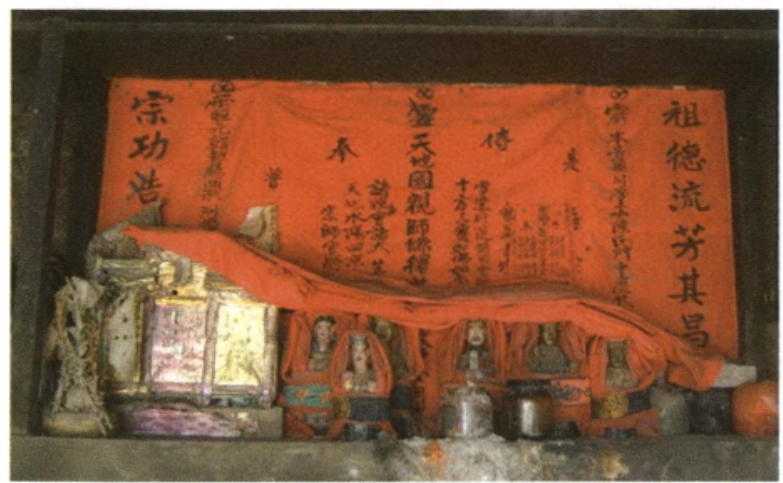

Fig. 5c
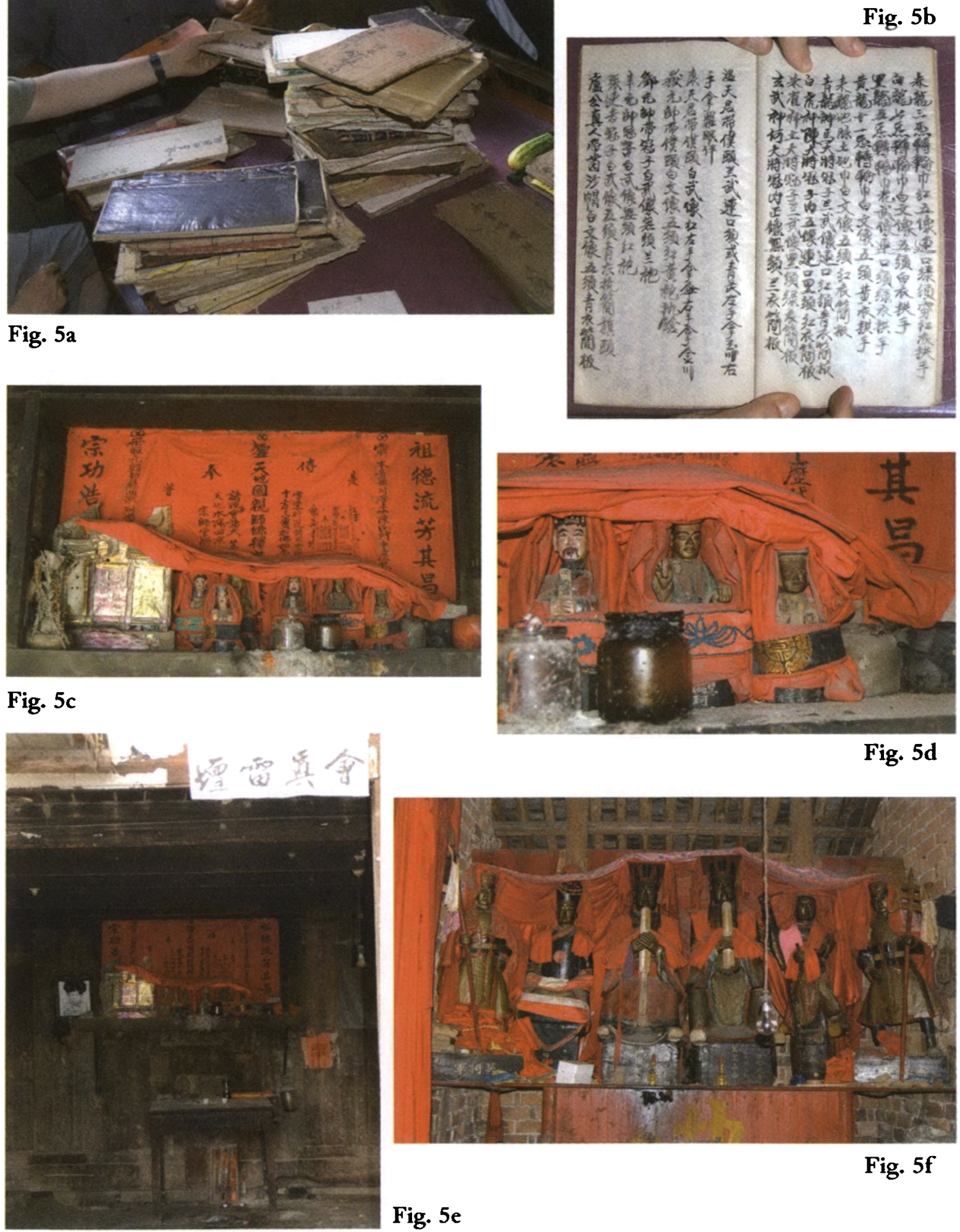

Fig. 5b

Fig. 5d

Fig. 5f

Fig. 5e

Fig. 5 : Les livres, l'autel et la production de Chen Yisong; $5 a$ : ses livres d'initiation (benjing) ; $5 \mathrm{~b}$ : deux pages de son Danqing xiangpu ; dans la dernière colonne à gauche, on lit la description de Lugong zhenren 虎公傎人 ; 5c, 5d : les statuettes de l'autel domestique de Chen Yisong et la représentation de son maître Hu Jiake 胡家听; $5 \mathrm{e}$ : la pièce qui sert d'autel du tonnerre ; $5 \mathrm{f}$ : certaines des sculptures pour un temple de Guanyin, que Chen a réalisées. Juin 2009. Photos : James Robson. 
Tableau des sculpteurs de patronyme Lu

\begin{tabular}{|c|c|c|c|c|c|}
\hline Nom & Titre & $\begin{array}{l}\text { Cote de } \\
\text { la pièce }\end{array}$ & $\begin{array}{l}\text { Nom de la } \\
\text { statuette }\end{array}$ & Adresse de consécration & Date de consécration \\
\hline 陸純陽 & 處士 & Т 0128 & 当君三[郎] & $\begin{array}{l}\text { 湖南肖(省) 宝慶府新訨 } \\
\text { 縣石馬三都張家山梓山 } \\
\text { 塆祠王祠下土地 }\end{array}$ & $\begin{array}{l}\text { 戊午年別月初十寅時 } \\
\text { 开光大吉[癸]酉年[[...] } \\
\text { 六月 }\end{array}$ \\
\hline [陸][-]安 & 處士 & Т 0286 & 当法元 & $\begin{array}{l}\text { 寶慶府新訨县大陽二[...][] } \\
\text { 底大水口庙王祠[...] }\end{array}$ & $\begin{array}{l}\text { 於乾隆[...]年(1781) } \\
\text { 辛五歲十二月初七日 } \\
\text { 乙亥良旦用辰時 [ ][...] } \\
\text { 大吉 }\end{array}$ \\
\hline 陸惠安 & (處士) & Т 0191 & $\begin{array}{l}\text { 天曹顕化夏 } \\
\text { 法輸 }\end{array}$ & $\begin{array}{l}\text { 湖南省長沙府安化縣常 } \\
\text { 億鄉西路觀音堂真仙廟 } \\
\text { 王雲宵排祠下土地 }\end{array}$ & $\begin{array}{l}\text { 乾隆四十七年(1782) } \\
\text { 王寅岁三月初八 }\end{array}$ \\
\hline 陸德[清] & [處]士 & Т 0742 & $\begin{array}{l}\text { 仁天顕化王 } \\
\text { 君斗三郎 }\end{array}$ & $\begin{array}{l}\text { 湖南省璸度府新訨縣石馬 } \\
\text { 五都湯家山庙王祠下土地 }\end{array}$ & $\begin{array}{l}\text { 取今嘉慶四年(1799) } \\
\text { 己未六月十八日開 } \\
\text { 點光明吉旦 }\end{array}$ \\
\hline 陸福南 & 處士 & Т 0090 & $\begin{array}{l}\text { 王君斗三郎 } \\
\text { 王君[-][-]真 } \\
\text { 官 (題記) }\end{array}$ & $\begin{array}{l}\text { 湖南省寶慶府新訨縣太 } \\
\text { 一都黄公各手毛周潮王 } \\
\text { 祠下土地 }\end{array}$ & $\begin{array}{l}\text { 道光十年(1830)八月 } \\
\text { 十五日(開)光吉旦 }\end{array}$ \\
\hline 陸明斗 & 處士 & Т 0031 & 陳君法亮 & $\begin{array}{l}\text { 湖南省寶慶府新訨縣大 } \\
\text { 陽二都點水寨雙江口庙[ } \\
\text { 王]祠下土地 }\end{array}$ & 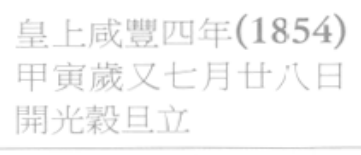 \\
\hline [陸]曰祥 & & Т 0252 & $\begin{array}{l}\text { 父師 劉 靜 } \\
\text { 派 }(1767 ?- \\
1839 ?)\end{array}$ & $\begin{array}{l}\text { 湖南省寶慶府新訨縣大陽 } \\
\text { 二都大木山廟王祠下土地 }\end{array}$ & $\begin{array}{l}\text { 咸豐五年(1855)乙卯 } \\
\text { 歲九月十二日(開)光 } \\
\text { 大吉 }\end{array}$ \\
\hline \multirow[b]{2}{*}{ 陸呈祥 } & 處士 & Т 0008 & $\begin{array}{l}\text { 地 主 許 君 } \\
\text { 三郎 }\end{array}$ & $\begin{array}{l}\text { 大陽二都 [風]穆 [ ]庙王 } \\
\text { 祠下土地 }\end{array}$ & $\begin{array}{l}\text { (光)緒五年(1879)己卯 } \\
\text { 六月十二日謹修 }\end{array}$ \\
\hline & 處士 & Т 0093 & 刘氏仙娘 & $\begin{array}{l}\text { 湖南省宝慶府新訨縣大陽 } \\
\text { 四都永溪橋庙王祠下土地 }\end{array}$ & $\begin{array}{l}\text { 取今光緒王午年 } \\
\text { (1882)二月十六日 } \\
\text { 開)光大吉 }\end{array}$ \\
\hline $\begin{array}{l}\text { [陸][先 }] \\
\text { 春 }\end{array}$ & 處士 & Т 0371 & 彭法清 & $\begin{array}{l}\text { 湖南省宝慶府新仩縣大 } \\
\text { 陽二都上桃溪庙王[祠][ } \\
\text { 下]土地 }\end{array}$ & $\begin{array}{l}\text { 光緒己卯年(1879)十 } \\
\text { 月[斗]九日(開)光大吉 }\end{array}$ \\
\hline \multirow{3}{*}{ [陸]春堂 } & 處士 & $\mathrm{T} 1023$ & 水師伍彥来 & $\begin{array}{l}\text { 湖南省宝慶府新仩縣大 } \\
\text { [陽]一都[則]木溪庙王祠 } \\
\text { 下土地 }\end{array}$ & $\begin{array}{l}\text { 擇取光緒 [己]丑年 } \\
(1889) \text { 四月十九日 } \\
\text { 開)光大吉 }\end{array}$ \\
\hline & 處士 & $\mathrm{T} 1035$ & 趙公[元][帥] & $\begin{array}{l}\text { 湖南省宝慶府新訨縣[大] } \\
\text { 陽二都大陽一都[涉]真山 } \\
\text { 廟王毛洲庙王 }\end{array}$ & $\begin{array}{l}\text { 光緒丙午年(1906)四 } \\
\text { 月廿八日(開)光大吉 }\end{array}$ \\
\hline & 處士 & Т 0329 & $\begin{array}{l}\text { 師(司)命灶府 } \\
\text { 神君 }\end{array}$ & $\begin{array}{l}\text { 湖南省宝慶府新訨縣大 } \\
\text { 陽二都 } \\
\text { 鍋坻山奉前廟王祠下土地 }\end{array}$ & $\begin{array}{l}\text { 民国元年(1911 ?) } \\
\text { 皇上王子(1912)十二 } \\
\text { 月十八日(開)光大吉 }\end{array}$ \\
\hline
\end{tabular}




\begin{tabular}{|c|c|c|c|c|c|}
\hline \multirow{4}{*}{ 陸遠美 } & 處士 & T 1024 & 師公劉法江 & $\begin{array}{l}\text { 口[南]楚省邵洲梅邑[]馬 } \\
\text { 五都廟山界廟王祠下土地 }\end{array}$ & $\begin{array}{l}\text { 天運甲戌年(1934 ?)九 } \\
\text { 月十八日黃道惟良開 } \\
\text { (光)大吉 }\end{array}$ \\
\hline & 處士 & Т 0002 & $\begin{array}{l}\text { 劉寬発(發) } \\
\text { 先生 }\end{array}$ & $\begin{array}{l}\text { 湖南省新訨縣石馬二都 } \\
\text { 中樂村塘山大坪垣庙王 } \\
\text { 祠下土地 }\end{array}$ & $\begin{array}{l}\text { 庚辰年 }(1940 \text { ?)十一月 } \\
\text { 廿七(開)光 }\end{array}$ \\
\hline & [處]士 & Т 0667 & $\begin{array}{l}\text { 祖公刘紹陶 } \\
\text { 巫 名法 海 } \\
(1820-\text { ?) }\end{array}$ & $\begin{array}{l}\text { 湖南省新化縣石馬 }[\text { 三] } \\
\text { 都家溪石桥边庙王祠下 } \\
\text { 土地分烟 }\end{array}$ & $\begin{array}{l}\text { 民國甲申年(1944)別 } \\
\text { 月初二日(開)光大吉 }\end{array}$ \\
\hline & 處士 & T 0254 & $\begin{array}{l}\text { 先考[刘]華 } \\
\text { 序佛名法 } \\
\text { 道(1899- } \\
1953)\end{array}$ & $\begin{array}{l}\text { 湖南省新訨縣大陽二都大 } \\
\text { 木山庙王祠下土地分烟 }\end{array}$ & $\begin{array}{l}\text { 公元一九 五三年 } \\
\text { (1953)九月十一日開 } \\
\text { 光大吉立 }\end{array}$ \\
\hline
\end{tabular}

attributs et mudrās, etc. Ce manuel fait penser au xiangyi pu cité plus haut ${ }^{3.4}$, qui d'ailleurs provient d'une localité peu éloignée, même si le contenu n'est pas présenté de la même façon (la succession des divinités n'est pas la même). En confrontant les deux manuels, on trouve des indications similaires et d'autres divergentes ${ }^{35}$, autrement dit les représentations échappent à de strictes codifications.

La dernière figure (fig. $5 \mathrm{f}$ ) nous montre des sculptures de taille importante, réalisées par Chen. Dans le même temple, d'autres statues ont été réalisées par Lu Jiacan 陸家橴, Chen revendiquant par ailleurs une production importante de pièces de toutes sortes, faites en commun ${ }^{36}$. Comme le montre le tableau ci-dessous, dans notre corpus nous trouvons dix-sept statuettes domestiques ${ }^{37}$, pour la plupart réalisées dans le district de Xinhua par une dizaine de sculpteurs de patronyme Lu 陸 $^{38}$. Leurs noms, mentionnés dans les certificats et non sur le corps des statuettes, sont soit accompagnés du titre de chushi, soit dénués d'appellation.

Des sources orales et une généalogie familiale permettent d'esquisser une présentation plus complète de leur $\operatorname{cas}^{3 \%}$. Conservé par les sculpteurs contemporains

34. Voir Hu Nenggai, art. cit. et plus haut, notes is et 17.

35. Nous avons confronté les êtres véritables Lu 篦 et Yang 㛫. Dans le Xiangyi pu, la description des deux est la même - visage barbu à cinq touffes, la coiffure en crêpe de fonctionnaire, une tablette à la main, des bottes —, mais Lu est habillé en rouge et Yang en bleu (虎公貞人:

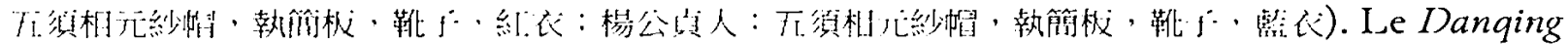
xiangpu explique que $\mathrm{Lu}$, avec cinq touffes de barbe, porte le même type de chapeau et de tablette que l'indique le Xiangyi pu, mais aussi qu'il s'agit d'une représentation lettrée (wen $丈)$, au visage blanc et à la veste bleu-vert; pour Yang, seul est décrit le type de chapeau et qu'il s'agit, là aussi,

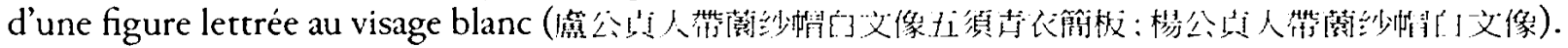

36. Chen Yisong, 2011, s. p.

37. Toutes font partie de la collection Fava. À propos du corpus étudié, voir note 45.

38. Plus exactcment, on a comptć onzc noms mais deux sont incomplets et ils pourraient se référer à une seule personne.

39. Ces informations ont été réunies pendant une mission sur le terrain en juin 2009 par Alain Arrault et James Robson, que l'auteur remercie pour la mise à disposition des documents 
Lu Jiacan et son fils Lu Shenglin 陸警林, résidant à Pingkou 坢 $\square$, au nord de Xinhua, le Lushi liuxiu zupu 陸氏六修族譜 a été imprimé en 1994. Il inclut la liste des caractères générationnels (paiyu 派語) ${ }^{40}$, et le nom de Lu Jiacan et Lu Shenglin comme membres de la $29^{\mathrm{C}}$ et de la $30^{\mathrm{C}}$ génération. Avant eux, sont notés les noms de certains sculpteurs de statuettes que nous avons mentionnés dans le tableau :

Le fils unique de Lu Sifu 嗣福, membre de la $26^{\mathrm{e}}$ génération, Lu Chengxiang 我祥 (182941-1897), époux d'une dame de la famille Peng 彭 (I833-I90I), a eu quatre fils : Xianbo 先柏, Xianchun 先春, Xiandong 先栋 et Xianquan 先杖.

Le deuxième fils de Lu Chengxiang, membre de la $27^{\circ}$ génération, Lu Xianchun (1855-1924), époux d'une dame de la famille I iu 劉 (1860-1942), a eu quatre fils :

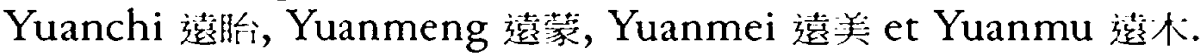

Le troisième fils de Lu Xianchun, membre de la $28^{\circ}$ génération, Lu Yuanmei (189I-1967), époux d'une dame de la famille He 何 (1908-1992), a eu trois filles et

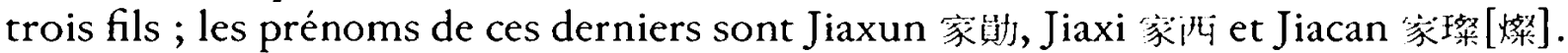

Lu Jiacan, membre de la 29e génération, a eu deux fils : Shengmei 整梅 et Shenglin 繁林, qui sont donc membres de la $30^{\circ}$ génération.

Ces informations peuvent être complétées par les renseignements donnés par $\mathrm{Lu}$ Jiacan et Lu Shenglin, qui décrivent ainsi les personnages représentés sur l'autel domestique et reproduits à la fig. 6c. De bas en haut, y sont exposés Tumu 土. $\mathrm{q}$ et Tugong 土公 (non visibles dans la photographie), puis sur une étagère le nécessaire pour la peinture et de l'encens ; plus haut, en dehors du premier personnage qui est Hu Fali 胡法利, les autres sont tous des membres de la famille Lu : Lu Xianliang 陸先, Lu Zongliang 宗良, Lu Fatian 法天, Lu Yuanmei, Lu Chuntang 春堂. alias Xianchun, Lu Chengxiang, Lu Siyou 思友. Dans le registre supérieur, deux

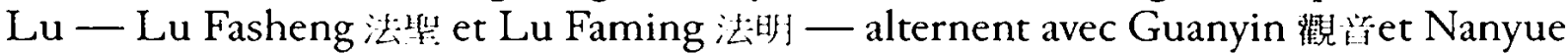
dadi 南䜌大耑 à gauche, Laozi 老于 au centre et Boyi fuzu 低衣佛礼 à droite. Parmi ces personnages, on reconnaît trois noms qui coïncident avec la généalogie, ainsi que Lu Xianliang, qui devrait être de la $27^{\circ}$ génération. Toujours selon la liste des caractères générationnels de la généalogie, Lu Zongliang et Lu Siyou pourraient être des membres des $24^{\circ}$ et $25^{\circ}$ générations ${ }^{42}$. Le seul « externe », Hu Fali, est lui aussi connu comme sculpteur de statuettes, et plus exactement d'une pièce consacrée en

récoltés afin de rédiger cette section de l'article. Les indications récoltées à propos de cette généalogie des Lu ne sont pas complètes; des informations disponibles en ligne qui répertorient l'édition de 1994 expliquent qu'elle est la sixième édition depuis 1722, et qu'une nouvelle édition a été rédigée en 2000.

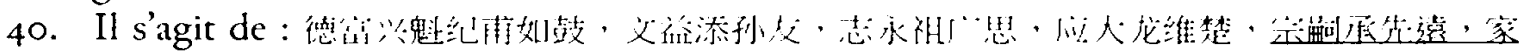

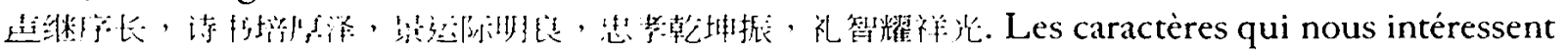
sont soulignés.

41. La date indiquée est yichou 乙 H: de l'ère Daoguang, mais elle n'existe pas, nous l'avons donc interprétée comme jichou L'tf: (1829).

42. Lu Zongliang est ainsi décrit dans les témoignages oraux de ses descendants; par contre il n'y a pas de mention de Lu Siyou. 
1905, dans une localité proche de Xinhua ${ }^{+3}$. Il pourrait avoir joué un rôle d'initiateur, en raison de son nom d'initié qui est, comme nous le verrons plus bas, assez rare pour les Hu. Pour les Lu portant des noms d'initié (Fatian, Fasheng et Faming), aucune identification n'a été établie. Par ailleurs, parmi toutes les statuettes examinées, on ne trouve ni Lu représentés ni fidèles - commanditaires de ce nom dans les certificats. Cet autel est particulièrement intéressant, d'autant plus que certaines de ces statuettes représentent les sculpteurs eux-mêmes : Lu Jiacan conservait ainsi les images de son père, grand-père et arrière grand-père, et ces derniers sont aussi parmi les auteurs de certaines pièces conservées jusqu'à nous (voir dans le tableau plus haut). Quatre pièces portent le nom de Lu Yuanmei. Réalisées entre 1934 et I953, elles témoignent d'une activité menée par ce dernier entre ses 40 et 60 ans. Une pièce de 1879 fut consacrée par Lu Xianchun, âgé de 24 ans. Elle représente un certain Peng Faqing 彭法清, qui pourrait être un parent du côté maternel. Le nombre de ses statuettes se monte à quatre, si nous acceptons l'explication donnée par Lu Jiacan selon laquelle Xianchun s'appelait aussi Chuntang. Trois pièces ont été consacrées entre 1889 et 1912 et ces dates font de lui le contemporain de Hu Fali. De même, si la permutation du caractère cheng (承 pour 呙) dans le nom de Lu Chengxiang est admise, alors nous pouvons lui attribuer deux voire trois pièces réalisées entre 1855 et $1882^{44}$. Dans ce cas, le père et le fils auraient travaillé de manière contemporaine, car deux pièces portant leurs noms sont datées de 1879 , à quelques mois de distance, et ont été consacrées à deux adresses de la juridiction du deuxième secteur $(d u)$ de Dayang 大陽二都. Quant aux Lu contemporains, ils pratiquent tous les deux la sculpture, ainsi que le gendre de Jiacan, de patronyme Zhou 周. Ces trois sculpteurs travaillent [et travaillaient] à d'autres pièces que les statuettes : chez Lu Jiacan se trouvaient des masques de théâtre en préparation, des tablettes funéraires prêtes à ĉtrc livrćcs aux clients (sous la forme d'un petit autel portatif avec deux tablettes inscrites, un objet bien plus « orthodoxe » que les représentations figurées des défunts), des « bâtons de commandement » (lingpai 令牌), mais aussi un porte encens ancien en forme de petit bouddha et des panneaux en bas-relief pour le palanquin de la mariée et qui, selon le témoignage de Lu Jiacan, ont été sculptés par son père, Lu Yuanmei.

\section{Les graveurs du passé}

Quant aux documents plus anciens, c'est-à-dire les certificats de consécration inclus dans les statuettes elles-mêmes, on peut en tirer une double série de considérations, les unes concernant les appellations utilisées pour ces " techniciens " des " petits rites » et du bois sculpté, les autres à propos de quelques cas mieux représentés.

43. La pièce To7rg porte le nom de dcux sculpteurs I lu, dont l'adresse est 新化憬石㫮二 妇”济树.

44. Elles occupent une partie, sur un fond gris, du tableau des sculpteurs de nom patronymique Lu. Les autres apparaissent sur un fond blanc. 


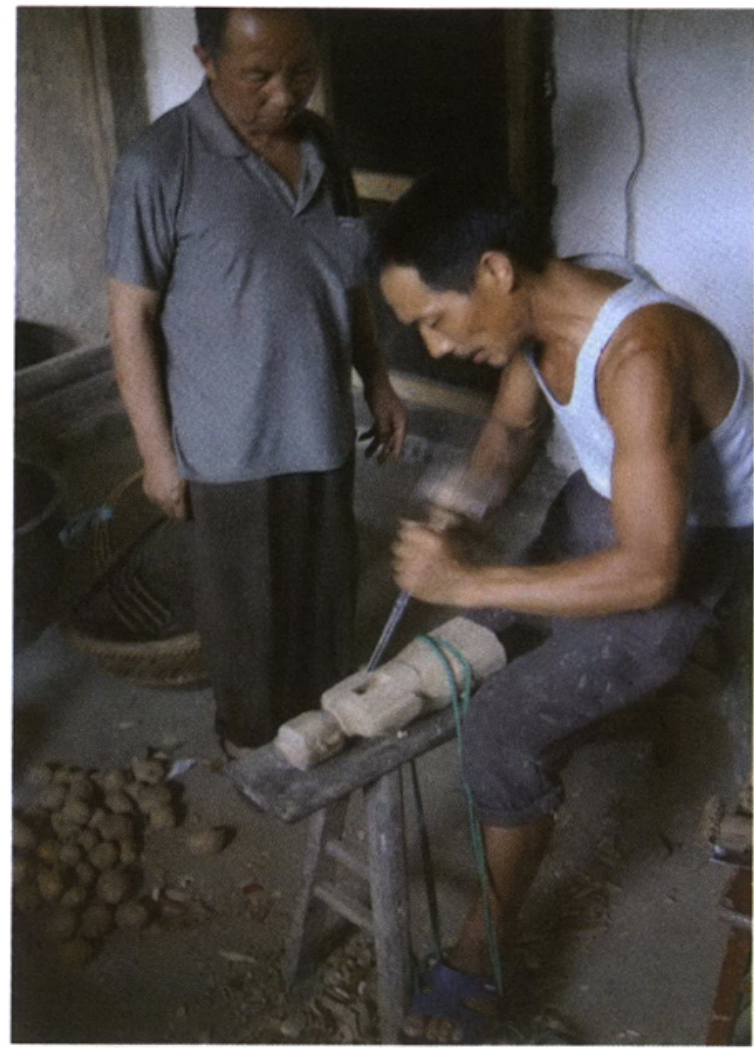

Fig. 6a

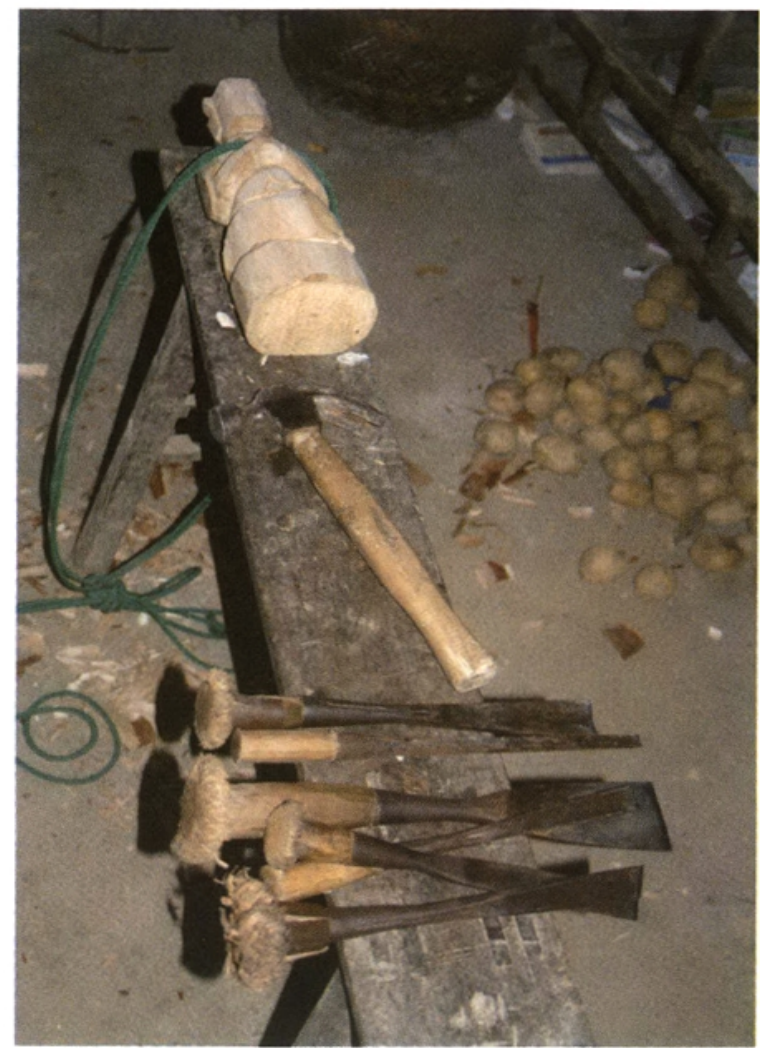

Fig. $6 b$

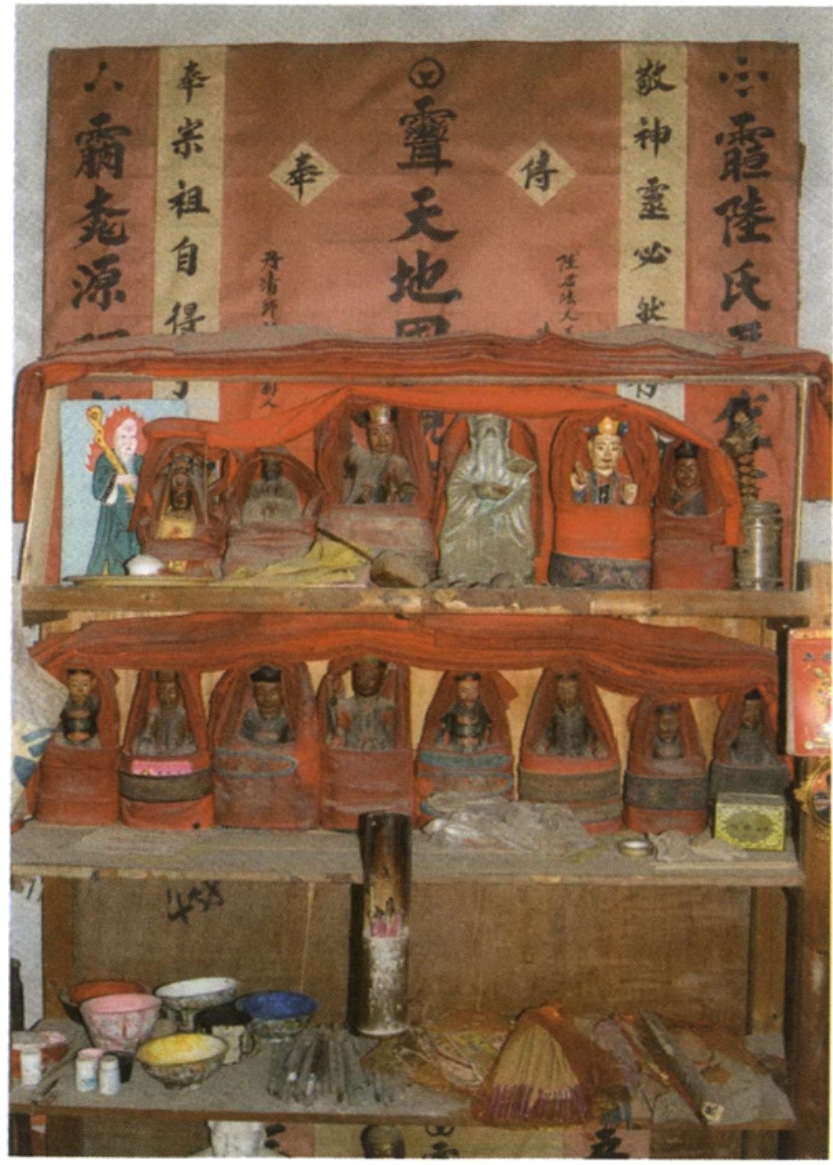

Fig. 6c

Fig. 6 : 6a : Lu Jiacan enseigne à son gendre; la statuette est tenue par une corde tendue par le pied de ce dernier ; $6 b$ : lcs outils utilisés ; $6 c$ : une partie de l'autel domestique de Lu Jiacan ; en bas à gauche sont disposés les couleurs et les pinceaux nécessaires à son travail de " maître des couleurs". Photos : James Robson. 
Sur la base des certificats examinés dans les trois collections, nous avons élaboré le tableau qui figure à la fin de cet article (voir Appendice). Il en résulte qu'environ 500 noms, sur un total d'un peu plus de 1400 portant des informations ${ }^{45}$, indiquent ceux que, à l'époque du catalogage, nous avions décidé d'appeler en français « auteurs (sculpteur, créateurs, ...) » (en chinois kanzaozhe 刊造者) des statuettes ${ }^{46}$, sans trancher entre la création matérielle et la consécration. Plus exactement, 60 pièces font mention d'un intervenant générique ou d'une personne dont le nom a été perdu complètement ou en partie, ce qui rend donc impossible une identification. Dans 432 cas, les noms complets, ou au moins les noms de famille, sont présents, pour un total de 76 patronymes différents. Parmi eux, 27 noms de famille n'apparaissent qu'une seule fois (mais les fautes d'écriture ne sont pas à exclure ${ }^{47}$, ce qui laisse à penser qu'une seule personne de la famille fut impliquée dans la sculpture et/ou la consécration d'une statuette. Dans le cas de dix familles, on trouve deux membres concernés et pour neuf autres familles, trois personnes. Quatre familles ont au moins quatre ou cinq « auteurs » de statuettes, trois familles six, sept ou neuf membres impliqués et deux patronymes sont communs à onze et à douze personnes.

Pour le reste, le nombre s'accroit : treize Luo 羅, quinze Zhou 周, seize Kang 橉,

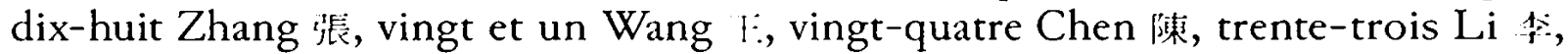
trente-cinq Liu 劉 et trente-huit $\mathrm{Hu}$ 胡. Bien évidemment, on pourrait dire que plus un nom est commun, plus sont nombreux les intervenants, mais ce n'est pas exactement le cas. De cette variété de patronymes, nous retenons surtout l'impression que la pratique était généralisée. Le grand nombre de personnes et de familles impliquées provient probablement du fait qu'un savoir-faire technique assez simple, pour sculpter et colorer les pièces, était transmis avec l'initiation religieuse, et que cela pouvait se faire en dehors de la ligne directe de descendance. Ces personnes vivaient probablement (en partie ?) de leurs prestations «techniques", mais la réalité qui s'esquisse à travers ces données est pourtant bien différente de celle d'autres professions du bois, relativement bien connues, par exemple pour les graveurs de planches à imprimer du Nord du Fujian 福建 ou du Sud de l'Anhui, où quelques clans semblent dominer en nombre et dans le temps, avec une transmission se faisant entre pères et fils, oncles et neveux.

45. Les trois collections comprennent un total de 3143 pièces, dont 1291 avec certificat et 127 sans certificat mais avec inscription sur le corps de la statuette. Voir le tableau i dans l'article d'Alain Arrault dans ce volume. Le nombre des pièces concernées est bien plus élevé, car certains noms reviennent pour plusieurs pièces. Cependant, une vingtaine de cas présentent deux ou plusieurs noms pour une seule pièce ; cela s'explique par le fait que ces gens ont travaillé ensemble, ou l'un après l'autre (dans ce cas on trouve plusieurs certificats avec des noms différents, ou un nom dans le certificat et l'autre sur la statuette).

46. En réalité, l'utilisation des caractères kan et surtout zao dans les certificats est restreinte, par exemple dans To400 ou T 0695.

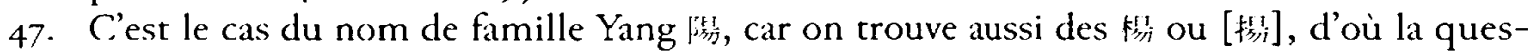
tion de savoir s'il ne s'agirait pas de différentes écritures ou de caractères fautifs. Sur ce point, voir aussi note 66 . Signalons encore l'utilisation de nombreux caractères en graphie simplifiée, ce qui a été respecté dans cet article. 
D'autres considérations générales concernent le nom d'initiation - le caractère fa 法 est associé à 99 noms, soit dans pratiquement $20 \%$ des cas, ce pourcentage varie toutefois d'une famille à l'autre - et les appellations, qui peuvent ou non accompagner les noms personnels ou être utilisées seules. L'appellation la plus utilisée en absolu est chushi (maître local), avec 160 cas, suivis par 79 cas où l'appellation est omise et $7 \mathrm{I}$ cas où l'on évoque un danqing fil't (maître des couleurs). Beaucoup moins nombreux sont les dizi 第手 (disciples) et les danqing dizi 掅弟了, respectivement 29 et 32 cas, et moins fréquents encore les chushi dizi 选 et les danqing chusbi f小is

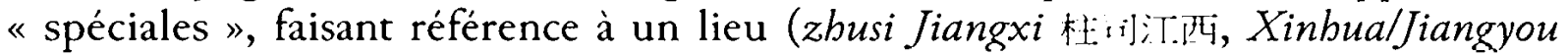
chusbi 新化/汇右成 ou inversés. Les autres se réfèrent à la pratique religieuse (le «fidèle » xinren 信人,

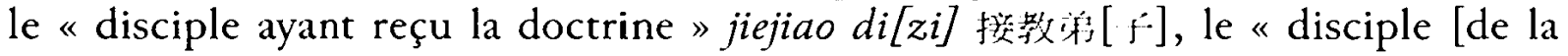

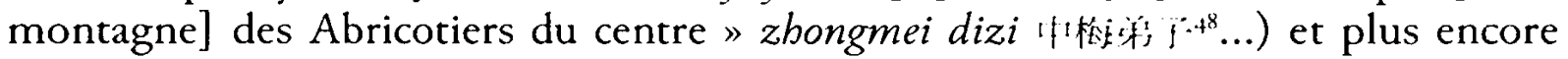
aux différentes étapes de la sculpture (diaoke chushi/jiangren 雕刻处.t/原人, diaoke

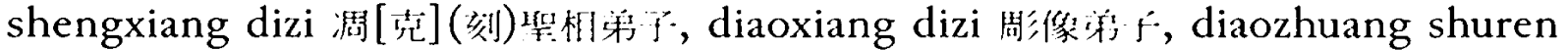

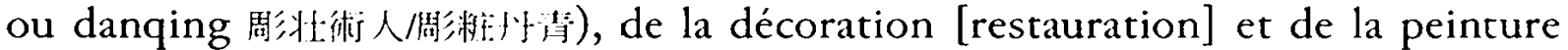

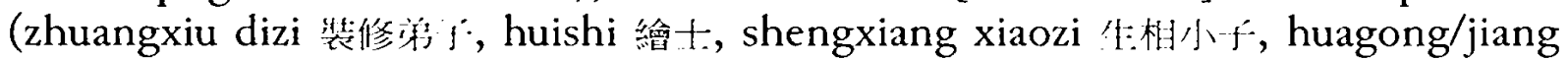
畫工/原), du remplissage de la cache et de la consécration (fengfu/kaiguang dizi 封服(腹)/開光弟，f) des statuettes.

Parfois l'appellation fait allusion au jeune âge des auteurs du certificat - mais il peut évidemment s'agir d'un âge symbolique - par exemple dans un certificat où l'on décrit deux fils 《plus petits que les genoux 》 (xixia nan 除卜男) du personnage représenté par la statuette ${ }^{49}$ (fig. 7a). Dans la même pièce, il existe encore quatre certificats, dont l'un sous la forme de formule propitiatoire manuscrite qui explique que la statuette permettra de répandre la puissance et la pratique du maître. Il est signé par une troisième personne ayant également une appellation particulière, associée à ce qui semble être un nom ou un surnom évoquant la culture ou la

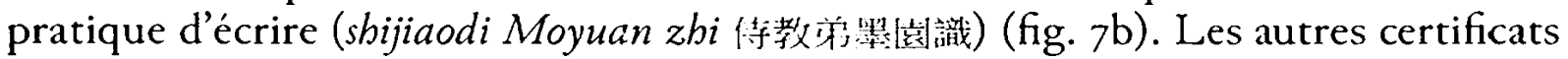
sont trois exemplaires d'une même (?) xylographie imprimée en rouge sur du papier jaunâtre (fig. 7 c). Dans les deux certificats, l'expression « dessiner et graver le visage d'or " (tuke jinrong 阔刻行) est mentionnée. Alors que le terme jinrong indique le portrait et est aussi employé à propos d'autres pièces (voir plus bas), l'expression complète fait penser à d'autres formes artistiques réalisées sur surface plate, tels que

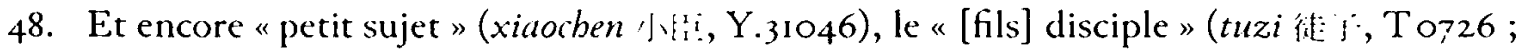

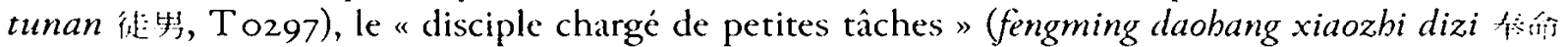

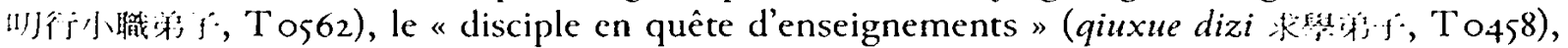

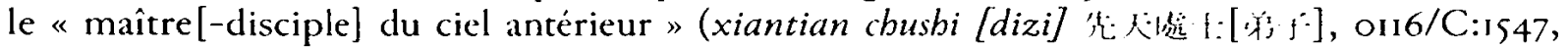

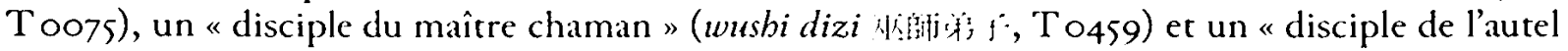

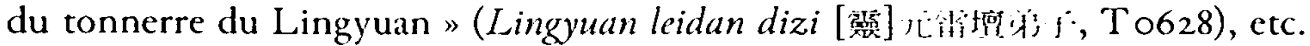

49. Voir T0746. Ce certificat est particulier dans sa formulation, qui commence comme

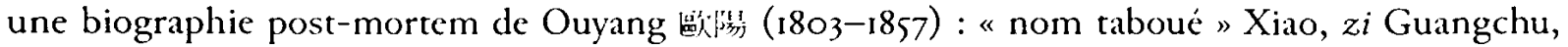

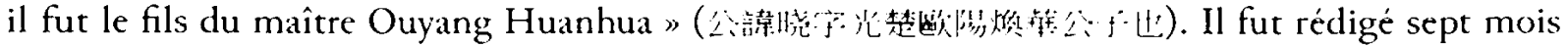

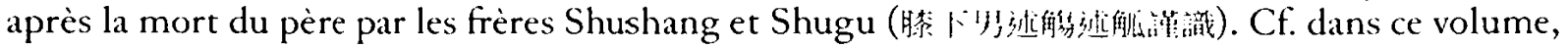
l'article de A. Arrault, p. 93, n. 6 I. 

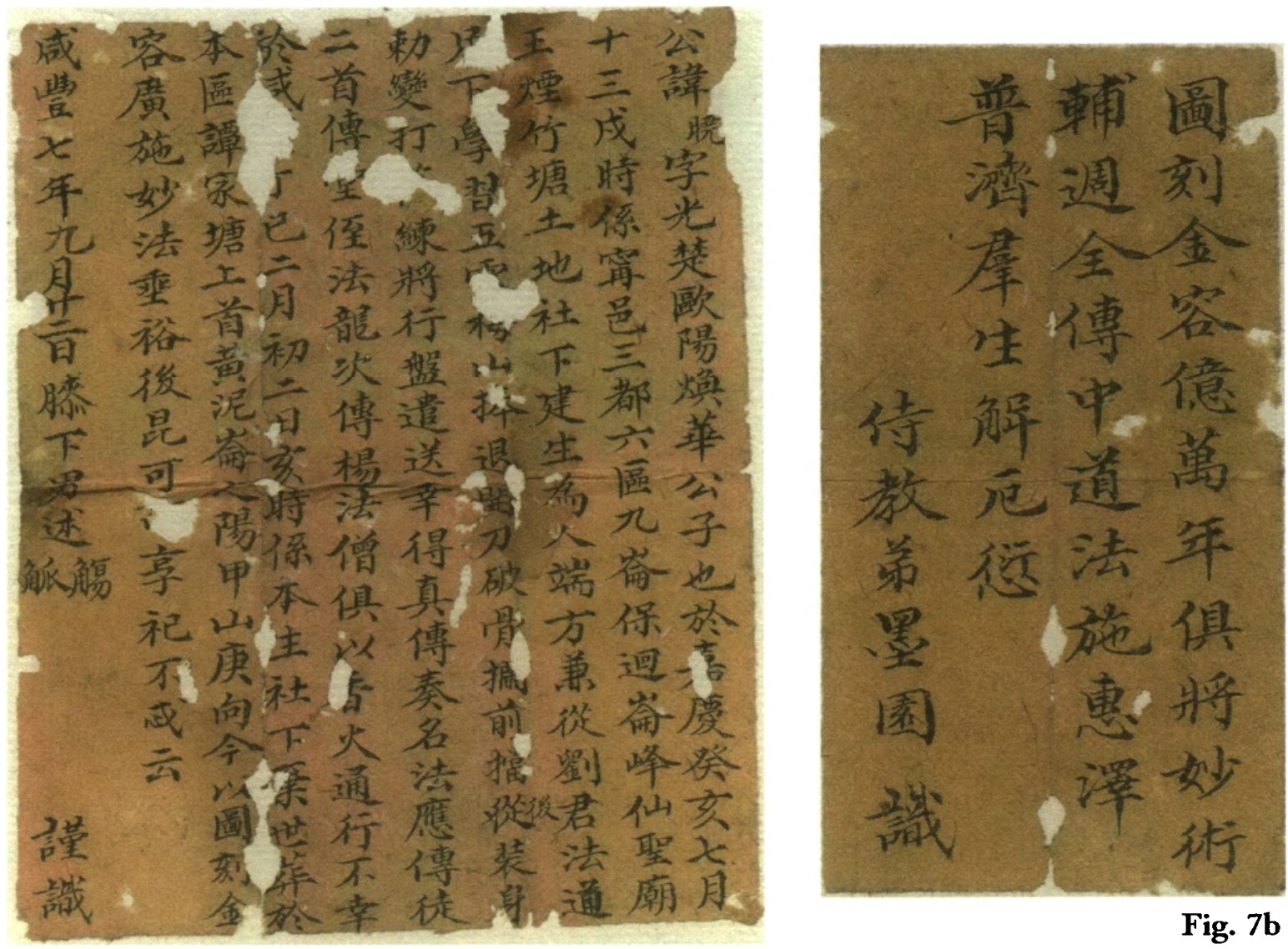

Fig. 7b

Fig. 7a

Fig. 7c

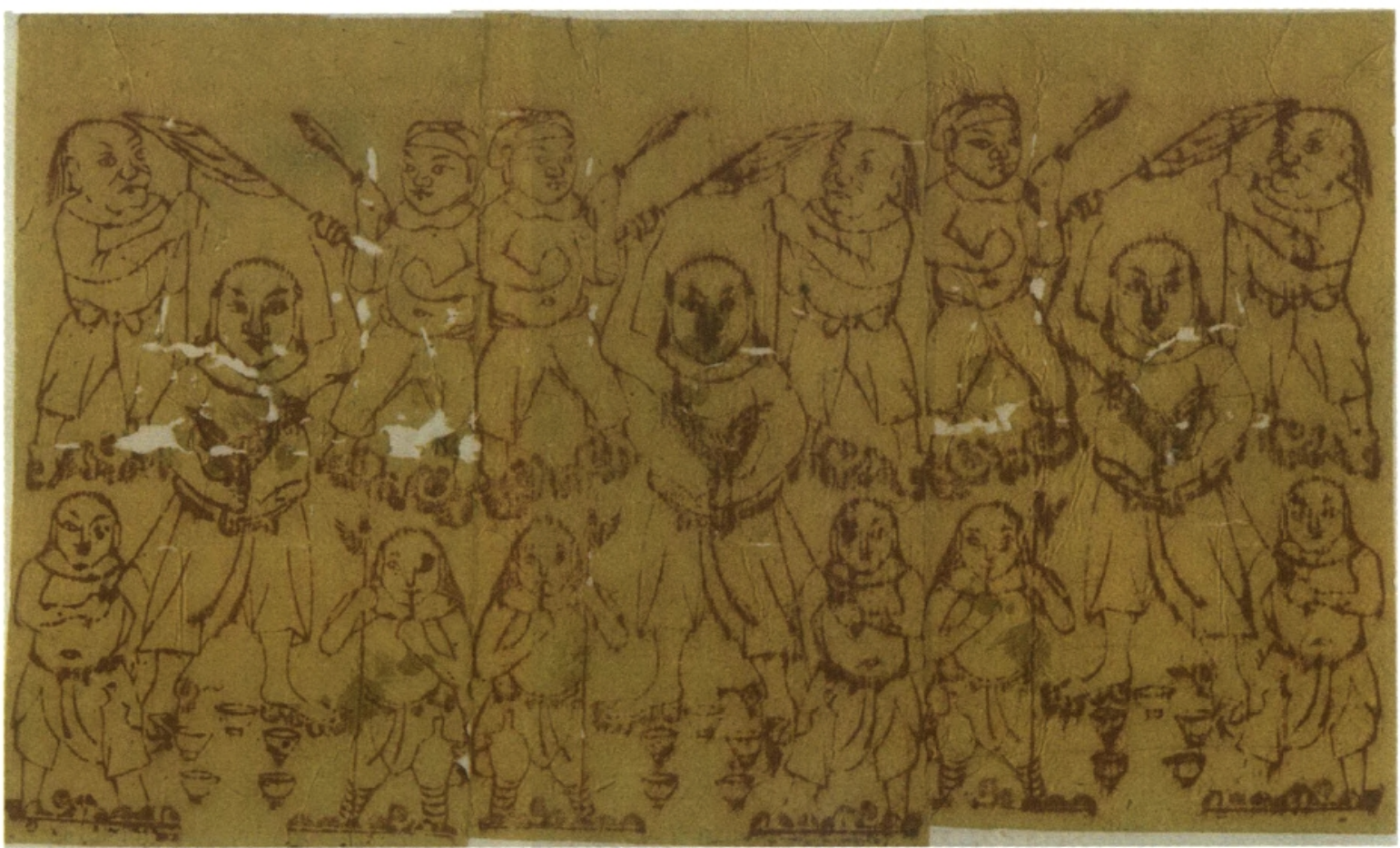

Fig. 7 : 7-a, 7-b, 7-c : certificats de la pièce de Ouyang Xiao, vers 1853, T 0746 ○ EFEO. 
les portraits peints sur rouleau ou la gravure de planches à imprimer. Sculpture et gravure pourraient avoir été pratiquées par une seule et même personne, auteur en même temps de la statuette et de la planche représentant Zhang Wulang 偯五郎' et

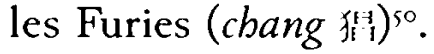

Dans notre analyse (voir la onzième colonne du tableau en annexe) sont également intéressantes les 36 personnes qui sont associées indifféremment à deux voire trois appellations : par exemple, elles sont appelées soit danqing cbusbi, soit chushiou danqing, sans qu'aucune logique précise puisse être dégagée pour expliquer ces changements. Ce genre de situation ne nous permet pas, pour le moment, de considérer ces termes (chushi, danqing, dizi et leurs composés) comme des titres reproduisant un ordre hiérarchisé précis. Le fait que les appellations uniques les plus fréquentes, pour une même personne soient tracées sur des certificats imprimés - par exemple

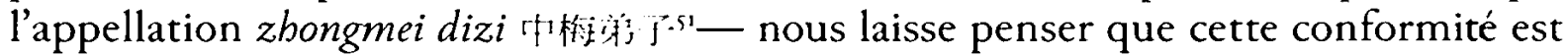
due à l'utilisation répétée des mêmes planches d'impression des certificats : si les mêmes personnes avaient dû rédiger leurs certificats à la main, auraient-elles été si précises et constantes dans l'usage des appellations ?

Parmi les expressions utilisées pour décrire la préparation des statuettes, les caractères diaoke 雕刻/凮刻 reviennent souvent dans l'explication des motivations qui ont poussé à sculpter la pièce, ainsi que dans les expressions désignant les commanditaires, telles diaoke xinsbi 雕刻信 $\mathrm{E}$ (plus rarement diaoke kanshi 雕刻刊 $1:$ : : dans ce cas, les deux caractères seraient à traduire par un verbe factitif « le croyant qui (a) fait graver la pièce ». À propos des « auteurs (sculpteurs, officiants ...) 》 de la pièce, le couple de caractères diaoke est associé aux appellations récapitulées plus haut ou employé sous forme verbale. Par exemple, vers 1826 , on trouve un diaoke

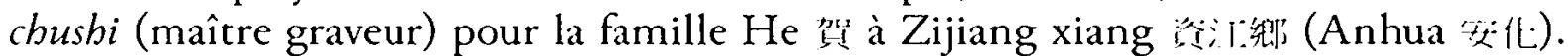
En 1907, c'est le dizi He Mingmo 贺明謨 qui est « commanditaire » de la statue de son maître d'initiation (dushi lititit), Chen Wanyou 陳萬友, et qui sculpte (diaoke)

50. L'image représentant Zhang Wulang qui sacrifie aux Furies ne manque pas d'imprécisions : les Furies ne sont que quatre et Zhang Wulang n'est pas représenté la tête en bas (à propos de ce personnage dans sa représentation "canonique ", voir Alain Arrault et Michela Bussotti, "Statuettes religieuses et certificats de consécration en Chine du Sud, XvII"-XvilI" siècle ", Arts Asiatiques, 63, p. 45, fig. I4a et b. Le personnage central est à la fois inclus et exclu du groupe, cette image montrant la nature ambivalente de nombreuses divinités capables de protéger et de nuire selon les cas. Par ailleurs le fait qu'il soit en train de sacrifier un coq, et que les coupelles à ses pieds soient au nombre de cinq, confirme qu'il est ici assimilé aux Furies. Les trois xylographies mesurant environ $20 \times 10 \mathrm{~cm}$ ont été marouflées ensemble. Celle sur la gauche est inversée et il est impossible à présent de dire si elle a été produite à partir d'une autre planche ou, si le papier étant très fin, l'encre a déteint de l'autre còté sans qu'on y prête attention au moment du marouflage. À moins qu'on ait utilisé une sorte de pochoir.

51. Sur le zhongmei dizi, voir dans ce volume l'article d'Alain Arrault, p. 92 note 59, et plus bas, où je présente le cas de Zhou Yaoxian. 
lui-même cette pièce ${ }^{52}$, ce qui est relativement rare ${ }^{i 3}$, dans le district de Xiangxiang 湘鄉影. En 1927, le chushi Peng Fashen 彭法身 grave (diaoke 雕刻) une 《sainte image 》 (shengxiang 聖像) d'un certain Li 李 à Xinhua, indiqué sans ambiguïté ${ }^{r 4}$.

Les caractères diaoke sont aussi employés dans l'appellation « artisan sculpteur » (diaoke jiang 雕刻压), assez rare mais utilisée très tôt pour les Li (première moitié du XVIIr" siècle) ${ }^{55}$, ainsi que dans un autre cas où le nom de famille manque. Cette dernière pièce est vraisemblablement du XIX" siècle et elle portait deux certificats très éloignés, un de 1892 et un plus ancien de I681, où est mentionné un certain «artisan graveur " Jinghuan 靜熼 (son nom de famille étant perdu) qui a « peint - écrit » $(b i \text { 筆) })^{56}$. Nous pourrions formuler l'hypothèse que l'utilisation du terme " artisan » (jiang [ケ.) précède le développement des appellations plus spécialisées que nous avons répertoriées dans le tableau. Le terme d'« artisan » reste par ailleurs assez rare, employé parfois dans des formules génériques sans qu'un nom de personne y soit associé. On écrit alors qu'on invite "un artisan » à graver (qing jiang diaoke 街近浾刻) ou qu'on lui commande une consécration en « pointant les yeux » [avec un pinceau] (mingqing jiang kaiguang dianmu 命請近開光点旦) ${ }^{57}$, cette deuxième formule montrant que les fonctions de maître sculpteur-auteur de la statue, ou de maître religieux-responsable du culte de consécration, ne sont pas perçues comme distinctes, même s'il s'agit d'《 artisans ».

Il arrive que nous hésitions entre une formule générique et une identification : près de Changsha 長沙, en 1934, est réalisée une statuette féminine (To856) et un certain Peng Huahong 彭苹鴻 la consacre, mais dans le certificat on peut lire qu'un artisan a été appelé à la maison pour la réparer et la décorer « de tout son cœur » (命沂於家弡心裝修), sans qu'on puisse trancher si la définition est générique, si l'on a invité une deuxième personne, ou s'il s'agit toujours de Peng ${ }^{58}$. Au milieu du $\mathrm{XIX}^{\mathrm{C}}$ siècle, on trouve le nom d'un certain Fu Famiao 傅法妙 sur deux pièces ; dans l'une, le certificat dit que ce danqing dizi a maladroitement ${ }^{59}$ écrit/peint et gravé （乎青第子傅法妙拙筆刊）; dans l'autre il est nommé chushi, et plus loin il est dit

52. Pour les $\mathrm{He}$, six pièces sont connues, une personne différente étant intervenue à chaque fois; les deux pièces en question sont $\mathrm{T} 0698$ et T 0656 : en raison de l'éloignement géographique des lieux respectivement invoqués, il n'y a probablement pas de lien. Pour des pièces commandées par les $\mathrm{He}$, voir aussi plus bas note in.

53. Il y aussi deux frères Luo qui, en 1917, sont en même temps les « fidèles " offrant la

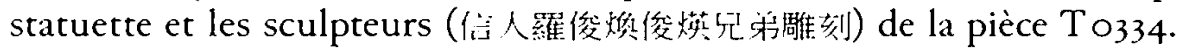

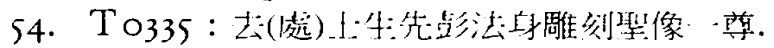

55. C'est le cas, dans Toro3, pour Li Yuli (雕刻[店李[館]力) en $1713 \mathrm{et}$, dans To785, pour Li Youbin 雕刻近晳又[庴] en 1749 .

56. L’expression utilisée est 雕刻l近人[-]靜紧策; ; voir To362.

57. Ces deux pièces datent respectivement de 1871 (T 0517) et de 1873 (To054).

58. Voir aussi le cas plus récent d'une statuette pour laquelle on convoqua il y a une trentaine

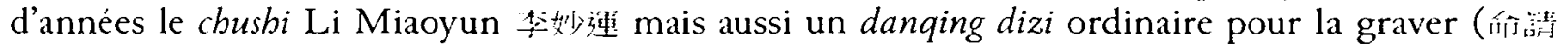

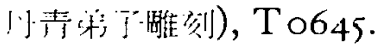

59. Ici on trouve l'expression zhuo bikan 推笽阠, mais la formule de modestie normalement utilisée se limite à « écrit d'une façon maladroite " (zhuobi 拙笔 pour les pièces T0551, To580, T0673 et zhuosbu 拙拉 pour les pièces Tro10, T0604). 
qu'on a commandé la décoration [de la statuette] à un artisan (以命匠彫装) ${ }^{60}$ sans qu'il soit possible de déterminer si cela concerne ou non Fu. Parfois le caractère jiang est associé à d'autres termes, tels que l'" artisan qui sculpte et décore " (jang

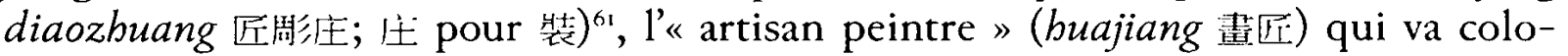
rer la statuette ${ }^{62}$. Le certificat parle encore de lui comme de l'«artisan »qui a été imploré pour « lever sa main » afin de sculpter le «visage d'or » d'un personnage féminin divinisé (la tante fidèle « sixième dame "Jielie liuniang gu shi 節烈六娘姑氏), qui a vécu au $X^{\mathrm{c}}$ siècle. Cet exemple est d'autant plus intéressant qu'on y explique que la sculpture, la décoration et la consécration ont été accomplies en seulement quinze jours ${ }^{63}$. Beaucoup plus récemment, le travailleur du bois (mujiang 木[近) est présenté en parallèle à la pratique religieuse : en 1983, Deng Mingchu 鄧明初, commanditaire et sculpteur d'une statue de Lu Ban 䡒班, se proclame « disciple qui a reçu l'enseignement » et qui a réalisé la pièce, car il a appris le travail du bois et la

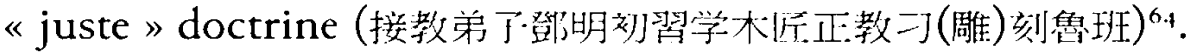

De la même façon que nous venons de le voir pour l'occurrence de jiang (artisan), on utilise parfois les différentes appellations répertoriées dans le tableau final d'une façon générique, afin de désigner celui qui sculpte les statuettes. Il arrive que la formulation soit élaborée, par exemple « inviter le danqing à graver les os du dragon et le corps d'or " (mingqing diaoke longgu jinshen 命請于f步雕刻龍崖金身) ${ }^{65}$.

Le terme « sculpter », que cela soit écrit diaoke 雕/周垓, simplement ke ou diao, ou dans des variantes [fautives] ${ }^{65}$, est parfois employé dans une formule impersonnelle pour les dates. Dans ce cas il n'a pas de sujet et l'expression indique le [début du] travail de sculpture, suivi de la consécration : c'est le cas pour un « [portrait

6o. Il pourrait s'agir du même $\mathrm{Fu}$, car les deux pièces sont respectivement datées de 1858 (Torro) et de 1868 (or88/C:163). À propos du caractère zhuang 浆, qui revient à plusieurs reprises dans les certificats, je me suis demandé si on aurait pu le traduire par " habiller ", du moment que les étapes finales de la peinture portent sur les détails des vêtements. Il ne faut pas non plus oublier que les statues sont souvent enveloppées dans un tissu rouge avant d'être installées sur les autels, autant de gestes qui peuvent rentrer dans le champ sémantique du caractère zhuang.

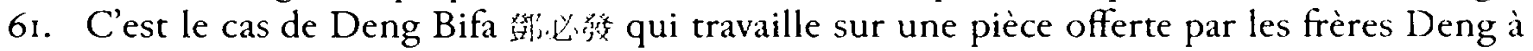

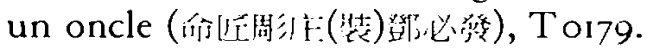

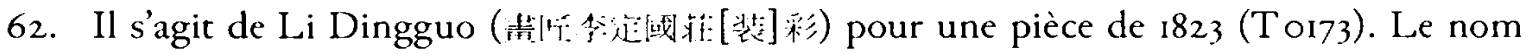
de Li Dingguo apparaît sur une autre pièce faite presque vingt ans après, dans le même canton de Changfeng (常舆貌) : cette fois il est désigné comme danqing dizi sans indication complémentaire.

63. Sur cette pièce (TIO06), voir dans ce volume l'article d'Alain Arrault, fig. I6, p. 70. L'artisan

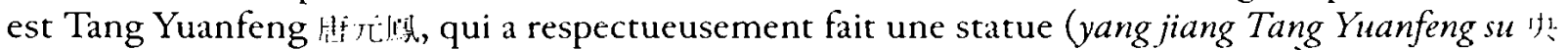

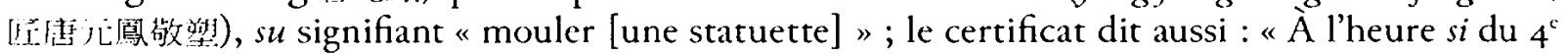
jour du $10^{\circ}$ mois de cette année, l'artisan a commencé ce travail. Il a sculpté le « visage d'or » et, les décorations terminées, il a pointé les yeux et ouvert la lumière à l'heure you du $29^{\circ}$ jour de ce

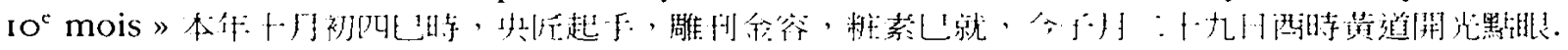

64. Voir To618.

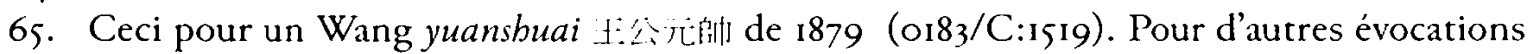
génériques, voir T 0257 , To66o et To661.

66. Les fautes de caractère sont nombreuses, par exemple dans une pièce de 1947 (Y.15044)

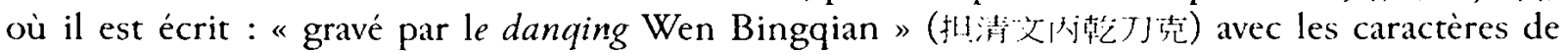
danqing fautifs et daoke 仃克 à la place de diaoke 雕刻. 

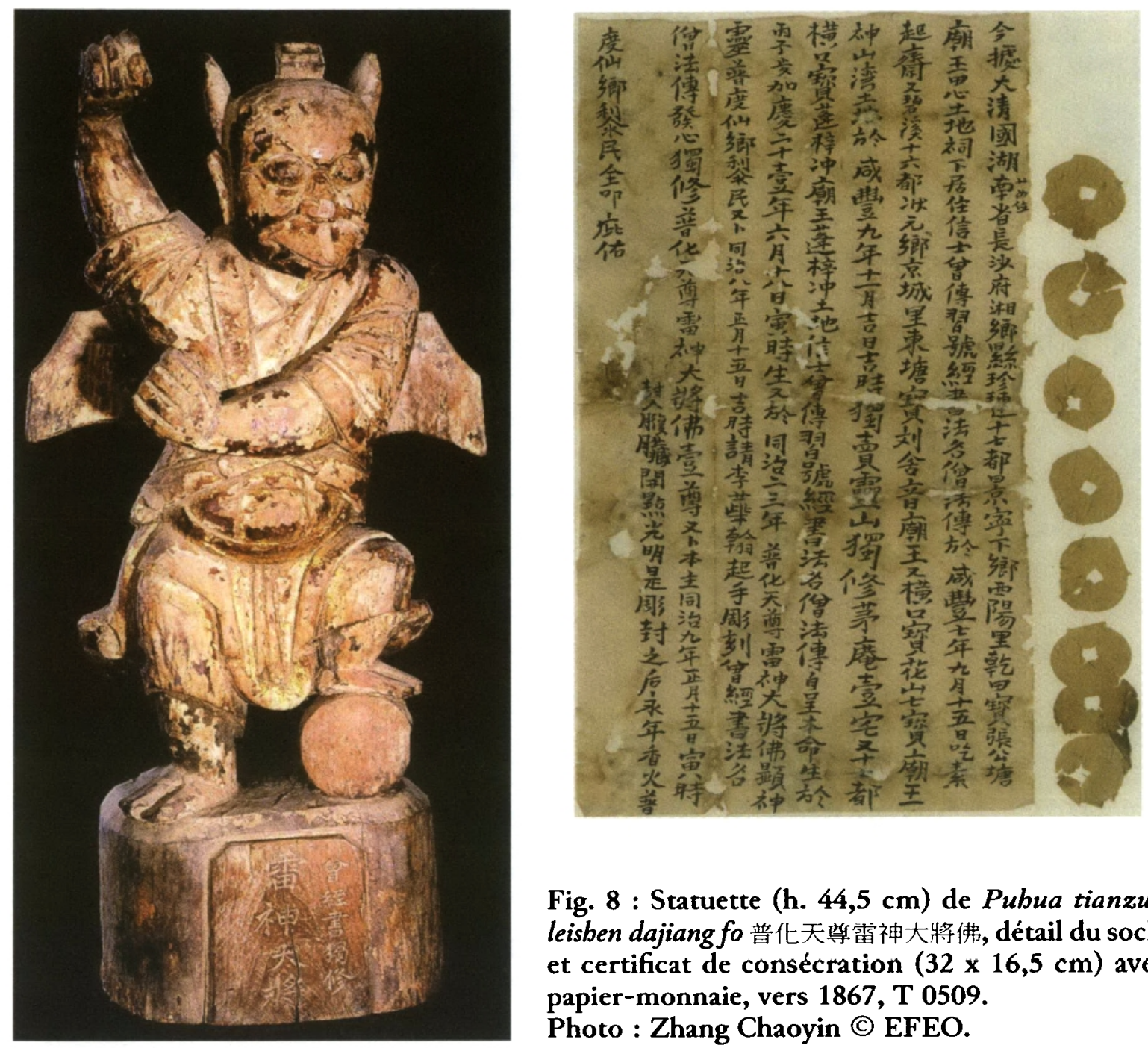

Fig. 8 : Statuette (h. $44,5 \mathrm{~cm})$ de Pubua tianzun leishen dajiang fo 普化天尊雷神大將佛, détail du socle et certificat de consécration $(32 \times 16,5 \mathrm{~cm})$ avec papier-monnaie, vers $1867, \mathrm{~T} 0509$.

Photo : Zhang Chaoyin (C) EFEO.

du] visage d'or glorieux, une statuette de jade lumineuse " (jinrong canlan 全容潔锞 yuxiang yinghuang 玉像焱煌) sculptée dans le district de Xinhua à partir du $14^{\circ}$ jour du huitième mois d'un an yimao 乙印 et consacrée avec grand bonheur le $30^{\mathrm{e}}$ jour du même mois ${ }^{67}$. Ce délai est bref, similaire à celui cité précédemment pour la statuette de la « sixième dame ». C'est cependant un délai vraisemblable pour un processus de préparation comparable à celui décrit, pour le contemporain Yang Hui, en ouverture de ce texte, en tenant compte des jours de travail et du temps de séchage de l'enduit et de la couleur. Mais parfois ce délai est bien plus long : trois ans s'écoulent entre la gravure et la consécration d'une statuette de Guanyin 觀音 commandée sous ère Qianlong 乾隆 (1736-1796) par des membres de la famille Xue 薛, dont de nombreuses femmes, épouses et filles ${ }^{68}$. Parfois il peut se passer un an

67. La datation complète est la suivante : 取卜乙卯年[八][月] 十四日起手彫刻取 [三]+日開光 大吉 ( $\mathrm{T} 0827)$. Les délais entre gravure et consécration varient au cas par cas, voir ci-dessus note 63, et plus bas notes 68-69 et, pour un délai encore plus court, cf. note 75 .

68. La pièce bouddhique Y.31010 est gravée en 1737 (乾隆 “年丁已歲中請....彫刻) et consacrée le $26^{\mathrm{c}}$ jour du neuvième mois de l'an 1740 (乾隆五年庚申太煘九月小六月卌午黃道点像開光安居香 
exactement, par exemple pour une représentation du dieu du Tonnerre (leishen 雷神) sculptée par un certain Liu Huahan (李苹翰起手彫刻) dès le $15^{\mathrm{e}}$ jour du premier mois de 1869 , qui fut remplie [dans sa cache dorsale] et consacrée (封入(腹)臓開點 光明) un an après, ces dates ayant été choisies par divination. Cette pièce (fig. 8) ${ }^{69}$ est d'assez grande dimension et son commanditaire, Zeng Jingshu 曾經書, l'aurait fabriquée seul (duxiu 獨修) : il a probablement fait les finitions, et on peut aussi se demander s'il n'a pas lui-même écrit le certificat et réalisé le rituel de consécration.

Pour la statue de Shao Faxing 邵法興 (1288/1348- ?), ses descendants et leurs épouses nées Liu 劉氏 firent appel au chushi Xiong Baisui pour la graver (Xiong Baisui diaoke 熊百遂彫刻) en 1864 , puis, deux ans plus tard, à un danqing pour la peindre (danqing zhuangbua 斗青裝畫), et enfin à un « disciple du maître exorciste 》 pour " écrire [d'une main] pure » le certificat (wushi dizi Lu Faqing mushu 荝師弟子盧法 清沐書 ${ }^{70}$ ). Dans les cas où le délai entre les dates du personnage et la production de la statue a été long, nous constatons qu'il ne s'agit pas d'un ancêtre ou d'un maître proche, mais de divinités ou de personnages divinisés, sans cependant pouvoir en déduire l'existence d'une "règle ». Les données à propos de la statuette de Shao Faxing permettent de déduire que Xiong aurait été un simple sculpteur et que Lu aurait écrit le certificat et donc réalisé la consécration. Impossible en revanche de savoir si le danqing dont il est question était ou non une troisième personne ${ }^{71}$. Par contre, pour la statuette de Xie Falong 謝法隆, il est explicitement noté que

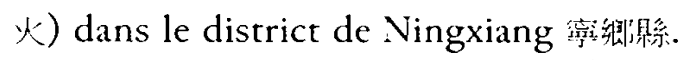

69. La pièce T0509, gravée dans le district de Xiangxiang 湘鄉憬, mesure avec son socle $44,5 \mathrm{~cm}$; sa cache contenait, en plus du certificat manuscrit, des médicaments et des monnaies

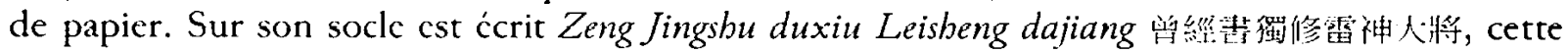
inscription ressemble à celles des sculpteurs qui gravent parfois leur nom. Nous avons choisi de donner un sens de locution verbale aux caractères duxiu 鹤修, qui sont aussi utilisés dans le certificat inclus dans sa cache à deux reprises : à propos de la statuette et à propos d'un ermi-

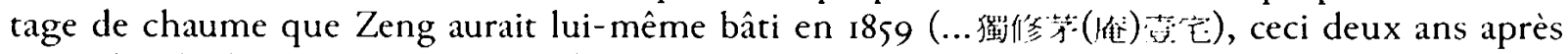
avoir décidé de devenir végétarien (bouddhiste ?). Zeng est né en 1816 et il note précisément ses

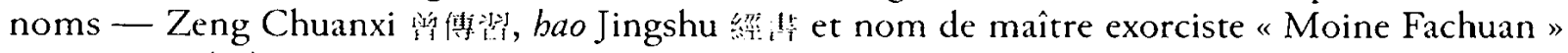
法多濖法傅 (sic). Par contre aucune des appellations généralement utilisées (chusbi, dizi...) n'est employée, et Zeng est vraisemblablement officiant et seul commanditaire. Comme le certificat le dit, une fois la gravure faite et la cache remplie, il fallait régulièrement brûler de l'encens pour

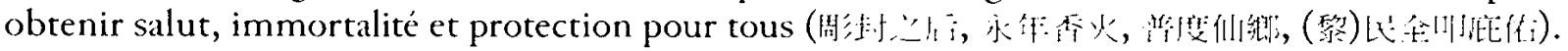

70. $M u$ signifie "laver/purifier». Ce caractère intervient souvent dans l'expression « d'une main pure" (mushou 沫 F: 0490/C:1588; T0370; T0650; Toorg etc.). On trouve une fois le caractère $m u$ associé à l'action d'écrire (danqing Yu Wanyu mushu fit tof que dans deux autres formules : selon les certificats d'un couple de dieux du Foyer (appelés ici directeurs du Destin des cuisines de l'Est, Jiutian dongchu siming fuijun 几

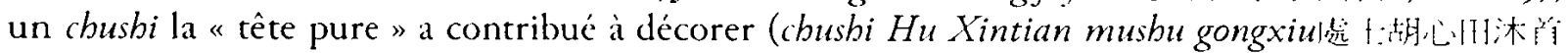

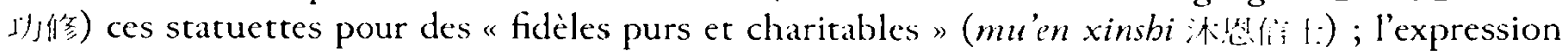
" pur et charitable " est utilisée aussi dans une statue récente pour un initié de nom Li Fakun

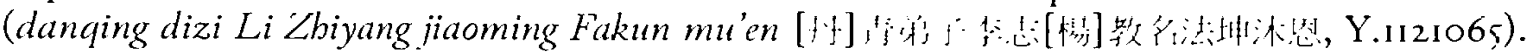

71. Cette pièce est produite à Anli, dans le canton de Chang'an du district de Anhua (' $2<1$ :

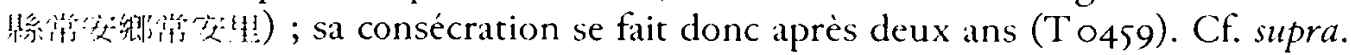


Wan Zirui 萬于瑞 l'a sculptée, et que, selon une inscription sur la pièce même, il a procédé à l'ouverture des yeux $x^{72}$.

Comme nous venons de l'évoquer plusieurs fois, en plus de sculpter, ces artisans

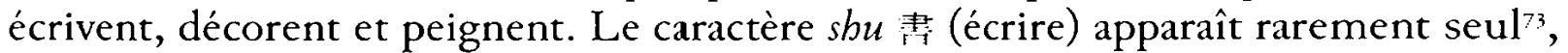
mais le plus souvent en couple, dans la formule «écrire respectueusement » (jingsbu 敬書 $)^{74}$. Parfois, par cette formule, le chushi note qu'il écrit respectueusement dans le certificat le compte rendu de son action ${ }^{75}$. L'expression shuli (書这 écrire et établir) ${ }^{76}$ ou la version plus complète (繪清敬䜣 peindre, écrire et établir respectueusement) ${ }^{77}$, et encore sbufeng (書封 écrire et sceller [la cache]), sbubua (書畫 écrire et peindre) et shuzbuang (書装 écrire et décorer) sont également présents ${ }^{78}$. On notera aussi l'indication générique « inviter un artisan-scribe à la maison pour brûler de l'encens

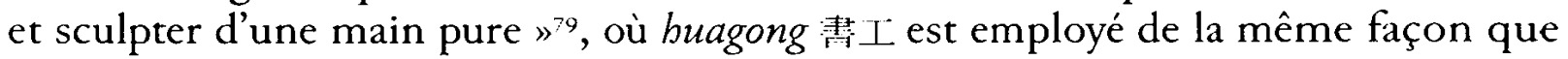
les composés avec jiang (artisan) cités plus haut.

Le caractère zhuang 装 (que nous pouvons comprendre comme " décorer ", " orner », " installer» ou dans le sens d'« habiller », « équiper d'ornements ${ }^{8 \circ}$ )

72. La pièce, que nous n'arrivons pas à dater, est faite à Xinhua (T604) et les indications

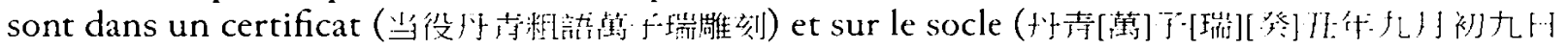

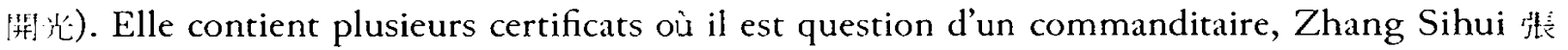
琶琶, mais aussi d'un certain Zhang Sizong 张琶聰, qui semble être un frère ou un cousin et qui a «maladroitement écrit » (zhuosbu fit fij) le certificat.

73. Par exemple dans le cas du cbusbi Yuan Tianwen 袁卡义 qui signe un certificat en 1770 ( $35^{\circ}$ année de Qianlong) pour une statuette qui porte aussi un certificat de $174^{8}$ (13 ${ }^{\circ}$ année de Qianlong. Voir or81/C:1648-2-2.

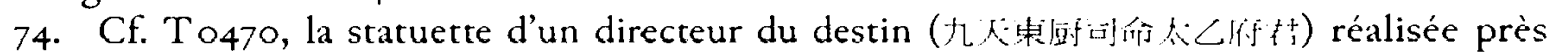
de Changsha en 1907, pour laquelle le danqing Yu Bin a « respectueusement écrit 》(情青 [ [斌]敬㕩) le certificat; idem pour une pièce très récente (1991) de Liu Guiqiu (從罗[刘][㭙]秋职

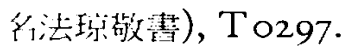

75. C'est le cas de To370, où le chushi clôt le certificat avec l'expression « respectueusement écrit 》 après avoir indiqué qu'il a sculpté et confectionné la pièce “ d'une main pure 》(處.t.t.t.

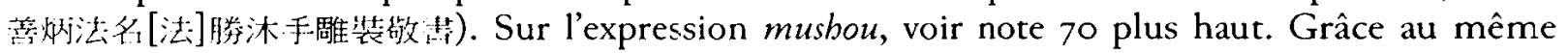
certificat on apprend que la pièce a été accomplie en neuf jours et consacrée à la maison en 1794

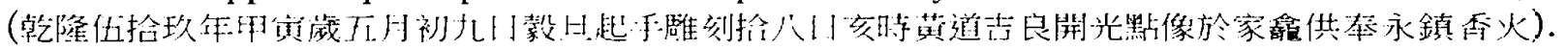
Nous rencontrons un exemple où parait l'expression tongshu 企草 (全 pour jiij, voir To630) en clôture du certificat, qui pourrait faire allusion aux autres tâches accomplies par le danging Huang

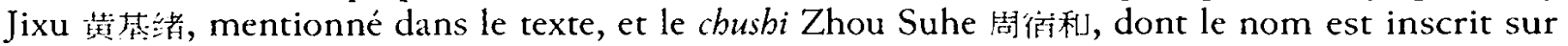
la statuette même.

76. C'est le cas pour une statuette d'assez fine facture (To546) : dans son certificat, on lit d'abord une longue liste de donateurs et leurs motivations, ensuite la date à laquelle, en 1930, on scelle respectueusement la cache (jingfeng 微封) au dos de la statuette, enfin le nom du danqing dizi

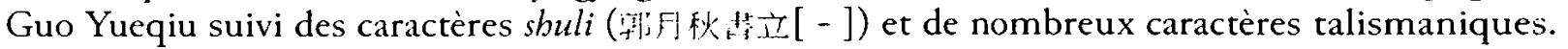

77. Cf. Y.I1320I.

78. Respectivement T 0720, T $0635-2-2$ et $0469 / \mathrm{C}: 932$.

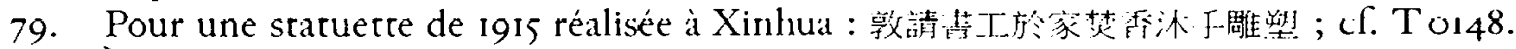

80. À propos des statuettes, comme nous l'avons déjà vu, les références au corps humain abondent (on leur pose une peau lors de leur production, on leur ouvre les yeux lors de la consécration, etc.). 
Fig. 9a

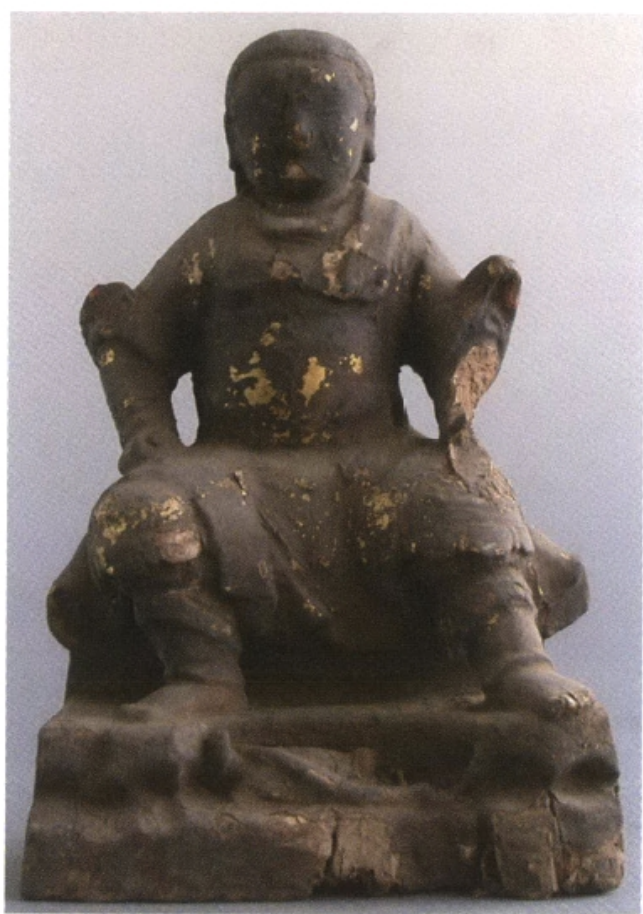

Fig. 9b

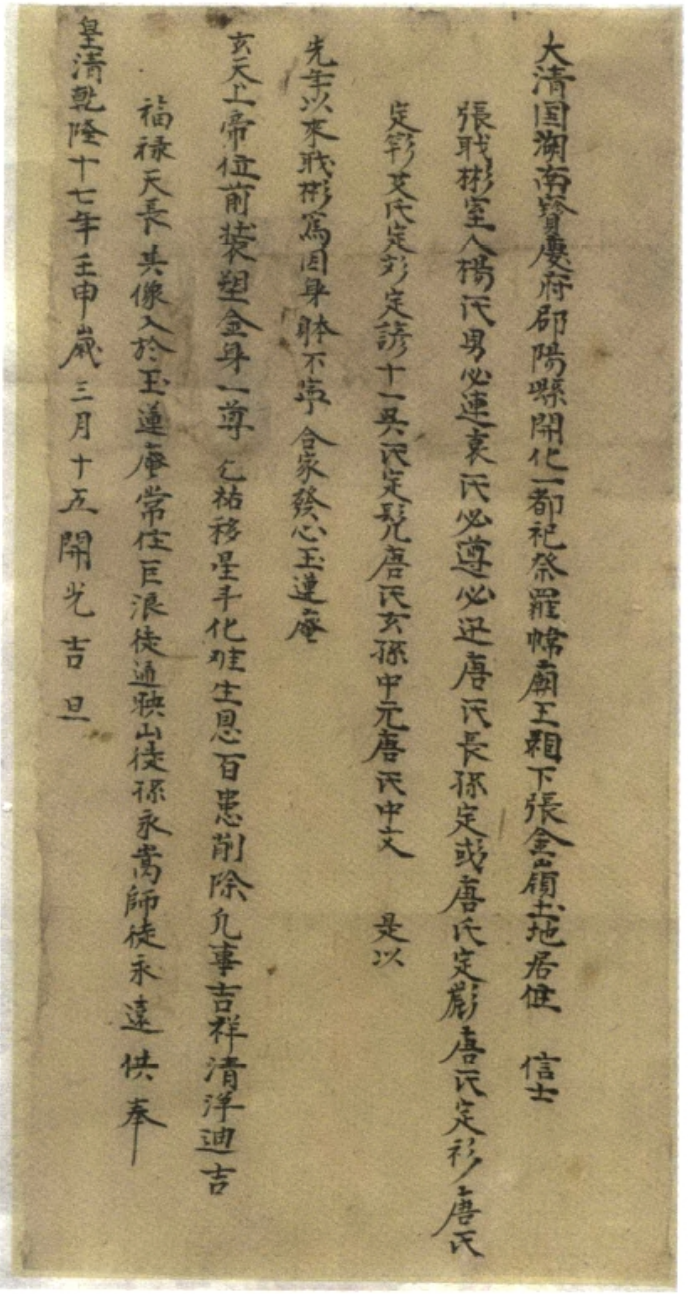

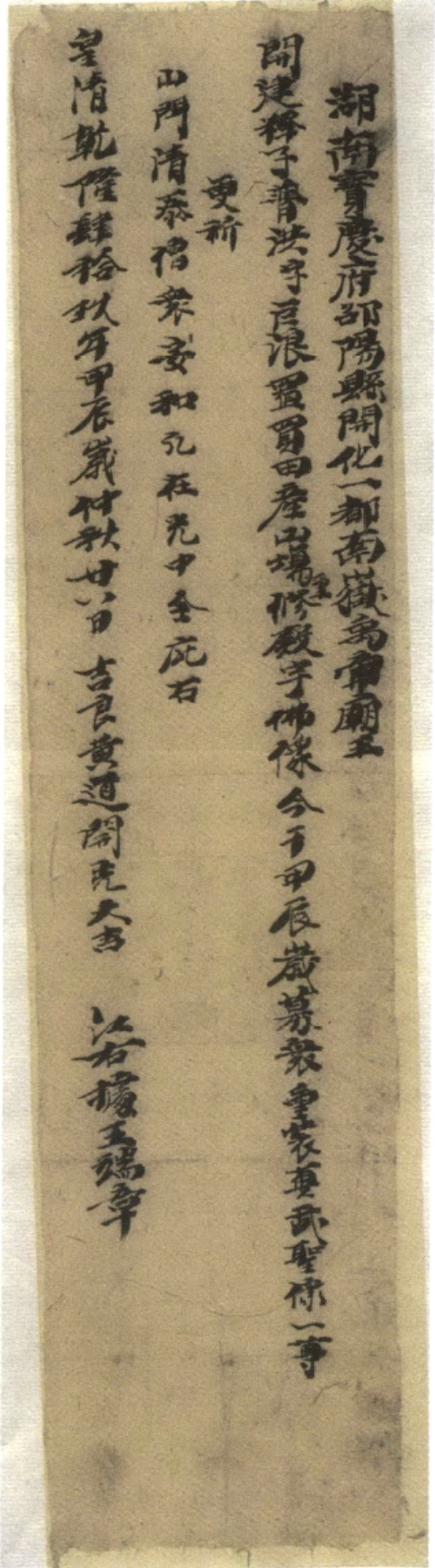

Fig. 9c

Fig. 9 : 9-a : Statuette de Xuantian shangdi 玄天上 帝, h. $27 \mathrm{~cm} ;$ 9-b : consacrée en 1752 (乾隆十七-年 王电歲) ; 9-c : redécorée et consacrée une deuxième fois sous le nom de Zhenwu 真武 en 1784 (터릴), par la volonté d'un certain Pu Hong qui s'attelle aussi à la réfection [des images] d'un temple (開建䆁于普洪字巨浪真嘪田産、山埸重修䐨宇佛像), 0842/C:919. Photo : musée du Hunan CEFEO. 
est utilisé seul ${ }^{81}$ ou dans de nombreux composés. En plus de shuzhuang 書装, on utilise xiuzhuang 修装 (《réparer et décorer 》) et chong/fuzhuang 重/復証 ( décorer à nouveau ») (fig. 9), qui font penser à l'intervention sur une pièce déjà existante ${ }^{82}$, mais surtout diaozhuang 閏雒裝 et ses variantes que nous avons déjà évoquées plus haut $^{8_{3}}$, ainsi que zhuangcai (裝彩, " décorer en couleurs", donc peindre) ${ }^{8_{4}}$.

Ceci s'exprime parfois dans des formules complexes : "le maître des couleurs a fait le portrait d'or et décoré de couleurs (zbuangcai) l'image de jade » (丹青弟千, 修 市金容, 装彩下相 $)^{85}$. Plus généralement, les expressions faisant allusion à la couleur sont nombreuses (avec une ambiguïté constante entre la magnificence des couleurs et la splendeur de la beauté, qui est propre au caractère cai 彩). Par exemple en 1947, à Changfeng, on invite pour une imposante image de Xiaojun sanlang 萧禾二 郎 un maitre des couleurs à la maison pour faire la statuette (sucheng shenxiang 成神像) et son portrait (caisu jinrong 彩朔 [=絮]食 ${ }^{86}$. Parfois cai est combiné aux caractères diao 彫/,雕 et diaoke 雕刻 ${ }^{87}$.

Ailleurs on parle de peinture ou de dessin (bua 畵 ou bui 繪 ${ }^{88}$ ), seuls ou associés avec d'autres tâches, par exemple dans l'appellation d'un commanditaire défini comme «le fidèle qui a demandé au maître des couleurs de graver et de peindre

8I. Souvent le « peintre décore » (tanqing zhuang fff青装), comme pour T0759; voir aussi To77r et To484.

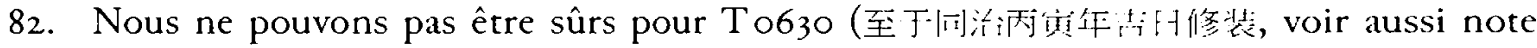
44), ni pour $0555 / \mathrm{C}: 838$ (闌法霜復装) pour lesquelles interviennent deux chushi de la famille Zhou. Par contre cela semble vraisemblable pour une pièce contenant deux certificats, de 1752 et 1784 , $0842 / \mathrm{C}: 919$, fig. 9. Également la pièce $\mathrm{T}_{0345}$ est consacrée, selon son certificat, une première fois en r 919 et repeinte et consacrée en 1928 si l'on se fie à une inscription sur la statuette elle-même

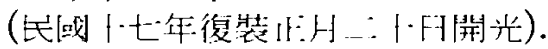

83. Nous avons cité Torro, or88/C:163, Tor79 aux notes 61, 62 ; rappelons encore T 0370, T0633, T0835, 0662/C:1557, Y.rizro66, etc.

84. Voir les expressions zhuancai (装彩) pour la statuette Tooro décorée en 1766 et zhuangcai

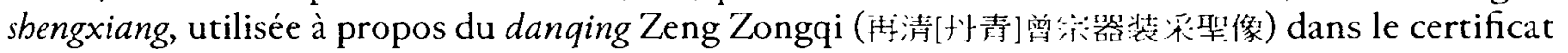
de Tor5r. Ou encore dans l'expression "sculpter et peindre" (周㧡装彩) pour une pièce de I898; dans ce certificat on utilise aussi le terme xiu, qu'on peut alors interpréter dans le sens de décorer

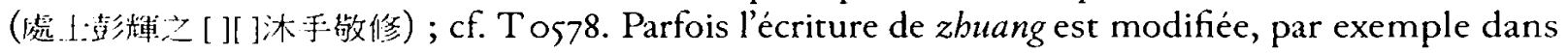
le certificat de To684, ou on lit 刻荘彩牛神像.

85. Cf. T0702 et To689, deux pièces réalisées en 1936 près de Changsha. Elles sont au nom

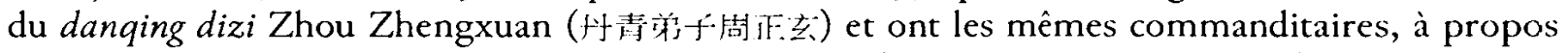
desquels on utilise une autre succession de caractères (...雕修神像装彩金容...倍人).

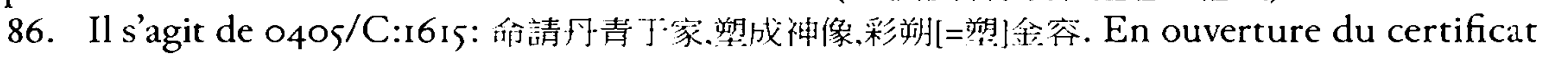
de cette pièce ainsi que dans celui de Tor2I, postérieure d'un an seulement mais réalisée à Xinhua,

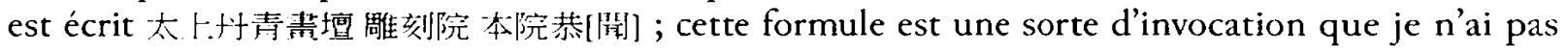
retrouvée ailleurs : «Autel de la peinture et de la couleur du Très Haut, Temple de la sculpture. Pour ce temple on demande respectueusement..."

87. Pour diaocai 彫雕彩, voir Y.1121039, o108/C:1488 et Toor9; pour diaoke cai 雕刻彩, voir T०528.

88. Signalons trois chushi qui dessinent (bui 繪) : To540, To824, 0760/C:781. On trouve

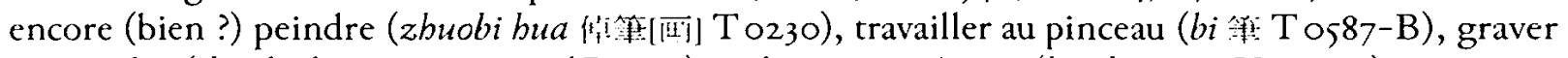

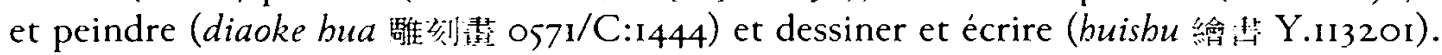




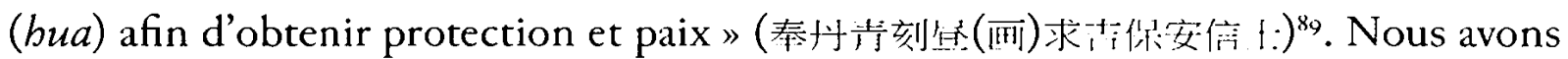
aussi le cas du chusbi Zhang Shuosheng 耏說盛, qui se déclare aussi bien sculpteur que peintre $^{90}$. Parmi les Chen, vers 1840 , Chen Xian [?] 陳咸 [ - ], zi Falun 法輪, sculpte une image et la peint en couleur (caibua $)^{91}$; d'autres décorent et/ou écrivent ${ }^{92}$. Dans les dernières années du XIX ${ }^{c}$ siècle, Chen Faming 陳法明, qui collabore avec

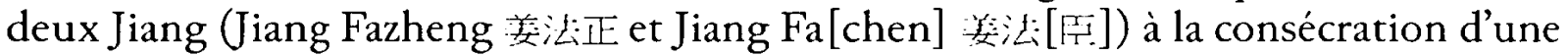
représentation du seigneur Zhang Fayu ( (j, 長君法注), note qu'il a gravé et décoré la resplendissante statuette ${ }^{93}$.

Si nous observons des patronymes en particulier, le cas des Hu est intéressant. Ils sont les plus nombreux et offrent un exemple qui pourrait contredire l'ensemble. Nous penchons pour les considérer comme particulièrement impliqués dans le travail matériel sur les statues pour plusieurs raisons. Il n'y a que deux noms d'initié parmi eux $^{94}$ et les cbushi sont prépondérants ( 32 sur 38 ), de la même façon que pour les Lu cités plus haut. Les autres ne sont que quelques disciples (dizi) et, dans deux cas, on utilise l'expression zhongmei dizi 中梅第-f. (le disciple [de la montagne] des Abricotiers du centre ${ }^{95}$. L'idée que les Hu seraient, avant tout, sculpteurs est aussi justifiée par le grand nombre d'inscriptions - une vingtaine - sur les pièces, portant leurs noms directement gravés ou écrits sur les socles des statuettes, ce qui renforce sans pour autant pouvoir le prouver un lien entre les $\mathrm{Hu}$ et le travail matériel du bois ${ }^{96}$. La plupart des pièces est sculptée dans le district d'Anhua, puis dans celui de Xinhua. Parmi celles sans lieu indiqué, une pourrait provenir de Ningxiang 寗狼縣. Cette pièce (To58I) consacrée en 1935 est de facture modeste. Elle comporte un

89. Ceci pour une pièce gravée par Li Fahu (李法瑚 刻) en 1867, voir To725: les comman-

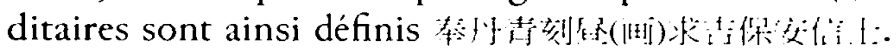

90. Pour une statuette consacree en 1823 dans le district d'Anhua, il aurait gravé et peint

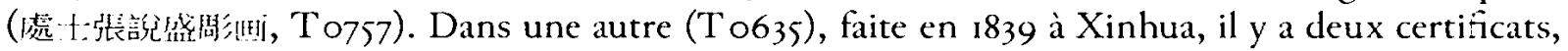

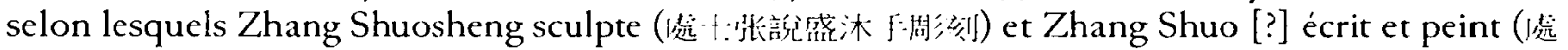

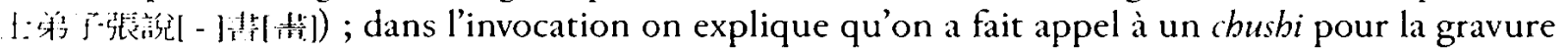

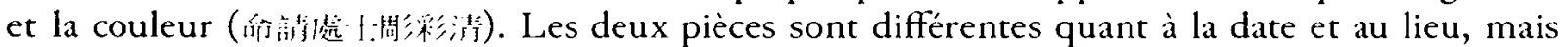
des similitudes dans des détails du décor des socles et dans le dessin des personnages associès aux écritures talismaniques des certificats font penser qu'il s'agit bien de l'œuvre d'une seule main.

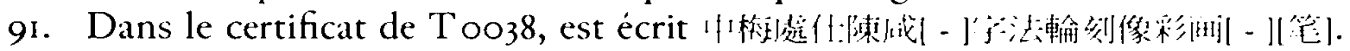

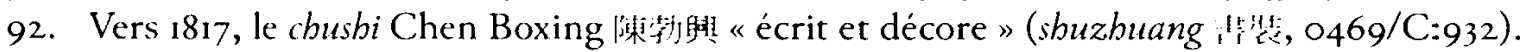

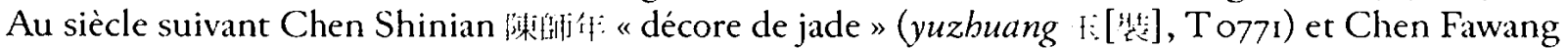

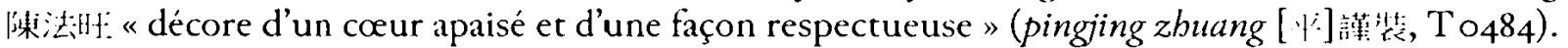

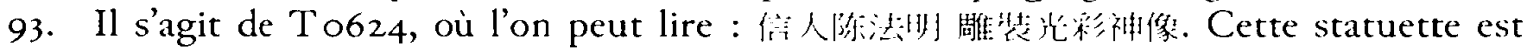
relativement grande $(46,8 \mathrm{~cm})$ et contenait plusieurs certificats (dont un daté de i894 et l'autre de r896); de l'un d'entre eux, on comprend que Chen Faming a été parmi les commanditaires et les auteurs ; il existe plusieurs statuettes au nom de Chen Faming mais un lien entre ces représentations et le sculpteur de To624 ne peut être confirmé pour des problèmes de date.

94. L'absence de noms d'initiés parmi les signatures tracées par les Hu sur statuettes et certificats est en contradiction avec le nombre important de $\mathrm{Hu}$ avec un nom d'initié qui sont cités dans certains benjing. Voir plus haut, les documents concernant Feng Xiaoyuan, p. 144-I48.

95. Parmi cux Hu Yuxuan 胡 1:䡮 compte huit statuettes à son actif.

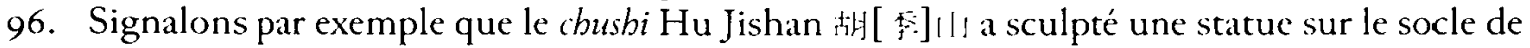
laquelle est noté qu'il a gravé une pièce ke yicun (刻 [...] 㥒) et les caractères diaoke (0386/C:1352). 


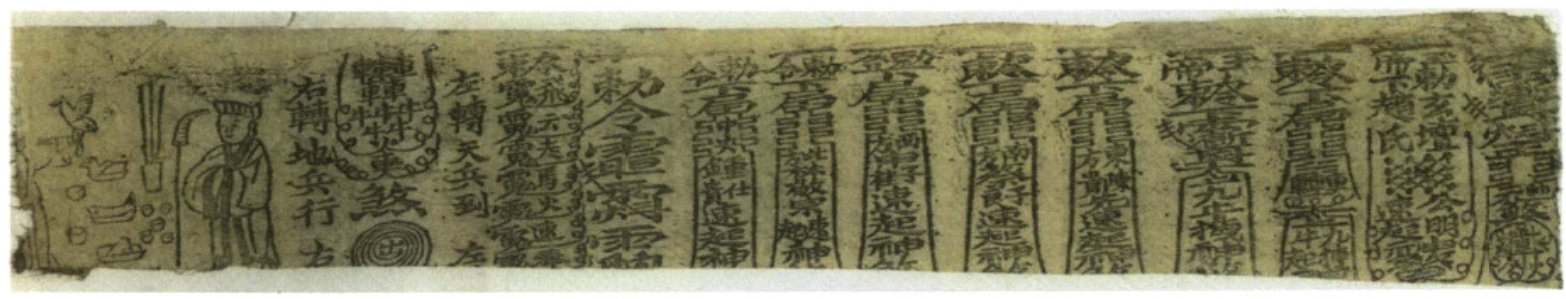

Fig. 10 : Certificat imprimé : les talismans, $6.5 \times 34 \mathrm{~cm}$, T 0581 CEFEO.

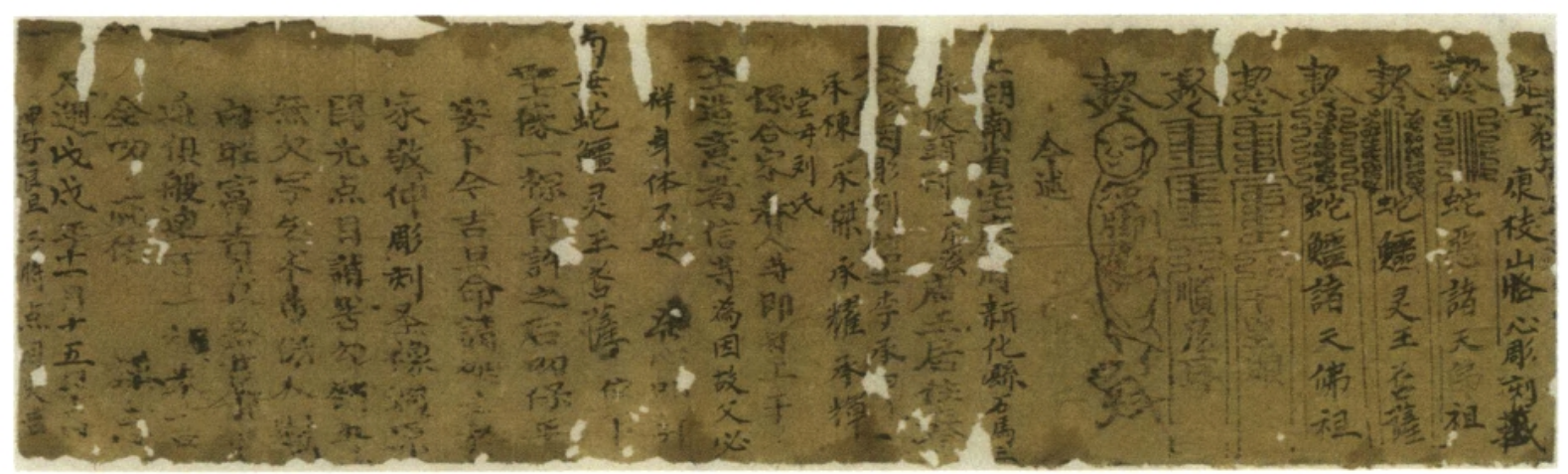

Fig. 11a

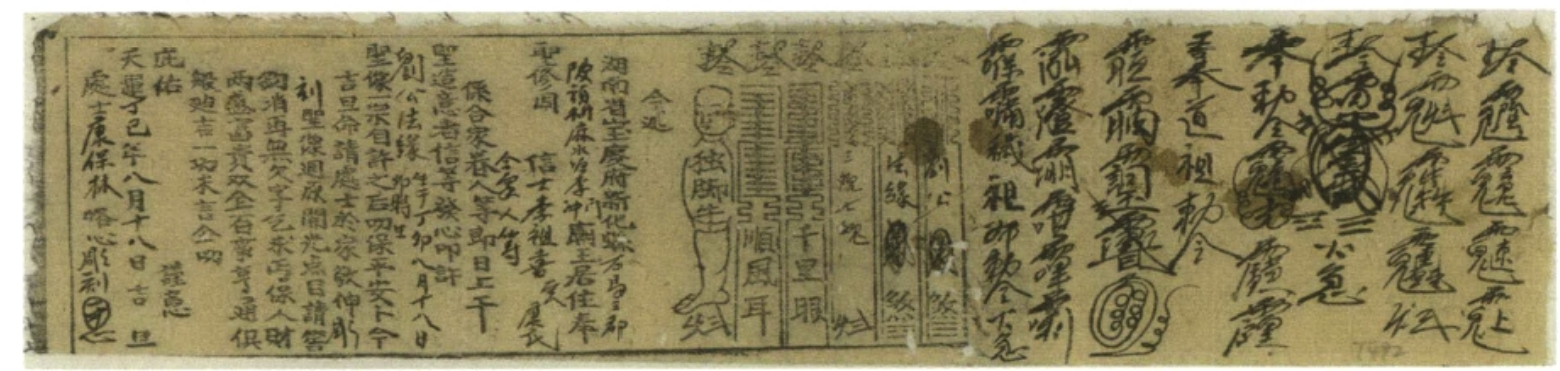

Fig. 11b

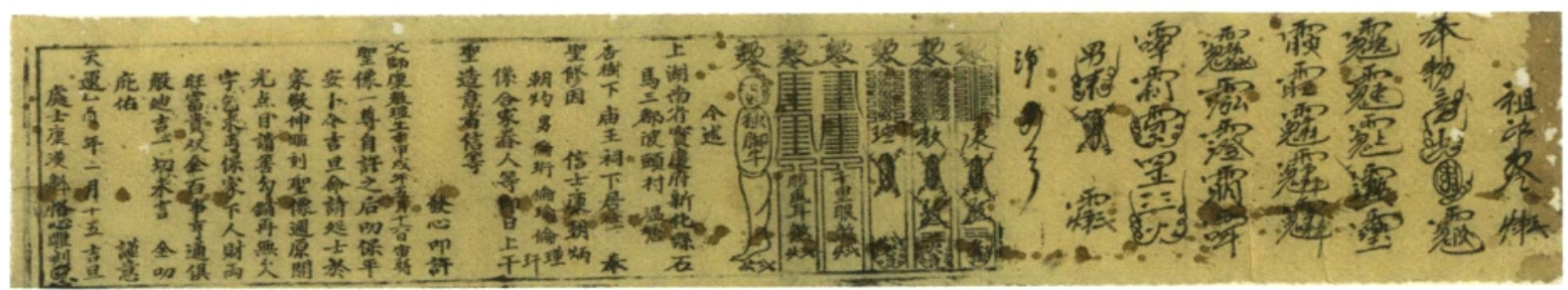

Fig. 11c

Fig. 11 : Certificats similaires, imprimés en partie, utilisés par les Kang 康 ; $11-\mathrm{a}$ : T 0626 $(9,5 \times 30,5 \mathrm{~cm})$; 11 -b : T $0492(8,2 \times 32 \mathrm{~cm}) ; 11-\mathrm{c}:$ T $0768(10,2 \times 51,6 \mathrm{~cm})$. CEFEO. 
certificat imprimé de formules talismaniques d'une écriture assez jolie (fig. Io), ce qui rappelle un autre aspect des activités de ces artisans, la gravure de planches à imprimer, sur lequel nous ne sommes malheureusement pas plus renseignés que pour la sculpture de la statuette. Son certificat révèle aussi une corrélation avec un autre document, sans que nous puissions entièrement la démontrer, si ce n'est par la ressemblance. Il s'agit d'une partie d'un imprimé de plus grande dimension par rapport auquel le nôtre ne serait qu'une moitié97. Un second document donne des explications rapides : il semble évident que le danqing Wu Ruikun (丹青吳瑞坤) l'a écrit et qu'il a travaillé à la pièce. Par contre, nous ne sommes pas certains que le disciple Hu Wanchun 胡萬春 soit un simple commanditaire du portrait de son maitre ou qu'il ait de plus participé à sa sculpture ${ }^{98}$.

Plusieurs Kang 逮 sont également concernés par la gravure. Une partie d'entre eux, vraisemblablement pendant la période républicaine (les dates vont de 1917 à 1945), a fait usage de certificats imprimés similaires (fig. II), où l'on explique que le chushi a été convoqué par [dans] une famille pour graver respectueusement une sainte image et lui 《ouvrir les yeux》(命請處士於家敬伸(神)彫刻聖像週原開光点目) 99 . Selon une autre formule répandue, le chushi Kang Shaohe 康紹河 va " graver de tout son cœur 》用心雕刻 une statue pour Kang Miaoling 隶竗零. Un deuxième certificat laisse supposer que c'est lui aussi qui se rend auprès du commanditaire pour consacrer la statuette à une date choisie ${ }^{100}$. Signalons encore le cas de

97. On pourrait s'interroger sur la raison qui poussa à n'utiliser qu'une partie de l'estampe, peut-être un rite réduit ne nécessitant que cette partie (payé par les commanditaires en conséquence). On y reconnaît une série de talismans associés à autant de divinités et à la convocation des troupes célestes et terrestres, ainsi qu'une scène [incomplète] d'un officiant accomplissant un sacrifice. Pour une reproduction complète de l'estampe, voir Arrault, Bussotti, 2008, p. 50-51, fig. 18 : il s'agit d'un certificat inclus dans la pièce To523 de 1942, donc un peu plus tardive que la nôtre (de 1935). Les deux statuettes partagent peut-être le même lieu de pro-

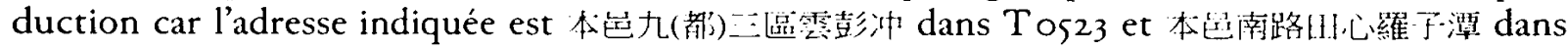
To581. Ce «lieu» (benyi 本迊) est un autre élément qui, en dehors du certificat imprimé, relie les statuettes ; To523 est le portrait de Li Fafu ffit富 (1888-1940), commandé par des membres de la famille L Li ; dans le certificat manuscrit on lit le nom du danqing dizi Yang Fakai 楊法侀 et dans celui imprimé le nom du danqing Guifa 殸泣, qui ont, tous les deux, "signé de tout leur coeur» (yongxin buaya 1 月, 心化护).

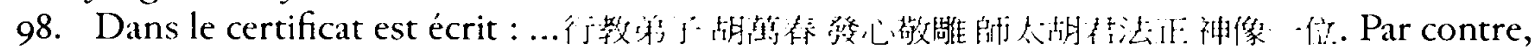
l'inscription sur un côté du socle fait penser que les deux ont travaillé ensemble : «Wu Ruikun

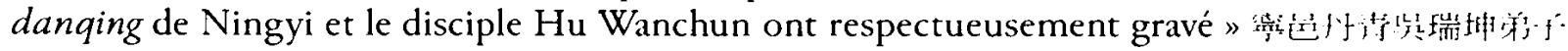
乩萬春敬雕. C'est justement cette inscription qui permet de localiser la pièce Tos $8 \mathrm{r}$.

99. Ils opèrent dans le village Pitou cun (陵頭村), dans le troisième $d u$ de Shima du district

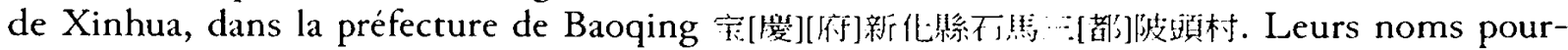
raient révéler des rapports de parentèle, en raison des caractères communs ( $y u$ Jì, shan $|1|)$. Ce

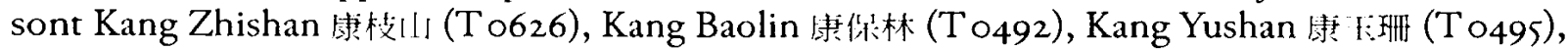

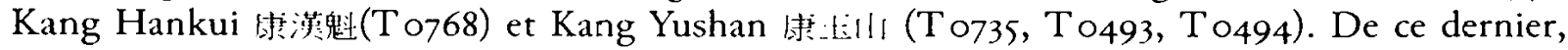
nous avons aussi des pièces dépourvues de certificats, mais sur le socle desquelles est inscrit son

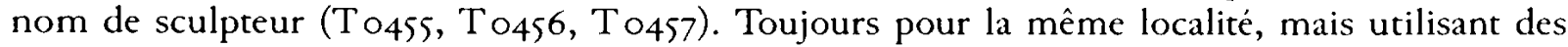

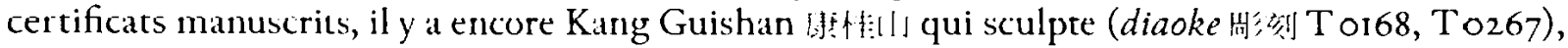
mais les pièces ne sont pas datées.

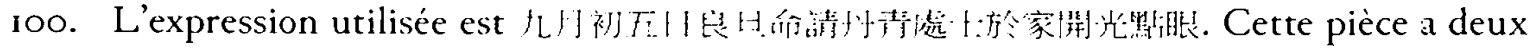


Kang Faxian 康法价, dont le nom est noté sur le socle d'une statuette suivi du caractère diao 彫, tandis que d'autres Kang semblent en avoir fait la consécration ${ }^{101}$, et celui du chushi dizi Kang Jiabi 康打[階] qui, déjà en I877, "grave scrupuleusement " (Kang Jiabi kexin diaoke 国打陛恪心雕刻). Toujours dans la même zone du territoire de Xinhua, les danqing Kang Daidi 接代[迪] et Kang Yingyuan 康映元 ont gravé (ke 刻) des statuettes, respectivement en 1876 et $1853^{102}$. Le nom de ce dernier, ou un homonyme, est mentionné sur une pièce faite dans le district d'Anhua en I86I. Dans ce district, Kang Faling 持法灭 avait aussi gravé une pièce consacrée en 1855 (mingqing

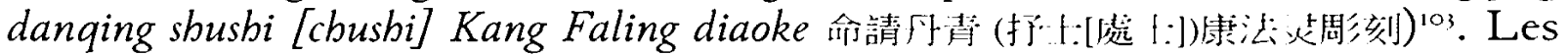
Kang semblent donc avoir opéré essentiellement dans le district de Xinhua.Souvent leur rôle de sculpteur est explicitement revendiqué, peu importe que dans le nom apparaisse ou non le caractère d'initié $f a^{104}$, ou que des appellations variées soient associées à leurs noms. C'est un élément qui fait la difference avec les $\mathrm{Hu}$, parmi lesquels les chusbi dominent.

À propos de quelques exemples individuels, dans un article précédent nous avons procédé en recensant une série de statuettes du village de Changfeng 常, qui ont des caractéristiques communes pouvant faire penser à une transmission de savoir-faire pendant plusieurs décennies entre les membres de trois familles ${ }^{105}$. Si l'intérêt de ce corpus-là est la "sérialité » des statues et de leurs certificats en partie pré-imprimés, ce qui implique des procédés de production répétés dans un atelier de sculpteurs, il n'empêche pas l'existence de personnalités qui se démarquent du groupe, tel le zhongmei dizi Zhou Yaoxian 周耀先, auteur d'une bonne vingtaine de pièces entre 1897 et $1941^{10 \hbar}$. Pour ces activités artisanales qui ne demandent finalement pas une initiation très complexe et qui pouvaient être conduites tout au long de la vie, ce laps de temps est important mais pas étonnant. Entre 1895 et 1940, pas moins de dix-sept statuettes peuvent être attribuées à Wang Rongguang : 溶光. Malgré le fait que la plupart de leurs certificats n'ont pas d'adresse, les quelques-uns

certificats, l'un indiquant celui qui a gravé, l'autre qui explique qu'un cbusbi a été invité pour la consacrer, dans un village du district de Xinhua ; cf. To258.

IOI. Dans cette pièce (To444), Kang Faxian 康法仙 travaille avec Zou Yunlu (diaoke xinsbi

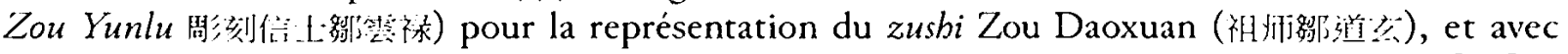

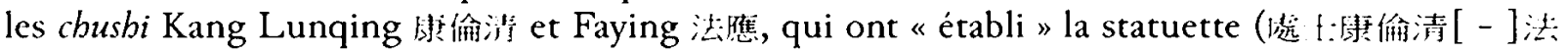

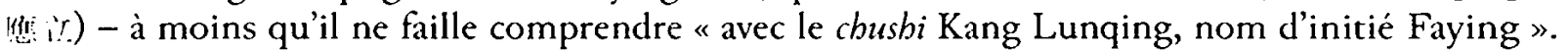
$L i$ ìt. signifie probablement ici une forme de consécration qui permet à la pièce d'« exister ». Le nom de Kang Faxian est lié à une autre statuette représentant Kang Faying, cette fois à Anhua ; cf. To66s.

102. Pièces To176, To258 et T0215.

103. Pièces Tozoo et T 0216.

I04. Nous avons compté cinq noms contenant le caractère fa sur un total de seize Kang, ce qui est tout à fait conforme à la moyenne d'un sur trois.

105. Voir Arrault et Bussotti, 2008, p. 50-54.

106. Ce sont les pièces : To449, To534, To343, Toor8, To276, T 0449, Too69, T 0460, To065, To174, T0531, To175, T0599, T 0219, T0536, T 0244, To272, T0337, T 0836, To271, Tol40, T 0765 . 
qui subsistent indiquent encore une fois Changfeng comme lieu de production ${ }^{107}$. Cependant, ces certificats ne sont pas imprimés mais manuscrits, à l'écriture très souple et cursive, légèrement inclinée à gauche, vers le bas. Ils sont accompagnés parfois d'un petit papier où est tracée la date de naissance du personnage représenté, ce qui semble être un élément caractéristique d'une partie des pièces consacrées par Wang Rongguang qui, tout au long de sa carrière, et à la différence de Zhou Yaoxian, change d'appellations (il est surtout danqing, mais aussi danqing dizi ou chushi). Les statues, en revanche, n'ont pas un style très uniforme, à l'exclusion du cartouche rectangulaire à fond clair apposé sur de nombreux socles. Dans les mêmes années (de 1896 à 1937), on a aussi quelques pièces signées par Wang Deguang 王德光, qui pourrait être le frère ou le cousin de Wang Rongguang, en raison du caractère guang (光) présent dans les deux noms. Il produit sept pièces, dont trois en 1904 pour les mêmes commanditaires. Le décor des vêtements de deux de ces pièces fait état d'une forte ressemblance ${ }^{108}$. Les trois certificats ont la même mise en forme, qui differe beaucoup de celle utilisée par Wang Rongguang : ici l'écriture est appliquée et lisible, sans caractères talismaniques. Wang Deguang est appelé deux fois

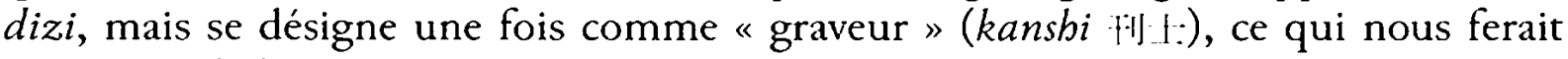
penser, vu le lien étroit entre les trois pièces, que les appellations sont utilisées par les Wang avec une certaine liberté. Dans trois autres pièces, réalisées tant au début qu'en fin carrière, il s'appelle danqing chushi ${ }^{\circ 9}$.

\section{Conclusion}

Ce qu'on déduit de ce triple corpus de statuettes et de certificats anciens est que, sauf quand les certificats de consécration imprimés viennent uniformiser les appellations, il y a une certaine liberté dans l'urilisation des termes par les auteurs des statuettes et de leur consécration. Ce constat déçoit ainsi l'attente de trouver une règle constante pour ces appellations en tant que "titre ", dont la recherche nous avait au début poussée à entreprendre cette analyse comparée d'un nombre élevé de données" ${ }^{10}$. Celles-ci ne permettent donc pas de dégager une hiérarchie claire entre ces artisans "initiés », qui devrait être propre à une tradition unique et organisée. D’ailleurs,

107. Les pièces avec adresse sont : To8ı19, T0428, T 0246 ; les autres sont : Y.II21053, Y.II22073,

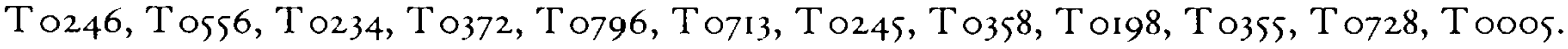

108. Les trois pièces en question sont T0773, To831, To729. Une autre pièce, To772, est faite

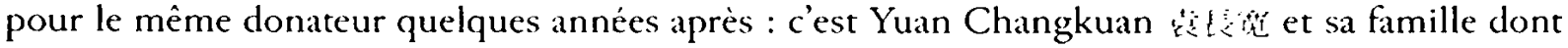
des épouses de nom Wang, ce qui pourrait constituer un lien avec Wang Deguang. Dans le dernier certificat, l'appellation est changée en danqing chushi et des caractères talismaniques sont utilisés.

109. Voir la note précédente, ainsi que la pièce T 0204 ; signalons aussi un remarquable Wang gong yuansbai l: 公佔i, aux yeux globulaires et avec une barbe appliquée, conservé au musée de Changsha $0035 / \mathrm{C}: 1640$. Le personnage est debout sur la roue de feu et la statue atteint $36,5 \mathrm{~cm}$.

1ro. Cette déception rappelle celle d'il y a quelques années quand, lors de l'étude matérielle des pièces et de lcurs descriptions, nous avions cherché à déduire une logique entre personnages représentés et codes vestimentaires, mais ceci n'avait pas apporté de résultats très concluants. Voir note 5 ci-dessus. 
même en analysant tous les (couples de) caractères qui désignent leur production, nous n'avons pas pu établir de règles définitives quant à savoir qui faisait quoi.

Prenons encore le cas d'un couple de statuettes des divinités du Foyer comman-

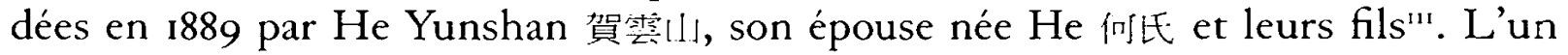
d'entre eux, He Xingyuan 驾星玨, reçut l'ordre de réaliser le “ travail de pinceau » (ming nan Xingyuan bi 乔男妩垣筆), le caractère bi pouvant le désigner en tant que "scribe " pour le certificat. Pour chaque statue, un danqing aurait été invité : pour la statuette masculine, Fu Yuanjun aurait 《fait et dessiné 》(傅雲峻繪造) ; dans l'autre certificat, c'est l'initié Fu Faqian qui, « le front prosterné contre terre et d'un coeur sincère, a respectueusement choisi " la date afin de consacrer la statue (叒行 傅法乾顶礼誠心謹擇…点像). Si une différence peut être détectée pour ce couple de statuettes, elle ne se trouve pas au niveau de l'appellation, mais elle vient du constat que celui qui a un nom d'initié (zouming 奏多) célèbre le rite, et que l'autre, n'en ayant pas, accomplit une tâche technique. À moins de considérer qu'il s'agit d'un même homme, qui se présente une fois sous son premier nom et une autre sous son nom d'initié. La multiplicité de noms est d'ailleurs un élément qui apparait avec évidence dans le cas cité plus haut du contemporain Chen Yisong 陳养松 et de ses maîtres, où jusqu'à trois noms d'initié différents sont attribués à la même personne, selon ses différentes compétences rituelles. Il est aussi frappant que, pour la famille $\mathrm{Hu}$, nous ayons rencontré beaucoup de noms d'initié pour les exemples les plus récents, tandis que ce n'est pas le cas pour le passé.

Malgré une masse considérable d'informations, des problèmes restent en suspens, moins sur les personnages représentés dans les statuettes que sur les hommes qui les ont créées. En premier lieu, nous avons renoncé, à la suite de l'analyse du corpus, à indiquer des statuettes anciennes qui représenteraient quelques-uns de nos « artisans » du bois et du rituel, si l'on exclut le cas de Dun Faxian (fig. 4) qui n'est pas un personnage comme les autres. Nous n'avons pas de portrait de ceux qui ont passé leur vie à sculpter le portrait des autres, à moins que les noms d'usage n'aient différé de ceux utilisés pour l'activité de sculpteur, de la même manière que les différents noms d'ordination, suivant les circonstances, pouvaient être sélectivement assignés aux statues ${ }^{112}$.

C'est probablement pour cette raison qu'il reste difficile d'établir les vrais liens existant entre personnes ayant le même nom de famille (nous pouvons parfois faire des hypothèses, sans plus ${ }^{13}$ ), ou de détecter des liens de parenté par alliance qui peuvent aussi avoir rendu possible une transmission, sauf dans le cas où les

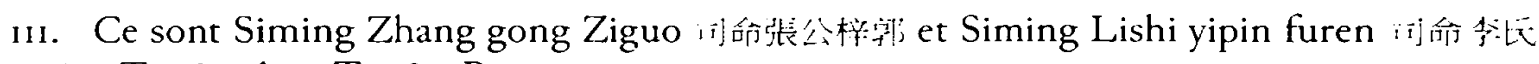
㟧答人: Tos $87-\mathrm{A}$ et $\mathrm{T} 0587-\mathrm{B}$.

112. Sur la base des informations à propos des Chen et des Lu, traitées dans la précédente section, nous savons que les graveurs contemporains conservent des statuettes de leurs aïeuls, qui sont également graveurs, ou de leurs maîtres : il est donc évident que cela devrait être le cas pour certaines des statuettes anciennes, mais nous ne sommes pas en mesure de le prouver.

113. C'est encore une fois le cas de Zhou Yaoxian, qui aurait été suivi par un fils ou un neveu,

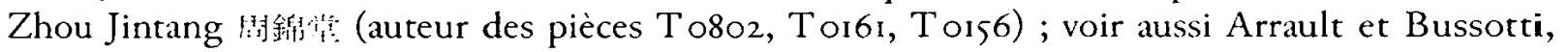
2008 , p. 54 . 
acteurs eux-mêmes fournissent des informations à ce propos, comme pour les Lu que nous avons rencontrés au fil de cet article. Leur histoire s'oppose aussi à un deuxième constat qui naît de la lecture des certificats anciens : il semblerait en fait que l'activité de sculpteur qui, malgré ses implications rituelles, était artisanale, ne se transmettait cependant pas de génération en génération, comme ce fut le cas pour d'autres travailleurs du bois. Ceci irait à l'encontre de l'idée d'un système «clanique » des professions transmises de père en fils et d'oncle paternel à neveu sur plusieurs générations, contrairement à d'autres exemples bien connus dans la Chine du Sud ${ }^{\prime \prime}$. Est-ce lié à la relative simplicité des statues à sculpter, qui permettait au plus grand nombre de se lancer facilement dans l'entreprise ? À la nécessité d'une initiation religieuse privilégiant le rapport maitre-disciple plutôt que ceux père-fils ou oncle-neveu ? À une "demande » locale telle qu'elle ne poussait pas les gens à créer un réseau familial spécialisé organisé, pour s'entraider sur place et pour éventuellement se déplacer plus aisément dans d'autres localités ? À un système familial où les rapports entre la branche paternelle et maternelle sont finalement représentés d'une façon plus égalitaire ? Ou ne serait-ce pas plutôt l'absence, jusqu'à présent, de documents alternatifs aux certificats de consécration qui ne nous permet pas de reconstituer ce monde dans tous ses aspects, une situation qui ne peut que motiver des recherches ultérieures?

I14. Je me réfère aux artisans que j’ai le plus longuement étudiés, les graveurs de planches xylographiques de la période pré-moderne : des grandes familles comptant des dizaines de membres actifs sur plusieurs générations, par exemple dans l'Anhui du Sud ou dans le Fujian du Nord. Dans le cas du Hunan, il serait intéressant de mener une comparaison avec les producteurs de nianbua 年偖: et surtout des zhima 纸致, du Sud de la province. Ces imprimés sont largement reproduits et répertoriés, mais il est possible que d'autres approches de recherche puissent révéler des activités religieuses associées à celles de gravure et d'impression des planches. La production de nianbua, initialement liée à des manufactures de papier, a eu ses années de gloire essentiellement pendant la première moitié du $\mathrm{xx}^{\circ}$ siècle, avec des ateliers gérés par les membres de la famille pendant quelques générations, dotés de nom (ce qui manque pour les sculpteurs de statuettes) et d'un système de distribution et de vente organisés dans d'autres localités, parfois éloignées. À propos des producteurs de zhima, des activités de type familial sur plusieurs générations sont signalées, mais d'autres détails manquenc. Voir les sections «Zuofang he yiren " 作㳩利藝人, “Tantou zhima

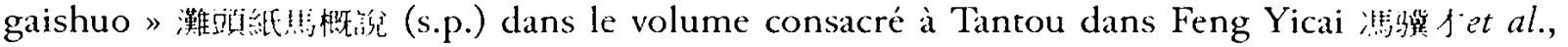

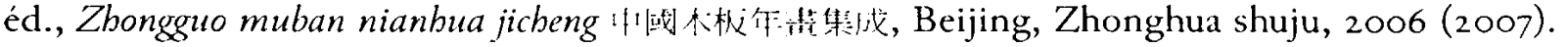




\section{Bibliographie}

Arrault, Alain

2008 "Analytic Essay on the Domestic Statuary of Central Hunan: The Cult to Divinities, Parents and Masters ", Journal of Cbinese Religions, 36, p. I- 53 .

Arrault, Alain et al. (éd.)

2006 Les statuettes du Hunan - I. Collection Patrice Fava, Paris, EFEO - catalogage informatisé, version de travail.

2006 Les statuettes du Hunan - 2. Collection du musée provincial du Hunan, Paris, EFEO - catalogage informatisé, version de travail.

2010 Les statuettes du Hunan - 3. Collection Yan Xinyuan, Paris, EFEO - catalogage informatisé, version de travail.

Arrault, Alain et Bussotti, Michela

2008 "Statuettes religieuses et certificats de consécration en Chine du Sud, XVII"XVIII" siècle ", Arts Asiatiques, 63, p. 36-6o.

Arrault, Alain et Robson, James

2009 «Rapports d'enquêtes de terrain de juin 2009 » notes non publiées.

Bussotti, Michela

2006 《Hunan zhongbu diqu “jiating jiaoxiang” de lüeshu”湖南山部地区“家廷雕 像” 的略逝 (Brève étude sur la production «familiale » de statuettes sculptées dans le centre du Hunan), inédit, version chinoise de la communication prononcée à l'International Convention of Asia Scholars de 2005.

2008 "Statuaria popolare cinese : le sculture lignee dello Hunan centrale e la collezione del Museo provinciale » (avec Alain Arrault), ArtDec, 9, P. 3-i4.

2010 «Rappresentazioni femminili nelle statuette religiose dell'Hunan centrale di epoca moderna e contemporanea ", in Paolo de Troia, ed., La Cina e il mondo, Sapienza Università di Roma, Facoltà di Studi Orientale, Roma, Edizione Nuova Cultura, p. 129-140.

Chau, Adam Yuet 周越

2006 "Superstition Specialist Households'?: The Household Idiom in Chinese Religious Practices ", Journal of Chinese Ritual, Theatre and Folklore, 153, p. $157^{-202}$.

Chen Yisong shifang yingyong Danqing xiangpu陳益松十一庁應用小清[青]像譜 (À utiliser par Chen Yisong dans les dix directions : Album des images du maître des couleurs), manuscrit de la collection Chen Yisong 陳益松, s.l., s.d.

CHEN Yisong 陳益松

[sous presse] «Xinhua xian Daxiong shan qu de bufen leitan gaikuang ji Huizhen leitan》新化縣大熊山區的部分雷壇概況及會苫雷增, dans Chen Zi'ai 陳于艾 et Hua Lan 華瀾 (Alain Arrault), éds., “Xiangzhong zongjiao yu xiangtu shebui” diaocha baogao ji“湘中宗教與郷”土社奥”調䍒.報告集. 
CHen Zi'ai 華瀾 et HuA Lan 華闌 (Alain Arrault) (éd.)

[sous presse] “Xiangzhong zongjiao yu xiangtu shebui" diaocha baogao $j i$ “湘叶宗” 教與楖，土社會”調查報售集, 3 vols., actes du colloque du même nom, Loudi 婁底 - Shuiche 水車, 24-29 juin 2006, Beijing 北宗, Zongjiao wenhua chubanshe 宗教文化出版社.

FENG Guanghua 奉光華

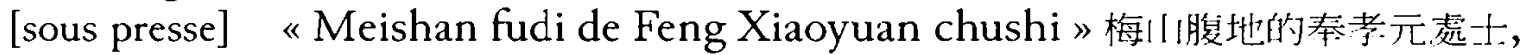
dans Chen Zi'ai 陳了·艾 et Hua Lan 華瀾 (Alain Arrault), éds., “Xiangzhong zongjiao yu xiangtu shebui” diaocha baogao ji “湘中宗教與纰中. 社曾”調查報 告集.

FENG Yicai 馮䩀才 et al. (éd.)

2006 Zhongguo muban nianbua jicheng 中國木板年盖集戊, “Tantou juan 》灘頭 菼, Beijing, Zhonghua shuju (réimprimé en 2007).

Hu Nenggai 胡能改

[sous presse] “Meishan zhima »梅打紙馬, dans Chen Zi'ai 陳于艾 et Hua Lan 華瀾 (Alain Arrault), éds., “Xiangzhong zongjiao yu xiangtu shebui" diaocha baogao $j i$ “湘中宗教與揤上社會”調查報售集.

“Hunan Lushi liuyuan” 湖南陸氏流原 site Lushu juanyuan 陸比家園 consulté le 22 janvier 20I2, http://www.lushi.hk/forum.php?mod=viewthread \&tid=229I.

Lushi liuxiu zupu 陸氏; 修族譜, texte imprimé de la collection de Lu Jiacan 陸家燃 et Lu Shenglin 陸警林, s.1., 1994.

Minjian jianzhi mubanbua 民間剪紙不版圭, 1995. in Hunan minjian meisbu quanji 湖

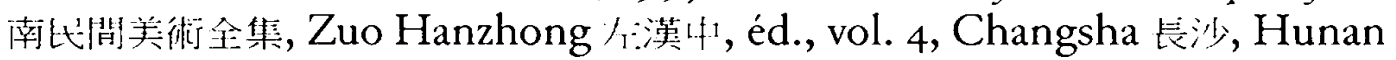
meishu chubanshe 湖献美術出版社, 1995 .

ZHANG Yanping 张燕仠.

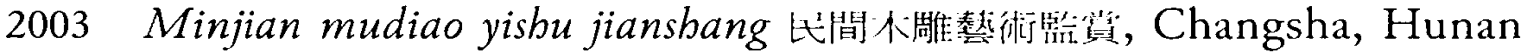
renmin chubanshe.

ZHou Jian 洼健

2000 Xiangcbu mudiao 洲楚林雕, Changsha, Hunan meishu chubanshe. 


\section{Appendice}

Les différentes appellations des sculpteurs dans trois collections de statuettes (voir tableau pages suivantes).

Abréviation :

SA : concerne un sculpteur qui se présente avec et sans appellation dans différents certificats. 


\begin{tabular}{|c|c|c|c|c|c|c|c|}
\hline $\begin{array}{l}\text { Nom de } \\
\text { famille }\end{array}$ & Nombre & $\begin{array}{l}\text { Disciple } \\
\text { 弟子 }\end{array}$ & $\begin{array}{l}\text { Disciple } \\
\text { maître } \\
\text { local } \\
\text { 處士弟子 }\end{array}$ & $\begin{array}{l}\text { Disciple } \\
\text { maître } \\
\text { des cou- } \\
\text { leurs } \\
\text { 丹青弟子 }\end{array}$ & $\begin{array}{l}\text { Maître } \\
\text { des } \\
\text { couleurs } \\
\text { 丹青 }\end{array}$ & $\begin{array}{l}\text { Maître } \\
\text { des } \\
\text { couleurs } \\
\text { - maître } \\
\text { local } \\
\text { 丹青處士 }\end{array}$ & $\begin{array}{l}\text { Maître } \\
\text { local- } \\
\text { maître des } \\
\text { couleurs } \\
\text { 處士丹青 }\end{array}$ \\
\hline Hu 胡 & 38 & 4 & & & & & \\
\hline Liu 劉 & 35 & 1 & 4 & 2 & 4 & 1 & 1 \\
\hline $\mathrm{Li}$ 李 & 33 & 1 & & 4 & 4 & 1 & \\
\hline Chen 陈 & 24 & & & & 3 & & \\
\hline Wang 王 & 21 & 1 & & 2 & 2 & & 2 \\
\hline Zhang 張 & 18 & & & & 3 & & \\
\hline Kang 康 & 16 & & 3 & & 2 & 1 & \\
\hline Zhou 周 & 15 & & & 2 & 2 & & \\
\hline Luo 羅 & 13 & & & & 1 & & \\
\hline Wu 吴 & 12 & & & 1 & 1 & 1 & \\
\hline Yang 楊 & 12 & 5 & & & 1 & & \\
\hline Lu陸 & 11 & & & & & & \\
\hline Peng 彭 & 9 & & & & & & \\
\hline Deng 鄧 & 9 & & & 1 & 1 & & \\
\hline Tang 唐 & 9 & & & 1 & 3 & & \\
\hline Zou 邹煼 & 9 & & & & 2 & & \\
\hline Jiang 姜 & 7 & 1 & & & 2 & 1 & \\
\hline Sun 孫 & 7 & & & & 1 & & 1 \\
\hline Zeng 曾 & 7 & 1 & & & 4 & & \\
\hline
\end{tabular}




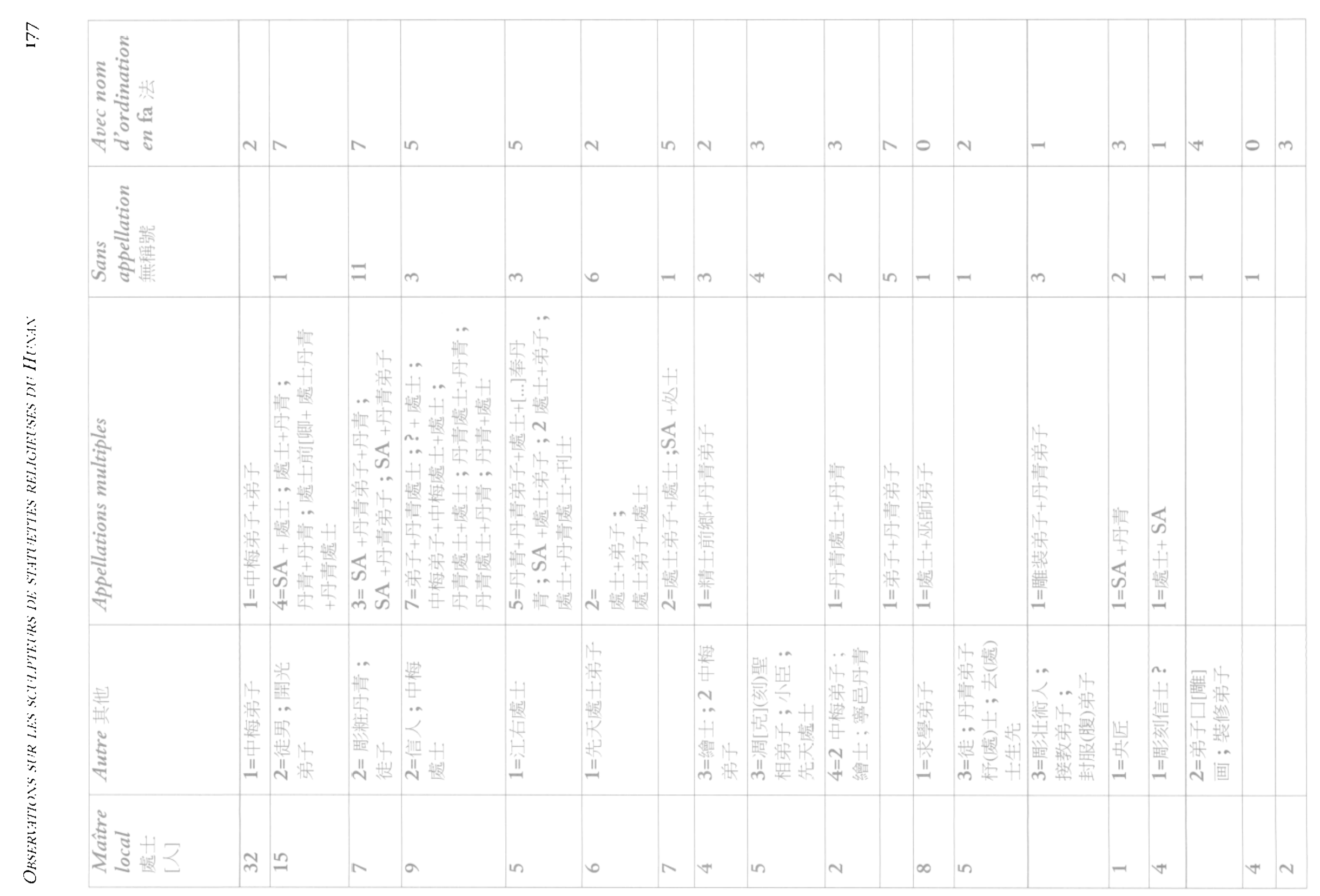




\begin{tabular}{|c|c|c|c|c|c|c|c|}
\hline $\begin{array}{l}\text { Nom de } \\
\text { famille }\end{array}$ & Nombre & $\begin{array}{l}\text { Disciple } \\
\text { 弟子 }\end{array}$ & $\begin{array}{l}\text { Disciple } \\
\text { maître } \\
\text { local } \\
\text { 處士弟子 }\end{array}$ & $\begin{array}{l}\text { Disciple } \\
\text { maître } \\
\text { des cou- } \\
\text { leurs } \\
\text { 丹青弟子 }\end{array}$ & $\begin{array}{l}\text { Maître } \\
\text { des } \\
\text { couleurs } \\
\text { 丹青 }\end{array}$ & $\begin{array}{l}\text { Maître } \\
\text { des } \\
\text { couleurs } \\
\text { - maître } \\
\text { local } \\
\text { 丹青處士 }\end{array}$ & $\begin{array}{l}\text { Maître } \\
\text { local - } \\
\text { maître des } \\
\text { couleurs } \\
\text { 處士丹青 }\end{array}$ \\
\hline $\mathrm{He}$ 賀 & 6 & 1 & & & 2 & & \\
\hline Wen 文 & 6 & & & 1 & $\begin{array}{l}\text { 1担清(丹 } \\
\text { 青) }\end{array}$ & & \\
\hline Xie 謝 & 6 & & & 3 & 1 & & \\
\hline Huang & 5 & 1 & & 1 & 2 & & \\
\hline 产 & 5 & 1 & & 1 & 2 & & \\
\hline Yuan 袁 & 5 & & & 1 & 1 & & \\
\hline Xiong 熊 & 5 & & & & & & \\
\hline Dai 戴 & 4 & & 1 & & 1 & & \\
\hline Liao 廖 & 4 & 1 & & 1 & & & \\
\hline Wei 魏 & 4 & & & 1 & 1 & & \\
\hline Xiao 蕭 & 3 & & & & & & \\
\hline Cao 曹 & 3 & & & 1 & & & \\
\hline Fu 傅 & 3 & & & & 2 & & \\
\hline $\mathrm{Gu}$ 喜 & 3 & & & & 3 & & \\
\hline Lu 盧 & 3 & & & & & & \\
\hline $\mathrm{Ma}$ 馬 & 3 & 1 & & & & & \\
\hline Tan 譚 & 3 & & & & & & \\
\hline Tao 陶 & 3 & & & 1 & 1 & & \\
\hline Tian 田 & 3 & & & & & & \\
\hline$Y u$ 余 & 3 & 1 & & & 2 & & \\
\hline Gao 高 & 2 & 1 & & & & & \\
\hline Gong 㤅 & 2 & & & & 1 & & \\
\hline Guo 郭 & 2 & & 1 & & & & \\
\hline Long 龍 & 2 & 1 & & & & & \\
\hline $\begin{array}{l}\mathrm{Ou}[\text { ] } \\
\text { 歐[ ] }\end{array}$ & 2 & & & & & & \\
\hline Pan 潘 & 2 & & & & 2 & & \\
\hline Su 蘇 & 2 & & & 1 & & & \\
\hline Yan 滒 & 2 & & & & 1 & & \\
\hline$Y u$ 俞 & 2 & & & & & & \\
\hline Xiang 向 & 2 & & & & & & \\
\hline Ding 丁 & 1 & & & & & & \\
\hline
\end{tabular}




\begin{tabular}{|c|c|c|c|c|}
\hline $\begin{array}{l}\text { Maître } \\
\text { local } \\
\text { 處士 } \\
\text { [人] }\end{array}$ & Autre 其他 & Appellations multiples & $\begin{array}{l}\text { Sans } \\
\text { appellation } \\
\text { 無稱號 }\end{array}$ & $\begin{array}{l}\text { Avec nom } \\
\text { d'ordination } \\
\text { en fa 法 }\end{array}$ \\
\hline & $\begin{array}{l}2=\text { =雕刻处士; 奉 } \\
\text { 命叨行小職弟子 }\end{array}$ & & 1 & 2 \\
\hline 2 & $1=$ 生相小子 & & 1 & 0 \\
\hline \multirow[t]{3}{*}{1} & & $1=$ 處士 $+\mathrm{SA}$ & & 3 \\
\hline & $1=$ 奉行彫像弟子 & & & 0 \\
\hline & & & 1 & 2 \\
\hline 1 & $\begin{array}{l}1=\text { 处士+处士猶 } \\
\text { 南山 }\end{array}$ & & 1 & 1 \\
\hline \multirow[t]{3}{*}{3} & 1=雕像弟子 & & 1 & 0 \\
\hline & & & 2 & 0 \\
\hline & 1=須至疏者右疏 & & 1 & 1 \\
\hline 1 & & & 1 [嗣孫] & 2 \\
\hline \multirow[t]{4}{*}{2} & & & 1 & 2 \\
\hline & $\begin{array}{l}2=\text { =請邑陽 } \\
\text { 叨行元皇弟子 }\end{array}$ & & & 2 \\
\hline & & 1=處士 +丹青弟子 & & 2 \\
\hline & & & & 1 \\
\hline 1 & $\begin{array}{l}2=\text { =巫師弟子； } \\
\text { 求學弟子 }\end{array}$ & & & 3 \\
\hline 2 & & & & 1 \\
\hline 2 & & & 1 & 0 \\
\hline 1 & & & & 0 \\
\hline \multirow[t]{2}{*}{1} & & & 2 & 2 \\
\hline & & & & 0 \\
\hline 1 & & & & 1 \\
\hline \multirow[t]{2}{*}{1} & & & & 0 \\
\hline & & $1=\mathrm{SA}+$ 丹青弟子 & & 0 \\
\hline 1 & & & & 0 \\
\hline \multirow[t]{3}{*}{1} & $\begin{array}{l}1=\text { 在[靈]元雷壇 } \\
\text { 弟子 }\end{array}$ & & & 1 \\
\hline & & & & 0 \\
\hline & $1=$ =新化處士 & & & 0 \\
\hline 1 & & & & 1 \\
\hline 1 & & & 1 & 0 \\
\hline \multirow[t]{2}{*}{2} & & & & 0 \\
\hline & & & 1 & 1 \\
\hline
\end{tabular}




\begin{tabular}{|c|c|c|c|c|c|c|c|}
\hline $\begin{array}{l}\text { Nom de } \\
\text { famille }\end{array}$ & Nombre & $\begin{array}{l}\text { Disciple } \\
\text { 弟子 }\end{array}$ & $\begin{array}{l}\text { Disciple } \\
\text { maître } \\
\text { local } \\
\text { 處士弟子 }\end{array}$ & $\begin{array}{l}\text { Disciple } \\
\text { maître } \\
\text { des cou- } \\
\text { leurs } \\
\text { 丹青弟子 }\end{array}$ & $\begin{array}{l}\text { Maître } \\
\text { des } \\
\text { couleurs } \\
\text { 丹青 }\end{array}$ & $\begin{array}{l}\text { Maître } \\
\text { des } \\
\text { couleurs } \\
\text { - maître } \\
\text { local } \\
\text { 丹青處士 }\end{array}$ & $\begin{array}{l}\text { Maître } \\
\text { local - } \\
\text { maître des } \\
\text { couleurs } \\
\text { 處士丹青 }\end{array}$ \\
\hline Fang 方 & 1 & & & & & & \\
\hline Fu 扶 & 1 & 1 & & & & & \\
\hline Guan 關 & 1 & & & 1 & & & \\
\hline Jiang 蔣 & 1 & & & & & & \\
\hline Li 黎 & 1 & 1 & & & & & \\
\hline Liang 梁 & 1 & & & & & & \\
\hline Lu 鲁 & 1 & & & & 1 & & \\
\hline Meng 孟 & 1 & & & & & 1 & \\
\hline Ning 䆜 & 1 & 1 & & & & & \\
\hline Shi 石 & 1 & & & & & & \\
\hline Shu 舒 & 1 & & & & & & \\
\hline Wan 萬 & 1 & & & & 1 & & \\
\hline Wen 溫 & 1 & & & & & & \\
\hline Wu 伍 & 1 & 1 & & & & & \\
\hline Xiao 肖 & 1 & & & & & & \\
\hline Yan 颜 & 1 & & & & & & \\
\hline Yan 延 & 1 & & & & & & \\
\hline Yang 陽 & 1 & & 1 & & & & \\
\hline Yang [揚] & 1 & & & & & & \\
\hline Yao 姚 & 1 & & & & & & \\
\hline Xian 顕 & 1 & & & & & & \\
\hline Xu 許 & 1 & & & & & & \\
\hline Xue 薛 & 1 & 1 & & & & & \\
\hline Seng 僧 & 1 & & & & & & \\
\hline Zhao 趙 & 1 & & & & & & \\
\hline Zheng 鄭 & 1 & & & & 1 & & \\
\hline Sous total & 432 & 27 & 10 & 26 & 62 & 6 & 4 \\
\hline Sans nom & 60 & 3 & 2 & 7 & 9 & 2 & 6 \\
\hline Total & 492 & 30 & 12 & 33 & 71 & 8 & 10 \\
\hline
\end{tabular}




\begin{tabular}{|c|c|c|c|c|}
\hline $\begin{array}{l}\text { Maître } \\
\text { local } \\
\text { 處士 } \\
\text { [人] }\end{array}$ & Autre 其他 & Appellations multiples & $\begin{array}{l}\text { Sans } \\
\text { appellation } \\
\text { 無稱號 }\end{array}$ & $\begin{array}{l}\text { Avec nom } \\
\text { d'ordination } \\
\text { en fa 法 }\end{array}$ \\
\hline & 1=丹青子弟 & & & 0 \\
\hline & & & & 0 \\
\hline & & & & 1 \\
\hline & & $1=\mathrm{SA}+$ 处士 & & 1 \\
\hline & & & & 1 \\
\hline \multirow[t]{9}{*}{1} & & & & 1 \\
\hline & & & & 0 \\
\hline & & & & 0 \\
\hline & & & & 1 \\
\hline & & & 1 & 0 \\
\hline & 1=柱司江西 & & & 0 \\
\hline & & & & 0 \\
\hline & $1=$ 江右處士 & & & 0 \\
\hline & & & & 0 \\
\hline 1 & & & & 1 \\
\hline 1 & & & & 0 \\
\hline \multirow[t]{2}{*}{1} & & & & 0 \\
\hline & & & & 0 \\
\hline \multirow[t]{2}{*}{1} & & & & 0 \\
\hline & $1=$ 本處楮士 & & & 0 \\
\hline 1 & & & & 0 \\
\hline \multirow[t]{2}{*}{1} & & & & 0 \\
\hline & & & & 1 \\
\hline 1 & & & & 0 \\
\hline \multirow[t]{2}{*}{1} & & & & 0 \\
\hline & & & & 0 \\
\hline 150 & 47 & 35 & 65 & 96 \\
\hline 10 & $\begin{array}{l}\text { 6=雕刻匠人; } \\
\text { 膝下男; 侍教 } \\
\text { 弟 ; 2[匠 ; } \\
\text { 丹青及[-][-] }\end{array}$ & 1=丹青處士 + 丹青 & 14 & 2 \\
\hline 160 & 53 & 36 & 79 & 98 \\
\hline
\end{tabular}

